CAROLA GEAN CARLA CAVERO GUTIERREZ

ANÁLISE DINÂMICA DE UM PROCESSO CONTÍNUO DE PASTEURIZAÇÃO EM TROCADORES DE CALOR A PLACAS 


\section{ANÁLISE DINÂMICA DE UM PROCESSO CONTÍNUO DE PASTEURIZAÇÃO EM TROCADORES DE CALOR A PLACAS}

Tese apresentada à Escola Politécnica da Universidade de São Paulo para obtenção do Título de Doutor em Engenharia Química

São Paulo 2013 


\section{ANÁLISE DINÂMICA DE UM PROCESSO CONTÍNUO DE PASTEURIZAÇÃO EM TROCADORES DE CALOR A PLACAS}

Tese apresentada à Escola Politécnica da Universidade de São Paulo para obtenção do Título de Doutor em Engenharia Química

Área de Concentração: Engenharia Química

Orientador: Prof. Dr. Jorge Andrey Wilhelms Gut

São Paulo 2013 
Este exemplar foi revisado e corrigido em relação à versão original, sob responsabilidade única do autor e com a anuência de seu orientador.

São Paulo, 4 de outubro de 2013.

Assinatura do autor

Assinatura do orientador

Cavero Gutierrez, Carola Gean Carla

Análise dinâmica de um processo contínuo de pasteurização em trocadores de calor a placas / C.G.C. Cavero Gutierrez. -versão corr. -- São Paulo, 2013.

$139 \mathrm{p}$.

Tese (Doutorado) - Escola Politécnica da Universidade de São Paulo. Departamento de Engenharia Química.

1.Pasteurização (Processos; Análise) 2.Trocadores de calor I.Universidade de São Paulo. Escola Politécnica. Departamento de Engenharia Química II.t. 


\section{DEDICATÓRIA}

Ao meu amado filho Samuel Alexandro, por ser minha luz e preencher minha vida de muita alegria. 


\section{AGRADECIMENTOS}

Meu maior agradecimento é dirigido a minha querida família, por ter sido o meu contínuo apoio e fonte de carinho ao longo da minha vida. Agradeço especialmente a minha mãe por sua paciência e bondade infinita, por ter me ensinado com amor a importância da construção e coerência de meus próprios valores. Ao meu querido esposo Manuel Alberteris, amigo e companheiro, pelo apoio, carinho e incentivo constante, por estar sempre presente em todos os meus passos.

Agradeço ao professor Dr. Jorge Andrey Wilhelms Gut. Foi uma imensa honra e orgulho tê-lo como orientador desde o mestrado, por toda a dedicação, disponibilidade e por todos os valiosos ensinamentos que fizeram possível a realização deste trabalho.

À professora Dra. Carmen Cecília Tadini por todas as contribuições, presença e apoio constante no desenvolvimento da pesquisa.

Agradeço de coração a todas as pessoas que fazem e fizeram parte do LEA Laboratório de Engenharia de Alimentos da USP, amigos muito queridos e companheiros que fizeram parte dessa longa trajetória, trocando conhecimentos e compartilhando momentos felizes e difíceis. Muito obrigada a cada um deles!

Agradeço à Camila Freitas, doutoranda da Faculdade de Veterinária da USP, pela ajuda no fornecimento do leite cru.

Agradeço ao Conselho Nacional de Desenvolvimento Científico e Tecnológico, CNPq, pela bolsa concedida durante os anos do curso.

A todos que direta ou indiretamente colaboraram para meu crescimento como pessoa e como profissional na execução deste trabalho, meus sinceros agradecimentos. 


\section{RESUMO}

A pasteurização é um processo térmico para inativar micro-organismos patogênicos e deterioradores em alimentos líquidos. O controle do processo é fundamental para a manutenção da temperatura de pasteurização, de forma que a modelagem dinâmica se torna útil no desenvolvimento, nos testes de controladores e nos procedimentos de operação. $O$ objetivo deste trabalho foi o desenvolvimento e a validação experimental da modelagem dinâmica de um pasteurizador a placas com três seções de troca térmica para estudar sua operação em regime transiente. A modelagem consiste em balanços diferenciais de energia entre canais e placas do trocador, perda de calor para o ambiente do tubo de retenção e conexões e as respectivas condições iniciais e de contorno. Os coeficientes de troca térmica do equipamento foram determinados experimentalmente. Na simulação foram adotados métodos de diferenças finitas e a resolução matemática foi realizada através do software gPROMS. O modelo foi aplicado para representar o comportamento de um pasteurizador a placas de escala laboratorial (Armfield FT43A), operando em duas condições: sem e com a influência da incrustação na seção de aquecimento do trocador. Para a validação do modelo foram realizados ensaios experimentais da partida e de perturbação das vazões de alimentação do processo. Foram inseridos termopares em diversos pontos do equipamento e as temperaturas foram registradas com um sistema de aquisição de dados. Para estudar a influência da incrustação na pasteurização, foram realizados ensaios experimentais com dois tipos de leite para se ter alta e baixa incrustação. As placas do trocador foram pesadas e fotografadas antes e depois dos ensaios de incrustação para avaliar o depósito formado. Foram utilizados modelos genéricos de incrustação para a simulação desse efeito sobre o processo de pasteurização. Através da comparação dos resultados experimentais e simulados foi verificada que a modelagem matemática para a operação transiente do processo de pasteurização analisado foi muito satisfatória.

Palavras-chave: Pasteurização. Trocador de calor a placas. Modelagem matemática. Incrustação. Simulação dinâmica. 


\begin{abstract}
Pasteurization is a thermal process used to inactivate pathogenic and deteriorative microorganisms in liquid foods. Process control is essential for the temperature maintenance of pasteurization, so that the dynamic model is an important tool in the development, controller tests, and also in the procedure of operation. The aim of this work was the development and experimental validation of the dynamic model of a plate pasteurizer with three sections of heat exchange studying the transient state operation. The model consists of differential equations of thermal energy balance between channels and plates of heat exchanger, heat loss to the environment of the holding tube and connections and their respective initial and boundary conditions. The heat transfer coefficients of plate heat exchanger and tubes were determined experimentally. In the simulation, finite difference methods were adopted and the math solving was performed using the gPROMS software. The model was applied to represent the behavior of a plate pasteurizer in laboratory scale (Armfield FT43A), operating in two conditions: free of fouling and with fouling influence on the heating section of the heat exchanger. Experimental tests of the start-up and of disturbances in flow rates of the process were performed for the model validation. Thermocouples were inserted at various points of the equipment and the temperatures were recorded with a data acquisition system. In order to study the influence of the fouling, experimental tests were performed with two kinds of milk to obtain high and low fouling. Plates of the heat exchanger were weighed and photographed before and after of the fouling tests for evaluate the deposit formed. Generic models of fouling were used to simulate the effect of fouling on the pasteurization process. Through the comparison of experimental and simulated results, it was verified that the mathematical modeling for the transient operation of the pasteurization process was very satisfactory.
\end{abstract}

Key words: Pasteurization. Plate heat exchanger. Mathematical modeling. Fouling. Dynamic simulation. 


\section{LISTA DE FIGURAS}

Figura 3.1 - Esquema de uma unidade de pasteurização HTST destacando as seções do trocador de calor a placas (GUT; PINTO, 2003b).

Figura 3.2 - Modelos de trocadores de calor a placas de diferentes escalas (ARMFIELD, 2012; ALFA LAVAL, 2011).

Figura 3.3 - Trocador de calor a placas aberto e suas partes principais (GUT; PINTO, 2003b).

Figura 3.4 - Representação gráfica das placas e escoamento no trocador de calor a placas (GUT, 2003).

Figura 3.5 - Representação esquemática do número de canais do trocador de calor a placas (GUT, 2003).

Figura 3.6 - Exemplo de uma configuração de passes e passagens para um PHE com nove placas (GUT; PINTO, 2003b).

Figura 3.7 - Exemplo de arranjos de passes para um PHE com nove placas (GUT; PINTO, 2003b).

Figura 3.8 - Esquema da localização das conexões de alimentação do trocador de calor a placas placas (GUT, 2003).

Figura 3.9 - Tipos de escoamento vertical e diagonal em um trocador de quatro canais (GUT, 2003).

Figura 3.10 - Exemplo de configuração de um trocador de calor com 7 canais (GUT, 2003).

Figura 3.11 - Tendência do fator de incrustação em função do tempo.(A) Incrusração linear, (B) Incrustação assintótica e (C) Incrustação intermediária entre linear e assintótica (CHANGANI et al., 1997).

Figura 4.1 - Volume de controle para o balanço diferencial de energia num canal e numa placa genérica $\boldsymbol{i}$ do trocador de calor a placas.

Figura 4.2 - Volume de controle para o balanço de energia no tubo de retenção e trechos de tubo.

Figura 4.3 - Exemplo de um arranjo em série de um PHE com 12 canais indicando a direção do fluido e os valores dos parâmetros de configuração.

Figura 5.1 - Pasteurizador de laboratório ARMFIELD modelo FT-43A e placas do trocador de calor. 
Figura 5.2 - Esquema e foto do pasteurizador com indicação dos 12 pontos de medição de temperatura.

Figura 5.3 - Dimensões da gaxeta do trocador de calor a placas do pasteurizador ARMFIELD FT-43A, valores em milímetros (GUTIERREZ, 2008).

Figura 5.4 - Tubos de retenção (1) e (2) do pasteurizador ARMFIELD FT43A.

Figura 5.5 - Processamento do leite no pasteurizador de laboratorio ARMFIELD FT-43A e identificação de placas do trocador de calor.

Figura 5.6 - Tendência da incrustação linear em função do tempo (modelo 1 de incrustação).

Figura 5.7 - Tendência da incrustação assintótica em função do tempo (modelo 2 de incrustação).

Figura 6.1 - Gráfico de paridade da taxa de troca de calor experimental com a troca de calor calculada no PHE.

Figura 6.2 - Correlação dos valores ajustados experimentalmente e os valores encontrados na literatura para os parâmetros a1.e $a 2$ da equação de Nusselt. 92

Figura 6.3 - Coeficiente global de troca térmica com o ambiente em função da vazão no Tubo 1.

Figura 6.4 - Coeficiente global de troca térmica com o ambiente em função da vazão no Tubo 2.

Figura 6.5 - Coeficiente global de troca térmica com o ambiente em função da vazão no Tubo 3.

Figura 6.6 - Determinação da constante de tempo do termopar. .95

Figura 6.7 - Dados experimentais e simulados de temperatura da partida do pasteurizador. Linhas verdes representam dados experimentais e linhas azuis dados simulados. 96

Figura 6.8 - Dados experimentais e simulados de temperatura para o ensaio dinâmico de perturbação $A$. Linhas verdes representam dados experimentais e linhas azuis dados simulados. 98

Figura 6.9 - Dados experimentais e simulados de temperatura para o ensaio dinâmico de perturbação B. Linhas verdes 
representam dados experimentais e linhas azuis dados

simulados.

Figura 6.10 - Dados experimentais e simulados de temperatura para o ensaio dinâmico de perturbação $C$. Linhas verdes representam dados experimentais e linhas azuis dados simulados.

Figura 6.11 - Dados experimentais e simulados de temperatura para o ensaio dinâmico de perturbação $D$. Linhas verdes representam dados experimentais e linhas azuis dados simulados. 100

Figura 6.12 - Dados experimentais e simulados de temperatura para o ensaio dinâmico de perturbação $\mathrm{E}$. Linhas verdes representam dados experimentais e linhas azuis dados simulados.

Figura 6.13 - Dados experimentais e simulados de temperatura para o ensaio dinâmico de perturbação $F$. Linhas verdes representam dados experimentais e linhas azuis dados simulados. 101

Figura 6.14 - Coeficiente global de troca térmica experimental e MLDT da seção de aquecimento para o ensaio de incrustação com leite UHT. 104

Figura 6.15 - Coeficiente global de troca térmica experimental e MLDT da seção de aquecimento para o ensaio de incrustação com leite cru. 104

Figura 6.16 - Diferença de temperaturas do produto e do fluido de serviço na seção de aquecimento para o ensaio de incrustação com leite UHT. 106

Figura 6.17 - Diferença de temperaturas do produto e do fluido de serviço na seção de aquecimento para o ensaio de incrustação com leite cru. 106

Figura 6.18 - Influência da recirculação do leite cru na incrustação. 107

Figura 6.19 - Fotografia das placas da seção de aquecimento do trocador de calor com material seco incrustado após o ensaio com leite UHT (6 horas de operação). 109

Figura 6.20 - Fotografia das placas da seção de aquecimento do trocador de calor com material seco incrustado após o ensaio com leite cru (3 horas de operação). 
Figura 6.21 - Fotografia ampliada das placas incrustadas com material seco e material úmido após o ensaio de incrustação com leite UHT e leite cru. (a) e (c): incrustação úmida e seca de leite UHT; (b) e (d): incrustação úmida e seca de leite cru.

Figura 6.22 - Fotografia ampliada das placas incrustadas enfocando a formação de bolhas de ar: (a) Bennett (2007); (b) e (c) incrustação leite UHT.

Figura 6.23 - Estrutura do material de incrustação do leite sobre a superfície das placas do trocador de calor: (a) Bennett (2007);

(b) incrustação úmida leite cru e (c) incrustação úmida leite UHT.

Figura 6.24 - Massa seca incrustada sobre a superfície das placas da seção de aquecimento do trocador de calor.

Figura 6.25 - (a),(b): Temperaturas da simulação do processo de pasteurização sem incrustação comparadas com temperaturas do processo com incrustação (modelo 1). Linhas azuis representam temperaturas sem incrustação e linhas verdes temperaturas com incrustação.

Figura 6.26 - (a): Coeficientes globais de troca térmica da seção de aquecimento do processo de pasteurização sem incrustação comparados com os coeficientes do processo com incrustação, (b): Porcentagem do coeficiente global de troca térmica do lado I utilizado durante o ensaio de incrustação (modelo 1).

Figura 6.27 - (a),(b): Temperaturas da simulação do processo de pasteurização sem incrustação comparadas com temperaturas do processo com incrustação (modelo 2). Linhas azuis representam temperaturas sem incrustação e linhas verdes temperaturas com incrustação.

Figura 6.28 - (a): Coeficientes globais de troca térmica da seção de aquecimento do processo de pasteurização sem incrustação comparados com os coeficientes do processo com incrustação, (b): Porcentagem do coeficiente global de troca térmica do lado $I$ utilizado durante o ensaio de incrustação (modelo 2). 120

Figura 6.29 - Comparação das porcentagens de troca térmica utilizadas na seção de aquecimento para os dois modelos de incrustação simulados. 


\section{LISTA DE TABELAS}

Tabela 5.1 - Pontos de medição da temperatura do fluido no pasteurizador. .70

Tabela 5.2 - Características das placas do trocador de calor do pasteurizador ARMFIELD FT-43A (GUT; PINTO, 2004).

Tabela 5.3 - Parâmetros de configuração das três seções do trocador de calor a placas.

Tabela 5.4 - Identificação e dimensões do tubo de retenção e trechos de tubo do pasterizador.

Tabela 5.5 - Parâmetros de tempo e vazão utilizados no ensaio da partida do pasteurizador.

Tabela 5.6 - Parâmetros de tempo e vazões de operação para o ensaio dinâmico de perturbação $A$ com variação simultânea de três vazões.

Tabela 5.7 - Parâmetros de tempo e vazões de operação para o ensaio dinâmico de perturbação $B$ com variação simultânea de duas vazões.

Tabela 5.8 - Parâmetros de tempo e vazões de operação para o ensaio dinâmico de perturbação $\mathrm{C}$ com variação simultânea de duas vazões.

Tabela 5.9 - Parâmetros de tempo e vazões de operação para o ensaio dinâmico de perturbação $D$ com variação simultânea de duas vazões.

Tabela 5.10 - Parâmetros de tempo e vazões de operação para o ensaio dinâmico de perturbação E com variação de uma vazão.

Tabela 5.11 - Parâmetros de tempo e vazões de operação para o ensaio dinâmico de perturbação $\mathrm{F}$ com variação de uma vazão.

Tabela 6.1 - Valores ajustados dos parâmetros de troca térmica no PHE para a equação de Nusselt.

Tabela 6.2 - Valores dos coeficientes globais médios de troca térmica dos trechos de tubo com o ambiente. 


\section{LISTA DE ABREVIATURAS E SIGLAS}

BFDM Backward Finite Difference Method (Método de diferenças finitas para trás)

CFD Computacional Fluid Dynamic (Dinâmica dos fluidos computacional)

CFDM Centered Finite Difference Method (Método de diferenças finitas centradas)

DTR Distribuição de tempos de residência

FFDM Forward Finite Difference Method (Método de diferenças finitas para frente)

HTST High Temperature Short Time (Alta temperatura curto tempo)

MLDT Média logarítmica da diferença de temperaturas

PHE $\quad$ Plate Heat Exchanger (Trocador de calor a placas)

PID Proportional-integral-derivative (Proporcional integral derivativo)

UHT $\quad$ Ultra High Temperature (Ultra alta temperatura) 


\section{LISTA DE SÍMBOLOS}

$a_{\mathrm{i}} \quad$ Parâmetro numérico da equação de Nusselt $i=1,2$ ou 3 (-)

$A \quad$ Área de troca térmica do trocador de calor $\left(\mathrm{m}^{2}\right)$

$A_{C} \quad$ Área de seção transversal do canal do trocador $\left(\mathrm{m}^{2}\right)$

$A_{e} \quad$ Área de escoamento no canal $\left(\mathrm{m}^{2}\right)$

$A_{P} \quad$ Área de troca térmica de uma placa $\left(\mathrm{m}^{2}\right)$

$A_{T} \quad$ Área de troca térmica do tubo $\left(\mathrm{m}^{2}\right)$

$b \quad$ Espessura média do canal, distanciamento entre duas placas $(\mathrm{m})$

$C p_{i} \quad$ Calor específico do fluido localizado no canal $i$ (J/kg.K)

$C p_{P} \quad$ Calor específico da placa (J/kg.K)

$D \quad$ Diâmetro interno do tubo $(\mathrm{m})$

$D_{e} \quad$ Diâmetro equivalente da passagem do fluxo pelo canal $(\mathrm{m})$

$D_{P} \quad$ Diâmetro do orifício da placa $(\mathrm{m})$

$e_{p} \quad$ Espessura da placa $(\mathrm{m})$

E Eficiência da troca térmica $(\%)$

$G_{C} \quad$ Fluxo mássico por canal $\left(\mathrm{kg} / \mathrm{m}^{2} . \mathrm{s}\right)$

$h \quad$ Coeficiente convectivo de troca térmica $\left(\mathrm{W} / \mathrm{m}^{2} . \mathrm{K}\right)$

$i \quad$ Contador genérico (-)

$j \quad$ Contador genérico (-)

$J_{P} \quad$ Variável auxiliar da modelagem de troca térmica das placas (s)

$k \quad$ Condutividade térmica do fluido $(\mathrm{W} / \mathrm{m} . \mathrm{K})$

$k_{P} \quad$ Condutividade térmica da placa (W/m.K)

$L \quad$ Altura da seção de troca térmica da placa $(\mathrm{m})$

$L_{T} \quad$ Comprimento do tubo $(\mathrm{m})$

$m_{f} \quad$ Massa incrustada na área superficial de troca térmica $\left(\mathrm{kg} / \mathrm{m}^{2}\right)$

$N \quad$ Número de canais por passe (-)

$N_{C} \quad$ Número total de canais (-)

$N_{C}^{I}$ ou II Número de canais de escoamento para o lado I ou II do trocador (-)

$N_{P} \quad$ Número total de placas do trocador de calor (-)

$\mathrm{Nu} \quad$ Número de Nusselt (-)

NTU Número de unidades de transferência de calor (-)

$P \quad$ Perímetro molhado do canal $(\mathrm{m})$

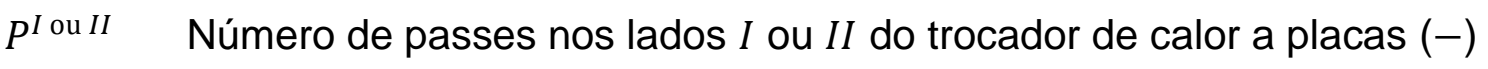


$P_{i} \quad$ Número de passes no lado correspondente ao canal $i(-)$

$P_{W} \quad$ Perímetro molhado $(\mathrm{m})$

Pr Número de Prandtl (-)

Q Taxa de calor trocado (W)

$Q_{\max } \quad$ Taxa máxima de calor trocado (W)

$q_{a q} \quad$ Vazão volumétrica do fluido de aquecimento (L/h)

$q_{\text {prod }} \quad$ Vazão volumétrica do produto (L/h)

$q_{\text {res }} \quad$ Vazão volumétrica do fluido de resfriamento (L/h)

Re Número de Reynolds (-)

$R_{f} \quad$ Fator de incrustação $\left(\mathrm{K} . \mathrm{m}^{2} \mathrm{~W}\right)$

$R_{\max } \quad$ Valor máximo do fator de incrustação $\left(\mathrm{K} \cdot \mathrm{m}^{2} \mathrm{~W}\right)$

$s_{i} \quad$ Variável dependente do sentido do escoamento: +1 se estiver no sentido ascendente $\mathrm{e}-1$ se estiver no sentido descendente (-)

$t \quad$ Tempo (s)

$t_{f} \quad$ Período de incrustação (s)

$t_{f_{0}} \quad$ Período de indução da incrustação (s)

$T_{i} \quad$ Temperatura do fluido no canal $i(\mathrm{~K})$

$T_{e} \quad$ Temperatura do fluido de entrada no tubo (K)

$T_{S} \quad$ Temperatura do fluido de saída do tubo (K)

$T_{P_{i}} \quad$ Temperatura na placa $i(\mathrm{~K})$

$T_{\infty} \quad$ Temperatura ambiente $(\mathrm{K})$

$U \quad$ Coeficiente global de troca térmica $\left(\mathrm{W} / \mathrm{m}^{2} . \mathrm{K}\right)$

$U_{1 \text { ou } 2}$ Coeficiente global de troca térmica do lado $I$ ou $I I$ do trocador $\left(\mathrm{W} / \mathrm{m}^{2} . \mathrm{K}\right)$

$U^{I \text { ou } I I} \quad$ Coeficiente global de troca térmica do lado $I$ ou $I I$ do trocador $\left(\mathrm{W} / \mathrm{m}^{2} . \mathrm{K}\right)$

$U_{C} \quad$ Coeficiente global de troca térmica do trocador limpo $\left(\mathrm{W} / \mathrm{m}^{2} . \mathrm{K}\right)$

$U_{f} \quad$ Coeficiente global de troca térmica do trocador sujo $\left(\mathrm{W} / \mathrm{m}^{2} . \mathrm{K}\right)$

$V_{C} \quad$ Volume interno do canal $\left(\mathrm{m}^{3}\right)$

$V_{P} \quad$ Volume da placa $\left(\mathrm{m}^{3}\right)$

$V_{T} \quad$ Volume interno do tubo $\left(\mathrm{m}^{3}\right)$

$w \quad$ Largura da seção de troca térmica da placa $(\mathrm{m})$

$W_{i} \quad$ Vazão mássica do fluido localizado no canal $i(\mathrm{~kg} / \mathrm{h})$

$W_{\text {hot }} \quad$ Vazão mássica do fluido quente $(\mathrm{kg} / \mathrm{h})$

$W_{\text {cold }} \quad$ Vazão mássica do fluido frio $(\mathrm{kg} / \mathrm{h})$

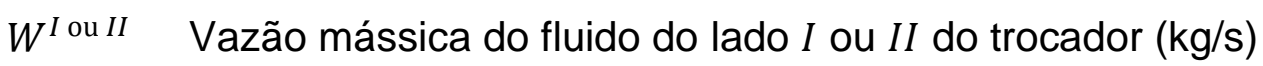


$x \quad$ Direção tangencial ao escoamento nos canais do trocador $(\mathrm{m})$

$x_{f} \quad$ Fração mássica de gordura presente no leite $(-)$

$x_{w} \quad$ Fração mássica de água presente no leite (-)

$Y_{f} \quad$ Parâmetro binário para tipo de fluxo nos canais (-)

$Y_{h} \quad$ Parâmetro binário para localização do fluido quente no trocador (-)

$Z \quad$ Variável auxiliar da modelagem de troca térmica do tubo (-)

\section{Símbolos Gregos}

$\alpha_{i} \quad$ Variável auxiliar da modelagem de troca térmica no canal $i\left(\mathrm{~K} \cdot \mathrm{m}^{2} \mathrm{~W}\right)$

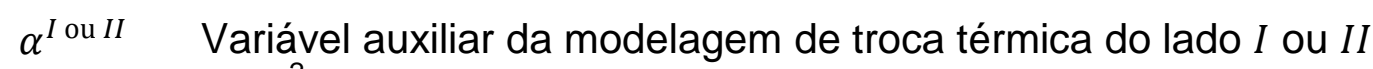
$\left(\mathrm{K} . \mathrm{m}^{2} \mathrm{~W}\right)$

$\alpha_{f} \quad$ Constante de velocidade cinética da incrustação $\left(\mathrm{s}^{-1}\right)$

$\alpha_{P} \quad$ Difusividade térmica da placa $\left(\mathrm{m}^{2} / \mathrm{s}\right)$

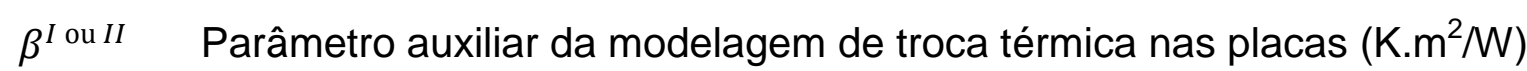

$\Delta T_{l m} \quad$ Média logarítmica da diferença de temperaturas (K)

$\eta \quad$ Adimensionalização do espaço axial na parte interna do canal ou no comprimento do tubo de retenção (-)

$\mu \quad$ Viscosidade do fluido (Pa.s)

$\pi \quad$ Constante pi $(\pi=3,1416)$

$\rho_{i} \quad$ Densidade do fluido no canal $i\left(\mathrm{~kg} / \mathrm{m}^{3}\right)$

$\rho_{P} \quad$ Densidade da placa $\left(\mathrm{kg} / \mathrm{m}^{3}\right)$

$\tau_{i} \quad$ Tempo espacial do fluido no canal $i$ (s)

$\tau_{T} \quad$ Tempo espacial do fluido no tubo (s)

$\emptyset \quad$ Parâmetro que define a posição da conexão de alimentação do trocador de calor $(\varnothing=1,2,3$ ou 4$)$

$\emptyset_{d} \quad$ Taxa de crescimento da massa incrustada na superfície do trocador de calor $\left(\mathrm{kg} / \mathrm{m}^{2} . \mathrm{s}\right)$

$\emptyset_{r} \quad$ Taxa de remoção da massa incrustada na superfície do trocador de calor $\left(\mathrm{kg} / \mathrm{m}^{2} . \mathrm{s}\right)$

$\Phi \quad$ Fator de alagamento da placa (-)

\section{Subscritos}

aq Seção de aquecimento do trocador

cold Fluido frio ou de resfriamento 


$\begin{array}{ll}\text { hot } & \text { Fluido quente ou de aquecimento } \\ i & \text { Elemento genérico } i \\ \text { in } & \text { Entrada do fluido } \\ j & \text { Elemento genérico } j \\ \max & \text { Máximo } \\ \min & \text { Mínimo } \\ \text { out } & \text { Saída do fluido } \\ \text { prod } & \text { Produto processado } \\ \text { reg } & \text { Seção de regeneração do trocador } \\ \text { res } & \text { Seção de resfriamento do trocador }\end{array}$




\section{SUMÁRIO}

1. INTRODUÇÃO

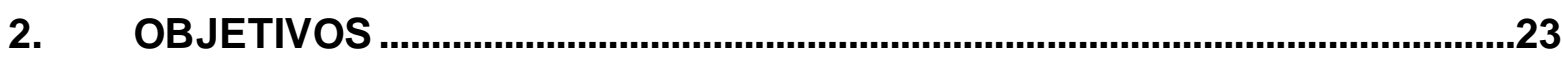

3. REVISÃO DA LITERATURA

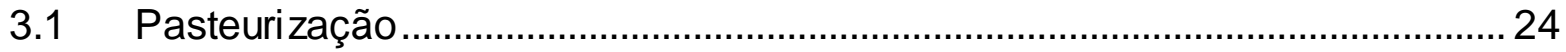

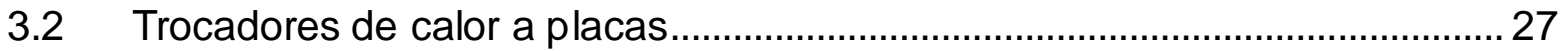

3.2.1 Configurações do trocador de calor a placas ....................................................30

3.3 Modelos dinâmicos de trocadores de calor a placas ....................................... 36

3.4 Efeito da incrustação em trocadores de calor ...................................................39

3.4.1 Fator de incrustação ......................................................................................

4. MODELAGEM MATEMÁTICA DO PROCESSO DE PASTEURIZAÇÃO......44

4.1 Modelagem de um trocador de calor a placas ................................................ 45

4.2 Modelagem do tubo de retenção e trechos de tubo ………………………....57

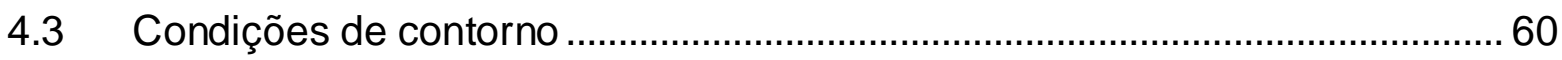

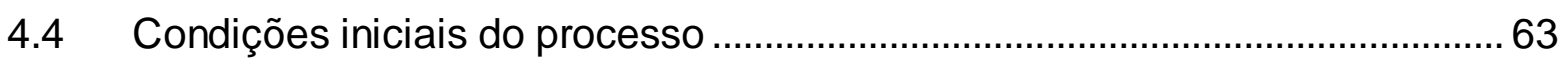

4.5 Modelagem da incrustação no trocador de calor a placas ................................ 64

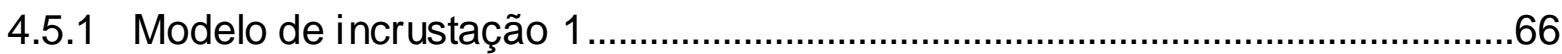

4.5.2 Modelo de incrustação 2..............................................................................6

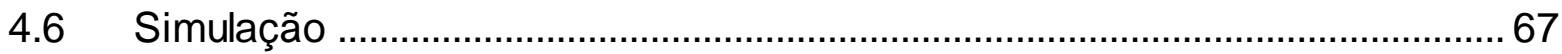

5. MATERIAIS E MÉTODOS

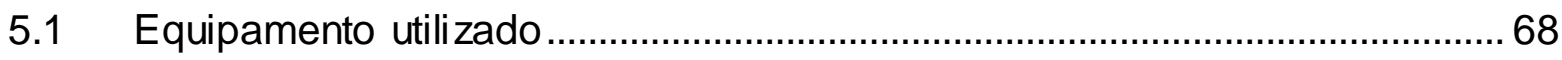

5.2 Determinação experimental dos coeficientes de troca térmica....................... 74

5.2.1 Determinação dos coeficientes de troca térmica no PHE ................................74

5.2.2 Determinação dos coeficientes de troca térmica no tubo de retenção e

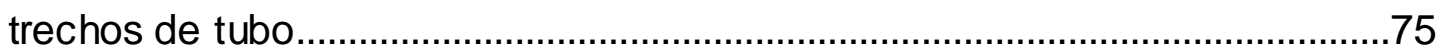

5.3 Determinação da constante de tempo do termopar .........................................76

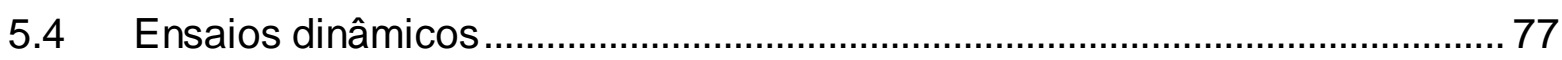

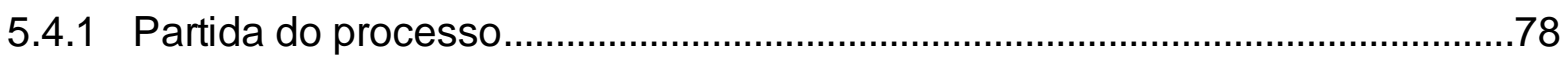

5.4.2 Ensaios com perturbações ............................................................................79 
5.5 Estudo experimental do efeito da incrustação ............................................. 82

5.6 Simulação do processo de pasteurização com influência da incrustação .... 85

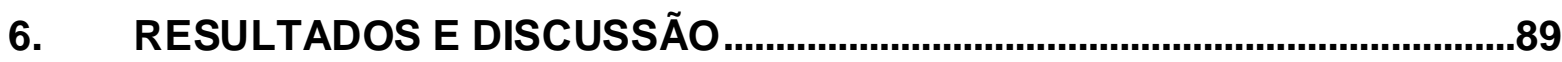

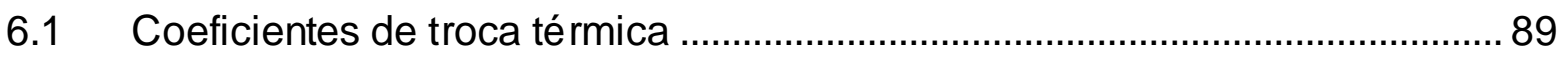

6.1.1 Coeficiente de troca térmica no trocador de calor a placas ............................89

6.1.2 Coeficiente global de troca térmica dos tubos ...............................................92

6.2 Resultado da constante de tempo do termopar ..............................................94

6.3 Resultado da partida do processo …………….........................................95

6.4 Resultado dos ensaios com perturbação …………………………...........97

6.5 Resultado do estudo experimental do efeito da incrustação .........................103

6.6 Resultado da simulação do processo de pasteurização com influência

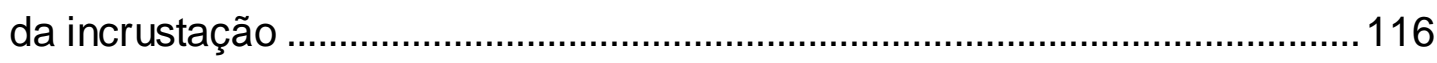

6.6.1 Resultados de simulação do modelo de incrustação 1 ................................117

6.6.2 Resultados de simulação do modelo de incrustação 2 …………………..... 119

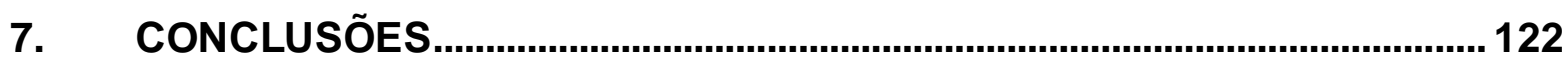

8. PERSPECTIVAS PARA TRABALHOS FUTUROS ......................................124

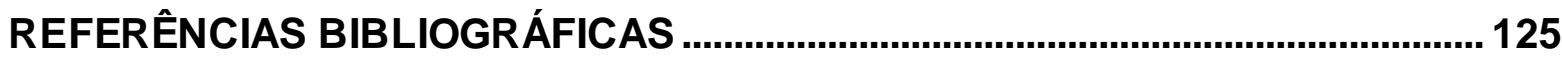

APÊNDICE A - Registro de temperaturas simuladas e experimentais do ensaio da partida do pasteurizador nos 12 pontos de

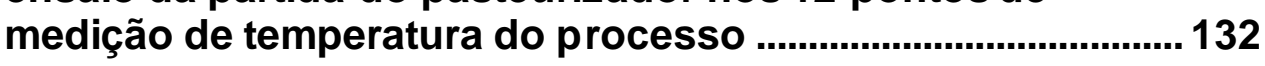

APÊNDICE B - Registro de temperaturas simuladas e experimentais do ensaio dinâmico de perturbação $A$

APÊNDICE C - Registro de temperaturas simuladas e experimentais do ensaio dinâmico de perturbação $B$

APÊNDICE D - Registro de temperaturas simuladas e experimentais do ensaio dinâmico de perturbação C

APÊNDICE E - Registro de temperaturas simuladas e experimentais do ensaio dinâmico de perturbação $D$

APÊNDICE F - Registro de temperaturas simuladas e experimentais do ensaio dinâmico de perturbação $E$ 
APÊNDICE G - Registro de temperaturas simuladas e experimentais do ensaio dinâmico de perturbação $F$

APÊNDICE H- Tabela de dados do ajuste experimental para a determinação dos coeficientes de troca térmica do trocador de calor a placas. 


\section{INTRODUÇÃO}

Qualidade e segurança microbiológica dos alimentos são as principais preocupações dos consumidores e principalmente das indústrias de processos de alimentos (FITO et al., 2007).

Atualmente, existe uma crescente busca de alimentos mais saudáveis, com melhor qualidade nutricional e sensorial e longa vida de prateleira. Por esta razão, as indústrias tentam aprimorar cada vez mais os processos de tratamento de alimentos, criando-se assim a necessidade de melhorar o entendimento dos processos envolvidos na produção dos mesmos (IGUAL et al., 2010).

O tratamento térmico é uma das principais tecnologias aplicadas na indústria de alimentos para a preservação de produtos alimentícios. O principal objetivo do processamento térmico é inativar os micro-organismos patogênicos e parte dos deterioradores, enzimas indesejadas e produzir um produto inócuo para o consumo, com vida de prateleira prolongada sem representar riscos para a saúde (PEREIRA; VICENTE, 2010).

Durante o tratamento térmico de alimentos, que pode ser contínuo ou descontínuo, ocorrem diversas alterações químicas, físicas e bioquímicas que podem afetar a qualidade e aceitabilidade do alimento. Para minimizar a perda das propriedades nutricionais e sensoriais do alimento e garantir a segurança microbiológica, os processos térmicos têm que ser bem conduzidos. Os parâmetros tempo e temperaturas do processo são específicos para cada alimento a fim de atingir o micro-organismo ou enzima mais termo-resistente presente no mesmo (LEWIS; HEPPELL, 2000).

A pasteurização é um tratamento térmico, no qual o alimento é submetido a um aquecimento por tempo determinado seguido de um rápido resfriamento (SANCHO; RAO, 1992). Este processo busca garantir a segurança microbiológica, aumentar a vida de prateleira e ao mesmo tempo preservar as características sensoriais e nutricionais do alimento (LEWIS; HEPPELL, 2000; GHANI; FARID; CHEN, 2002; PEREIRA; VICENTE, 2010).

A pasteurização contínua apresenta várias vantagens em comparação com a descontínua (ou pasteurização por lotes), como aumento na capacidade de 
produção, redução do tempo de produção e, sobretudo, redução no consumo de energia (FELLOWS, 2006).

No Brasil é obrigatório que todo o leite, assim como todos os derivados de lacticínios sejam fabricados a partir do leite pasteurizado (ANVISA, resolução - RDC № 267 , de 25 de setembro de 2003 , artigo 4.1.16).

Para a pasteurização de alimentos líquidos não muito viscosos normalmente são utilizados trocadores de calor a placas, PHE (Plate Heat Exchanger). Este tipo de trocador é o que melhor atende às exigências de higiene e limpeza das indústrias alimentícias e farmacêuticas, pois eles podem ser desmontados, limpos e inspecionados e apresentar maior facilidade no controle de temperaturas, essencial para os processos de pasteurização e esterilização (KIM; TADINI; SINGH, 1999; ZHENHUA et al., 2008; ABU-KHADER, 2012).

Nos processos de pasteurização, o controle da temperatura nas diferentes etapas do processo é muito importante, especialmente na saída do tubo de retenção, que é o encarregado de manter o produto no tempo e na temperatura definidos para o processo. Durante a passagem do produto através do tubo de retenção ocorre a destruição de micro-organismos e a inativação de enzimas, portanto, se a temperatura de saída do tubo de retenção for menor do que a estabelecida, o produto terá que ser novamente processado para garantir a segurança microbiológica. Pelo contrário, se a temperatura de saída for maior, o produto é sobreprocessado. Como consequência, em ambos os casos, haveria importantes perdas de qualidade do alimento, assim como incremento nos custos de produção (IBARROLA et al., 2002).

Outro fator que também afeta a pasteurização é o fenômeno de incrustação nas superfícies de trocadores de calor. Este fenômeno é um dos problemas mais críticos na indústria alimentícia, pelo fato de ser necessária a parada do processo para a limpeza e remoção do material incrustado, não só para garantir as condições sanitárias, mas também para garantir a boa eficiência térmica do equipamento.

A formação destas incrustações constitui um dos fenômenos de maior importância tanto no projeto quanto na operação do equipamento. A eficiência da troca térmica do processo é reduzida gradativamente com o aumento da quantidade do material incrustado na superfície do trocador, gerando perda de carga e aumento 
da resistência à transferência de calor, e podendo até chegar a obstruí-lo (PETERMEIER et al., 2002). Por outro lado, a parada obrigatória do trocador para limpeza e remoção do depósito reduz o tempo de funcionamento do equipamento, sendo que às vezes pode ser necessária mais de uma limpeza por dia, como consequência, resultando em um aumento no custo de produção (SANDU e SINGT, 1991; VISSER e JEURMINK,1997).

A fim de melhorar o processo, preservar a qualidade do produto e minimizar os custos de energia, a modelagem matemática e a simulação da transferência de calor na avaliação de tratamentos térmicos vêm se mostrando como poderosas ferramentas na garantia da segurança com mínimo comprometimento da qualidade nutricional e sensorial dos alimentos. Portanto, uma modelagem mais rigorosa do processo visando a otimização da qualidade do produto e dos custos de produção é necessária para um correto controle e operação de uma planta de pasteurização. 


\section{OBJETIVOS}

A fim de obter produtos alimentícios de melhor qualidade, com extensão de vida de prateleira, sem representar risco para a saúde, assim como reduzir custos de processamento é importante ter um bom conhecimento do processo de pasteurização e dos fatores que podem intervir neste processo.

O presente trabalho de pesquisa teve os seguintes objetivos:

- Desenvolver uma modelagem matemática de base fenomenológica para representar a operação transiente de um pasteurizador a placas composto por seções de aquecimento, retenção, regeneração e resfriamento e que contemple a incrustação.

- Aplicar a modelagem desenvolvida para estudar a operação de um pasteurizador experimental.

- Determinar experimentalmente os coeficientes de troca térmica do pasteurizador.

- Estudar a dinâmica do processo de pasteurização HTST usando o modelo desenvolvido, e analisar sua resposta diante de variações nas condições de processo e de formação de incrustação.

- Validar experimentalmente o modelo matemático desenvolvido para a operação transiente do processo de pasteurização HTST em trocador a placas.

Espera-se que este trabalho possibilite a melhoria de procedimentos de partida, controle e operação deste tipo de processo, visando à otimização da qualidade do produto e custo de operação. 


\section{REVISÃO DA LITERATURA}

Os processos térmicos de alimentos podem apresentar diferenças segundo a intensidade aplicada, estes podem ir desde processos brandos como é o caso da pasteurização, até processos mais rigorosos, como é o caso da esterilização comercial. A qualidade do alimento assim como a sua vida de prateleira dependerão da intensidade aplicada ao processo (FELLOWS, 2006).

No mercado, estão disponíveis diversos sistemas para tratamento térmico, tais como trocadores de calor a placas, trocadores de calor tubulares e de superfície raspada, assim como sistemas de injeção direta de vapor e autoclave para esterilização de alimentos enlatados, entre outros (MABIT et al., 2008; TUCKER; HEYDON, 1998).

No leite, os micro-organismos patogênicos mais importantes são o bacilo de Koch (causador da Tuberculose), Salmonella typha e Salmonella paratyphi (causadoras da Febre Tifoide), Brucillo melitensis (causador da Febre de Malta), Coxiella burnetti (causador da Febre de Q), Streptococcus, e outros microorganismos que muitas vezes não produzem alterações visíveis no leite que não podem ser detectadas sem aplicar análise microbiológica (CASP; ABRIL, 2003). Felizmente todos estes micro-organismos podem ser destruídos por um tratamento térmico brando como a pasteurização.

Assim como em outros alimentos, o micro-organismo mais termo-resistente no leite é o bacilo da Tuberculose, sendo assim, ele é considerado como referência no tratamento térmico do leite, já que qualquer tratamento térmico neste alimento que destrua este micro-organismo terá também destruído os outros, assegurando assim uma redução importante na flora microbiana.

\subsection{Pasteurização}

O processo de pasteurização recebe o nome em homenagem a Louis Pasteur, um químico microbiológico francês, quem entre os anos de 1854 a 1864 demostrou experimentalmente que tratamentos térmicos destruíam micro-organismos que estavam associados à deterioração dos alimentos e que eram causadores de 
doenças específicas (PARTRIDGE, 2000). Este processo inicialmente foi aplicado para o vinho, seguido para a cerveja e posteriormente para o leite e os outros alimentos e até hoje é uma das operações mais importantes no processamento de alimentos, lácteos e bebidas.

A pasteurização tem como objetivo principal a destruição de micro-organismos patogênicos e deterioradores e/ou enzimas indesejáveis presentes no alimento. $\mathrm{O}$ objetivo secundário é aumentar a vida de prateleira, com a mínima redução dos valores nutricionais e sensoriais do alimento. Dependendo do tipo de pasteurização utilizado $e$ as condições de armazenamento e embalagem, os produtos pasteurizados podem conter, ainda, organismos vivos capazes de crescer, o que limita sua vida de prateleira. Assim, a pasteurização é, muitas vezes, combinada com outros métodos de conservação e muitos produtos pasteurizados são estocados sob refrigeração (POTTER; HOTCHKISS, 1995; FELLOWS, 2006).

$\mathrm{Na}$ literatura são encontrados três tipo de pasteurização: lenta, rápida e muito rápida. Na pasteurização lenta são utilizadas temperaturas menores durante maior intervalo de tempo. Este tipo de pasteurização é a mais adequada para pequenas quantidades de leite, por exemplo, o leite de cabra, em que a temperatura utilizada é de $65{ }^{\circ} \mathrm{C}$ durante 30 min. A pasteurização rápida, também chamada como pasteurização HTST (High Temperature Short Time) é aquela na qual são utilizadas altas temperaturas durante curtos intervalos de tempo, aproximadamente $75{ }^{\circ} \mathrm{C}$ durante 15 a $20 \mathrm{~s}$ sendo mais utilizada para leite tipo A, B e C. A eficiência da pasteurização HTST é de aproximadamente $95 \%$, portanto, o produto precisa de refrigeração. $O$ tempo de prateleira para o leite pasteurizado sobre esta condição é de 5 dias. A pasteurização muito rápida ou pasteurização ultra alta temperatura, denominada UHT (Ultra High Temperature) também é conhecida como "longa vida", devido ao tempo de prateleira de 4 meses em estocagem a temperatura ambiente. As temperaturas utilizadas variam de $130{ }^{\circ} \mathrm{C}$ a $150{ }^{\circ} \mathrm{C}$, durante 3 a $5 \mathrm{~s}$, atingindo uma eficiência de 99,99 \%, nesta pasteurização todas as formas vegetativas das bactérias são eliminadas e o produto torna-se "comercialmente estéril", sendo possível a presença de algumas formas esporuladas que podem eventualmente sobreviver, mas que não conseguirão se desenvolver nas condições de estocagem (POTTER; HOTCHIKISS, 1995; LEWIS; HEPPELL, 2000; AZEREDO, 2004; FELLOWS, 2006). 
Entre os três processos térmicos apresentados, aquele que exige maior compromisso entre a segurança e a qualidade do produto final é a pasteurização HTST (LEWIS; HEPPELL, 2000). Na Figura 3.1 é apresentado um esquema de uma unidade de pasteurização HTST com trocador de calor a placas indicando as três seções de troca térmica e o tubo de retenção.
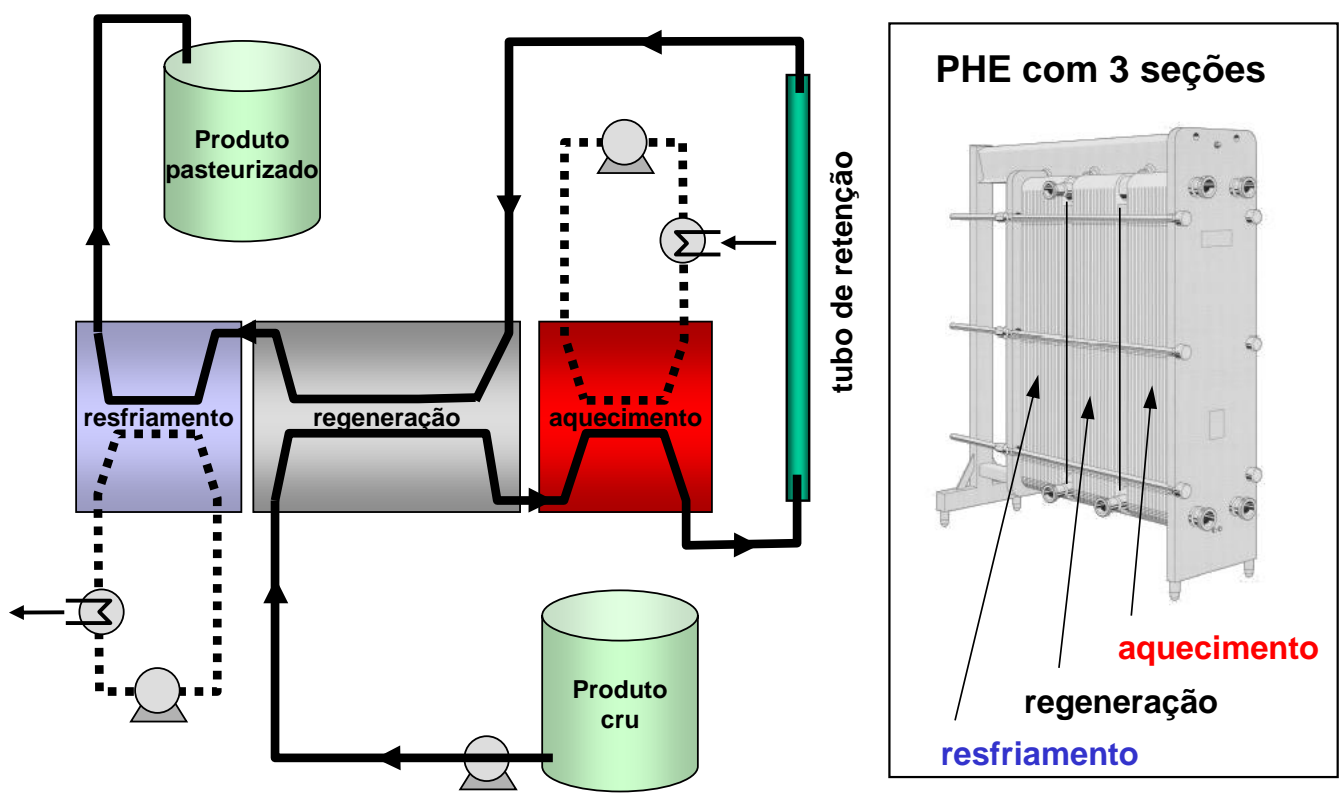

Figura 3.1 - Esquema de uma unidade de pasteurização HTST destacando as seções do trocador de calor a placas (GUT; PINTO, 2003b).

O processo de pasteurização apresentado está dividido em três seções de troca térmica: uma seção para o aquecimento do produto cru até a temperatura de pasteurização, outra seção para o resfriamento do produto pasteurizado até a temperatura de embalagem e uma seção para a recuperação de calor. Na seção designada "regeneração" do trocador de calor, o produto cru é pré-aquecido usando o produto quente pasteurizado.

O desenho e o controle da temperatura na saída do tubo de retenção são de extrema importância em um processo de pasteurização, já que esta etapa é a responsável por manter o tempo de retenção na temperatura de pasteurização determinada para garantir a pasteurização do produto. A temperatura de saída deste tubo deve sofrer uma mínima variação da temperatura de pasteurização desejada. Se a temperatura de saída for muito menor à temperatura estabelecida, o produto 
não será adequadamente pasteurizado, representando risco para a saúde, portanto, neste caso o produto é desviado de volta ao tanque de alimentação para ser novamente processado (perda de energia e incremento no custo do processamento). Se a temperatura de saída for superior à estabelecida, o produto será sobre-processado, ocasionando perda de qualidade e gasto adicional de energia para o aquecimento e resfriamento. Estudos quantificam que um desvio de 1 ㄷ $\mathrm{C}$ na temperatura adequada produz um erro de $25 \%$ no efeito de pasteurização (HASTING, 1992; IBARROLA et al., 2002).

Em processos de pasteurização, a combinação dos parâmetros tempotemperatura para um dado micro-organismo ou enzima alvo muda dependendo do alimento e de algumas de suas propriedades (viscosidade, porcentagem de lipídeos, sólidos residuais, etc.) e das regulamentações locais que variam de país a país.

Para um processo de pasteurização seguro e confiável é muito importante ter uma compreensão clara da função e operação do processo de pasteurização, assim como dos possíveis problemas práticos que podem se apresentar ao longo do processo como a incrustação e sua influência potencial na segurança do produto final (HASTING, 1992; MANIK, et al., 2004). Portanto, uma análise dinâmica do processo de pasteurização é de grande importância.

\subsection{Trocadores de calor a placas}

Os trocadores de calor a placas foram introduzidos por volta do ano 1930, para processos de aquecimento e resfriamento, e foram rapidamente aceitos por atingir altas taxas de transferência de calor com pequena diferença de temperatura. Estes trocadores tiveram grandes avanços nas últimas três décadas e, embora tenham sido criados especialmente para aplicações sanitárias, em indústrias de processamento de alimentos, eles também encontraram um lugar nas indústrias modernas em plantas de processos químicos, plantas de evaporação e condensação e em usinas de energia nuclear (SRIHARI et al., 2005; ABU-KHADER, 2012).

Atualmente os PHEs são extensivamente empregados em diversos processos de troca térmica entre líquidos e alimentos não muito viscosos (GUT; PINTO, 2003b). 
As vantagens dos trocadores de calor a placas em relação aos outros tipos de trocadores são apresentados a seguir (KAKAÇ; LIU, 2002; ABU-KHADER, 2012):

- Higienização viável, que permite a limpeza e a inspeção completa de cada placa;

- Alta taxa de transferência de calor, o que permite uma boa eficiência térmica mesmo com pequeno diferencial de temperatura entre os fluidos;

- Turbulência induzida no escoamento em baixa velocidade;

- Viabilidade econômica para fabricação em aço inoxidável;

- Construção compacta e modular que permite acomodar várias seções de troca térmica em um mesmo pedestal;

- Flexibilidade, que permite mudanças em seu arranjo, número de placas e de passes visando uma otimização do processo.

Outros benefícios dos trocadores de calor a placas são que o coeficiente de transferência de calor é alto e o trocador é compacto e as placas podem ser produzidas em série (KIM; TADINI; SINGH, 1999).

Uma das principais desvantagem dos trocadores de calor a placas são os limites operacionais de pressão e temperatura, sendo cerca de 20,4 bar e $150{ }^{\circ} \mathrm{C}$ respectivamente. Estas condições de operação podem ser estendidas até aproximadamente 40,8 bar e $800^{\circ} \mathrm{C}$ para unidades de trocadores de calor a placas de tipo lamela que não apresentem a flexibilidade das unidades de placas e gaxetas (ABU-KHADER, 2012).

Na Figura 3.2, são mostrados alguns exemplos de PHEs. 

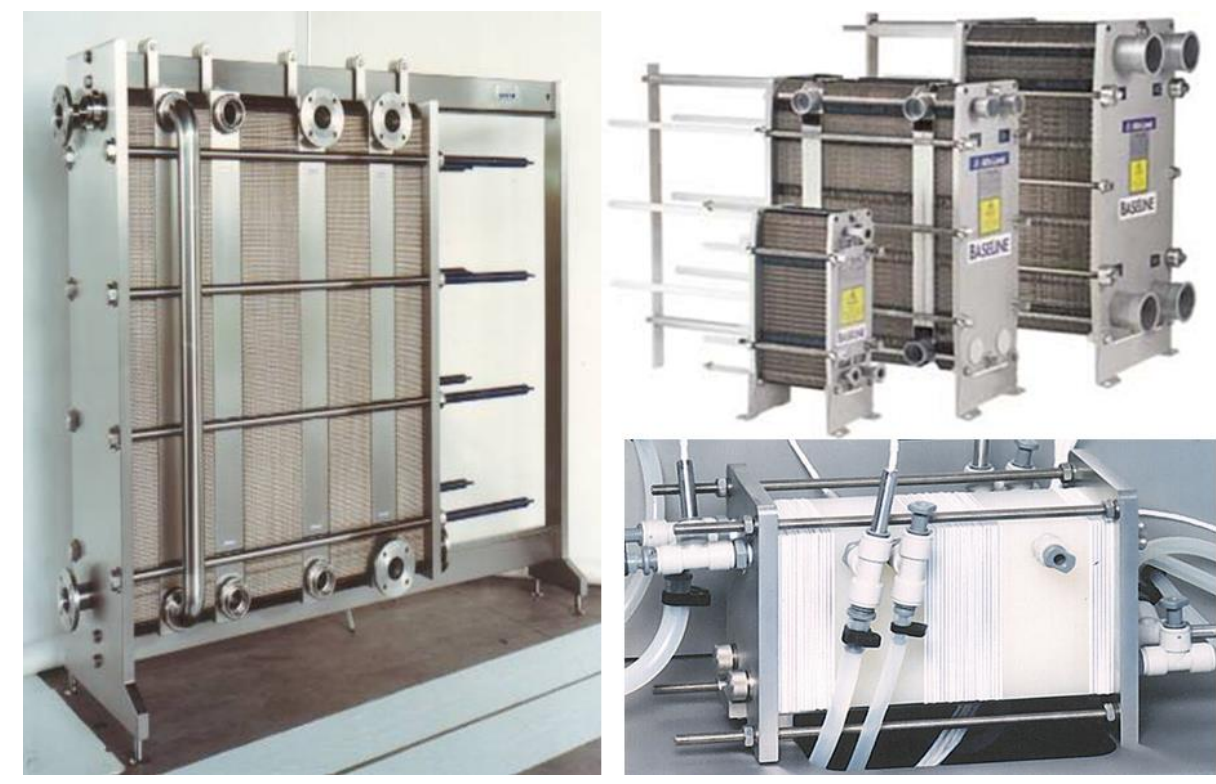

Figura 3.2 - Modelos de trocadores de calor a placas de diferentes escalas (ARMFIELD, 2012; ALFA LAVAL, 2011).

O trocador de calor a placas é composto basicamente por um pacote de finas placas metálicas prensadas em um pedestal, como mostra a Figura 3.3. O pedestal possui uma placa fixa e uma placa de aperto móvel, barramentos inferior e superior e parafusos de aperto. A placa fixa e a placa de aperto possuem bocais para conexão das tubulações de alimentação e de coleta dos fluidos (GUT et al., 2004).
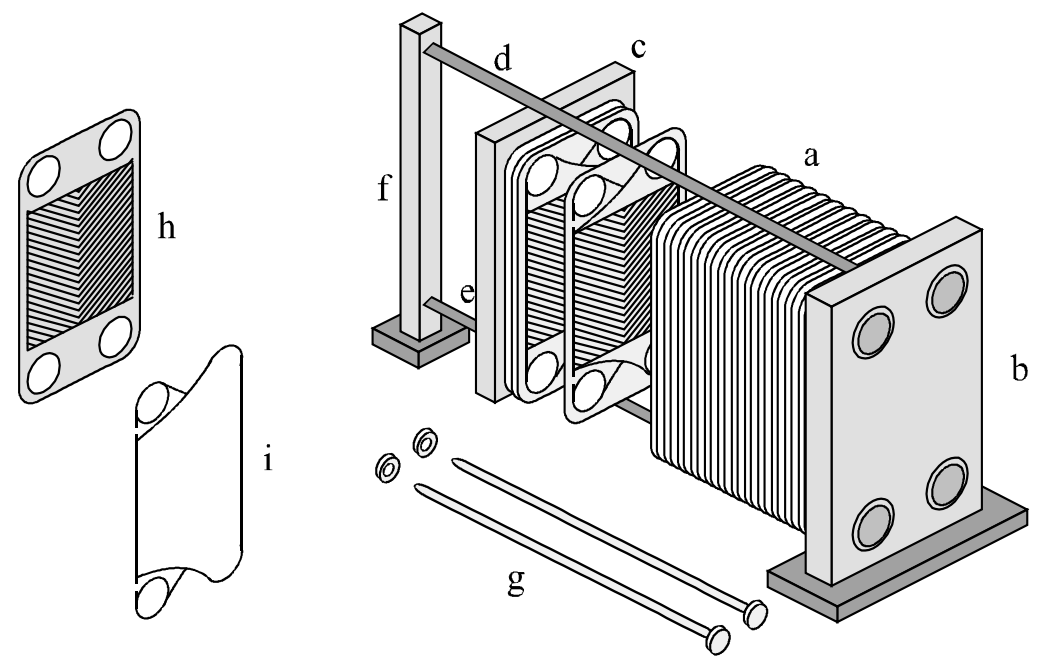

a. Pacote de placas aberto

b. Placa fixa com conexões

c. Placa de aperto móvel

d. Barramento superior

e. Barramento inferior

f. Coluna de sustentação

g. Parafusos de aperto

h. Placa corrugada chevron

i. Gaxeta

Figura 3.3 - Trocador de calor a placas aberto e suas partes principais (GUT; PINTO, 2003b). 
Cada uma das placas do PHE possui orifícios nos cantos para a passagem dos fluidos e são seladas nas extremidades por gaxetas de material elastomérico (também chamadas de juntas). Quando as placas são alinhadas e prensadas no pedestal, forma-se entre elas uma série de estreitos canais paralelos de escoamento onde os fluidos escoam e trocam calor através das placas metálicas.

O espaço compreendido entre duas placas é um canal de escoamento. O fluido entra e sai dos canais através dos orifícios nas placas e o seu caminho por dentro do PHE é definido pelo desenho das gaxetas, pelos orifícios abertos e fechados das placas e pela localização das conexões de alimentação. A configuração do PHE define as trajetórias dos fluidos quente e frio dentro do trocador e existe um grande número de possibilidades de configuração (GUT; PINTO, 2003a).

\subsubsection{Configurações do trocador de calor a placas}

Na Figura 3.4 é mostrada uma representação das placas e do escoamento no trocador de calor a placas.
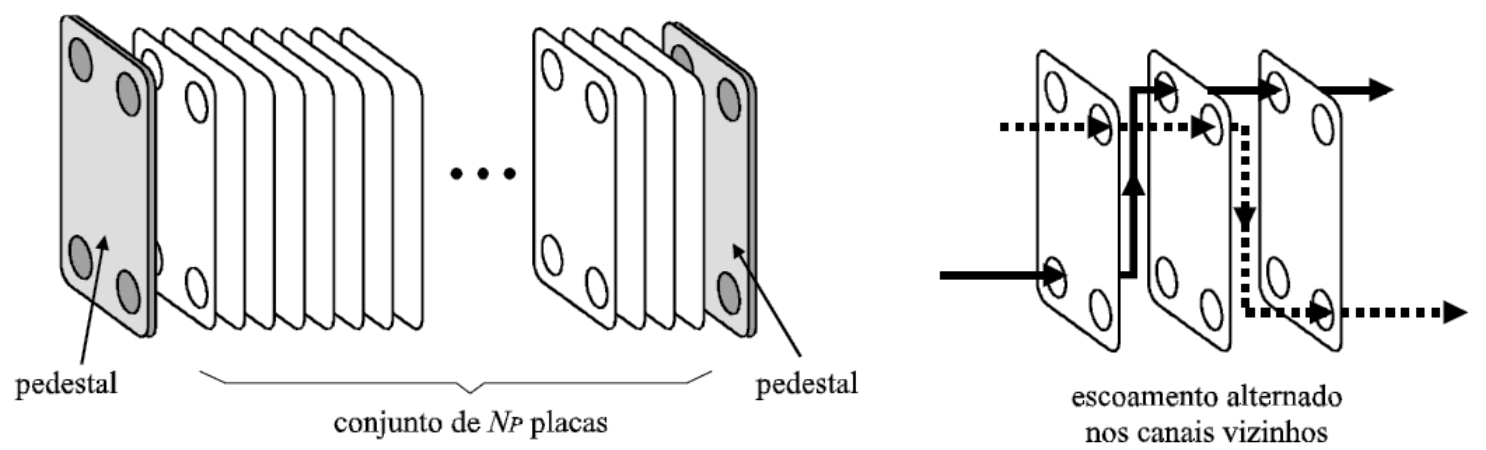

Figura 3.4 - Representação gráfica das placas e escoamento no trocador de calor a placas (GUT, 2003).

O número total de placas do pacote é designado como $N_{P}$ e o número de canais formados como $N_{C}$, em que $N_{C}=N_{P}-1$.

Para a configuração de um trocador de calor a placas são utilizados os seguintes parâmetros (GUT, 2003a): 
- $\quad N_{C}$ (número de canais)

- $\quad P^{I}$ e $P^{I I}$ (número de passes nos lados $I$ e $I I$ do trocador de calor a placas)

- $\emptyset$ (localização relativa das conexões de alimentação)

- $\quad Y_{h}$ (localização dos fluidos quente e frio)

- $\quad Y_{f}$ (tipo de escoamento no canal)

Cada um desses parâmetros mencionados é detalhado a seguir.

Os canais no trocador de calor são numerados de 1 até $N_{C}$ conforme 0 esquema da Figura 3.5. O lado I compreende o conjunto de canais de número ímpar e o lado II o conjunto de canais de número par. Portanto, cada lado possui um determinado número de canais de escoamento representados por $N_{C}^{I}$ e $N_{C}^{I I}$, respectivamente.

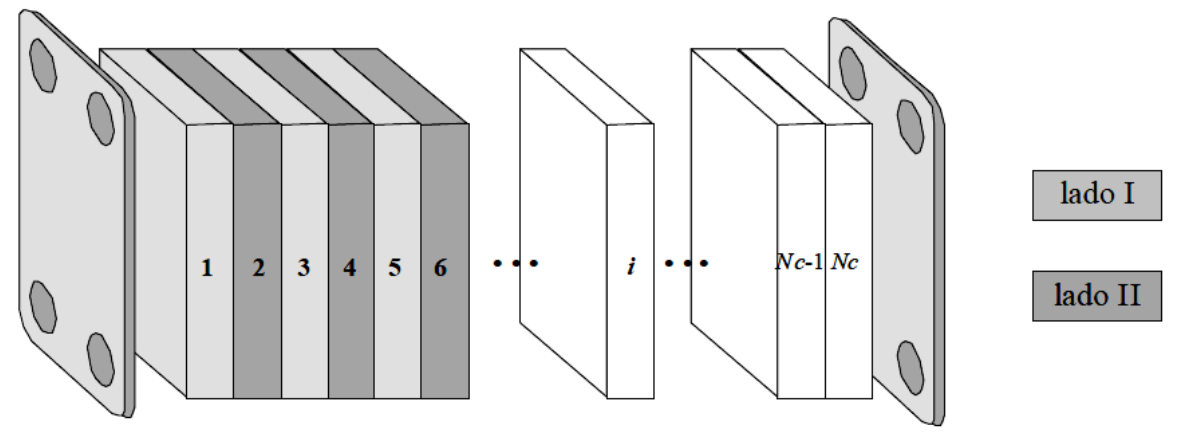

Figura 3.5 - Representação esquemática do número de canais do trocador de calor a placas (GUT, 2003).

A quantidade de canais pares e ímpares para cada lado do trocador de calor é calculado conforme as equações (3.1) e (3.2).

$$
N_{C}^{I}=\left\{\begin{array}{cc}
\frac{N_{C}}{2} & \text { se } N_{C} \text { é par } \\
\frac{N_{C}+1}{2} & \text { se } N_{C} \text { é ímpar }
\end{array}\right.
$$




$$
N_{C}^{I I}=\left\{\begin{array}{cc}
\frac{N_{C}}{2} & \text { se } N_{C} \text { é par } \\
\frac{N_{C}-1}{2} & \text { se } N_{C} \text { é ímpar }
\end{array}\right.
$$

A distribuição de fluxo dentro dos trocadores de calor a placas é feita em forma de "passes". O número de passes nos lados $I$ e $I I$ do trocador de calor é representado pelos parâmetros $P^{I}$ e $P^{I I}$ respectivamente. Da mesma forma, o número de passagens de cada lado é representado pelos parâmetros $N^{I}$ e $N^{I I}$ (GUT, 2003).

Estes valores são calculados por meio das equações (3.3) e (3.4):

$$
\begin{aligned}
& N^{I}= \begin{cases}\frac{N_{C}}{2 \cdot P^{I}} & \text { se } N_{C} \text { é par } \\
\frac{N_{C}+1}{2 \cdot P^{I}} & \text { se } N_{C} \text { é ímpar }\end{cases} \\
& N^{I I}= \begin{cases}\frac{N_{C}}{2 \cdot P^{I I}} & \text { se } N_{C} \text { é par } \\
\frac{N_{C}-1}{2 \cdot P^{I I}} & \text { se } N_{C} \text { é ímpar }\end{cases}
\end{aligned}
$$

O arranjo do trocador de calor a placas é representado da forma $P^{I} \times N^{I} / P^{I I} \times N^{I I}$ que pode ser interpretado como $P^{I}$ passes de $N^{I}$ passagens no lado $I$ e $P^{I I}$ passes de $N^{I I}$ passagens para o lado $I I$ do trocador.

A relação entre os três parâmetros $N_{C}, P^{I}$ e $P^{I I}$ é dada pelas equações (3.5), (3.6) e (3.7):

$$
\begin{aligned}
& N_{C}=N_{C}^{I}+N_{C}^{I I} \\
& N_{C}^{I}=N^{I} \cdot P^{I}
\end{aligned}
$$




$$
N_{C}^{I I}=N^{I I} \cdot P^{I I}
$$

Um exemplo de configuração de passes e passagens para um trocador com nove placas é mostrado na Figura 3.6. Os orifícios abertos e fechados das placas, assim como o desenho das gaxetas definem a direção e o sentido de escoamento para cada canal do trocador de calor.

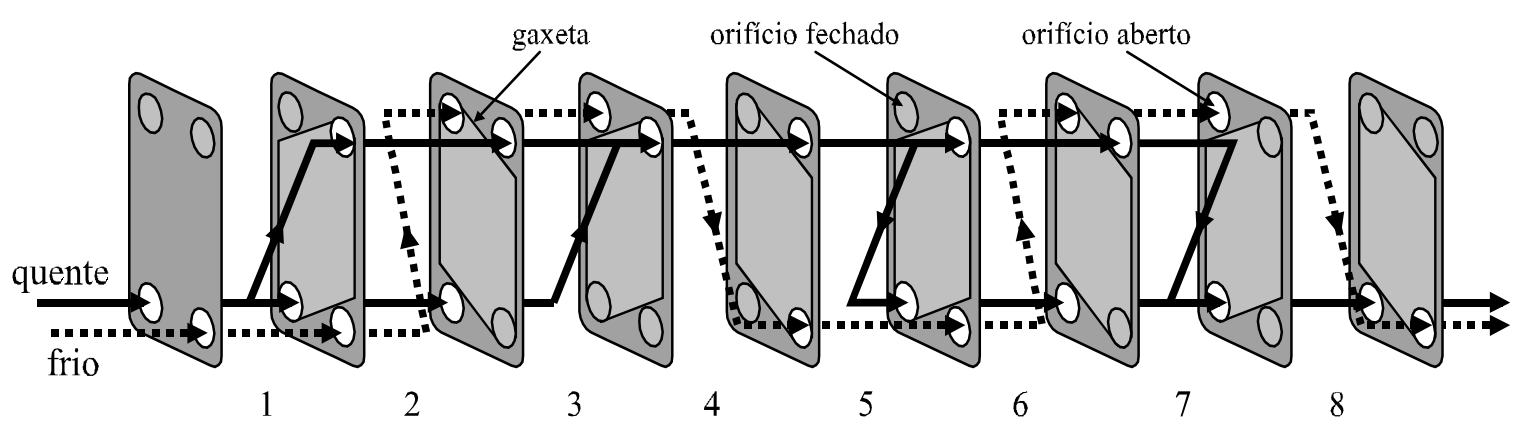

Figura 3.6 - Exemplo de uma configuração de passes e passagens para um PHE com nove placas (GUT; PINTO, 2003b).

Nesta figura é possível observar oito canais de escoamento, onde o fluido quente faz dois passes de duas passagens e o fluido frio faz quatro passes de uma passagem, portanto, a representação do arranjo do exemplo é $2 \times 2 / 4 \times 1$ (GUT;PINTO, 2003a).

Os tipos de arranjos mais comuns são aqueles em paralelo onde os dois fluidos fazem apenas um passe (arranjo $1 \times \mathrm{N} / 1 \times \mathrm{N}$ ) e aqueles em série onde os fluxos não sofrem divisões, ou seja, cada passe tem apenas uma passagem (arranjo $P \times 1$ / $P \times 1$ ). Na Figura 3.7 são mostrados exemplos de arranjos em paralelo e em série para PHEs de nove placas. 

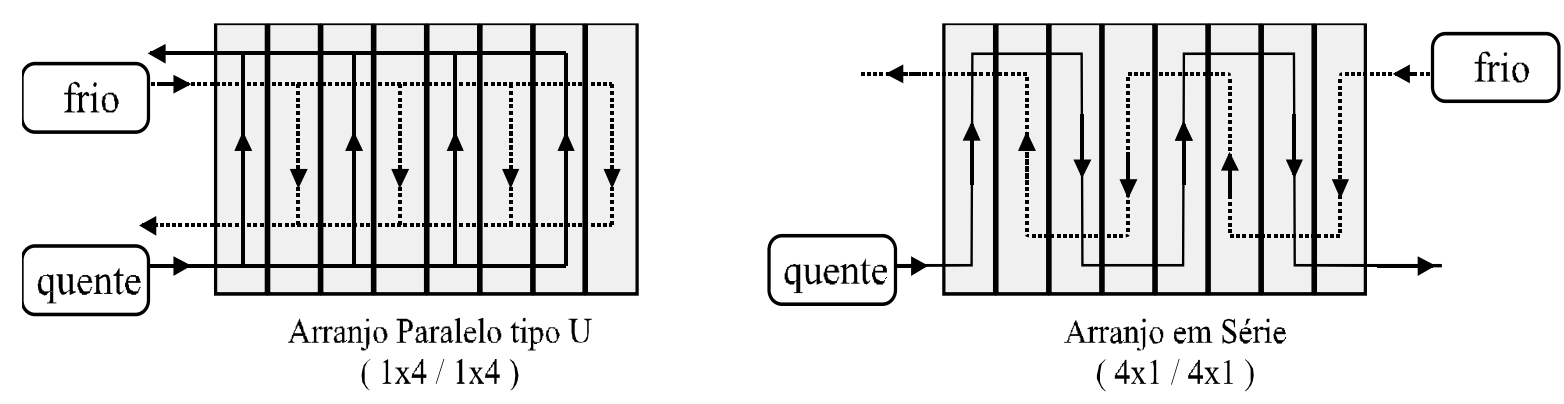

Figura 3.7 - Exemplo de arranjos de passes para um PHE com nove placas (GUT; PINTO, 2003b).

O parâmetro que define a posição da conexão de alimentação para cada lado do trocador é representado por $\emptyset$. A Figura 3.8 mostra um esquema da localização relativa das conexões de alimentação, onde $\eta$ representa a adimensionalização do espaço axial na parte interna do canal.

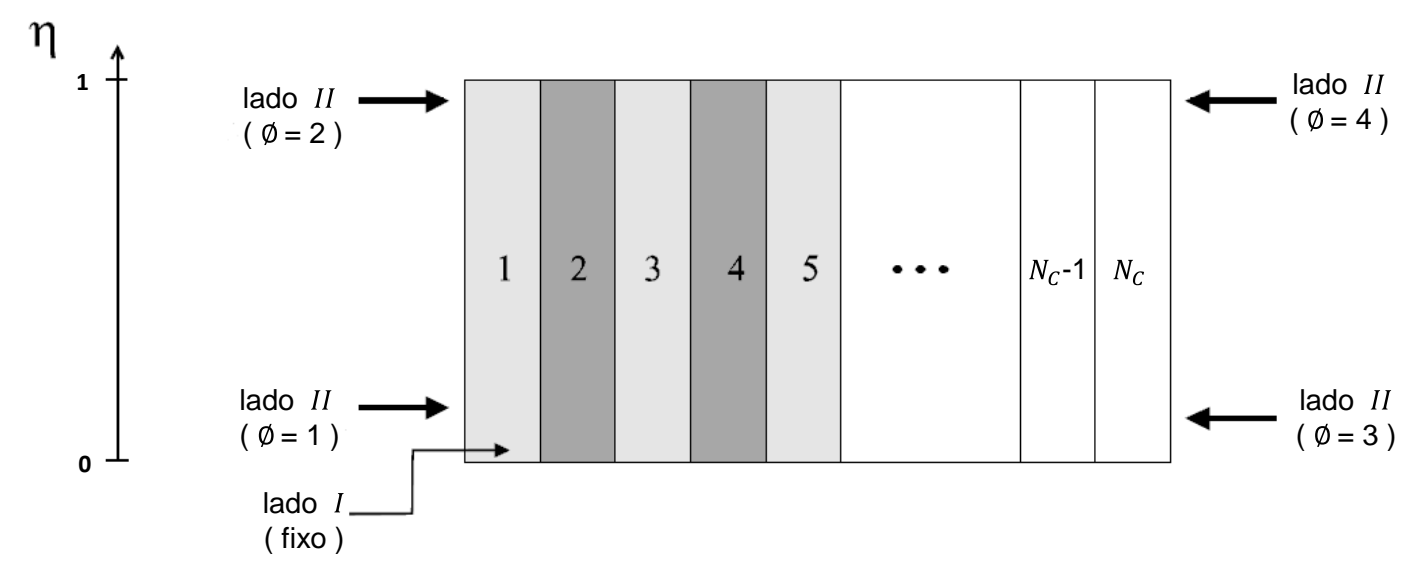

Figura 3.8 - Esquema da localização das conexões de alimentação do trocador de calor a placas placas (GUT, 2003).

A conexão de entrada de alimentação no lado $I$ do trocador é arbitrariamente fixada na posição de $\eta=0$ do primeiro canal como indicada na Figura 3.8. Para descrever a conexão de entrada para o lado $I I$, que não é fixa, o parâmetro $\varnothing$ pode adquirir quatro possíveis valores dependendo da localização da conexão de entrada para este lado, como indica a figura.

O parâmetro binário que descreve a localização dos fluidos quente e frio nos lados $I$ e $I I$ do trocador é designado como $Y_{h}$. O valor de $Y_{h}=1$ é dado quando o 
fluido quente preenche o lado I do trocador de calor. Por outro lado, se o fluido frio é o que preenche o lado $I$, então, o valor designado para este parâmetro é $Y_{h}=0$.

Para caracterizar o tipo de escoamento diagonal e vertical nos canais do trocador de calor a placas é utilizado o parâmetro binário $Y_{f}$. Para descrever um escoamento diagonal o valor deste parâmetro é $Y_{f}=1$ e para descrever um escoamento vertical o valor adotado é $Y_{f}=0$. Na Figura 3.9, são mostrados os dois tipos de escoamento para um trocador de calor de quatro canais.
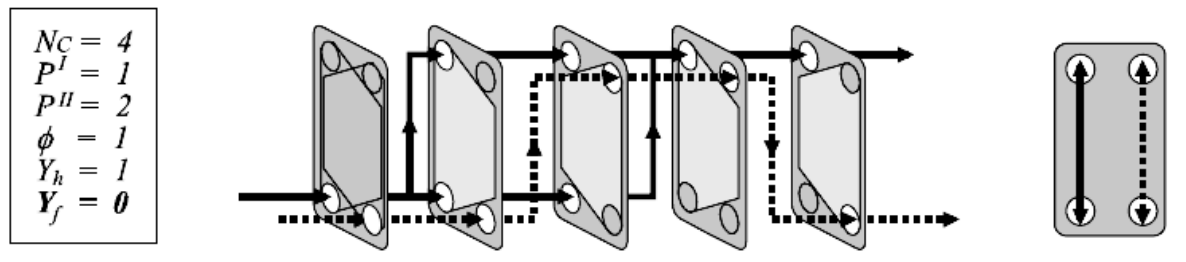

fluxo vertical

\begin{tabular}{|l|}
\hline$N_{C}=4$ \\
$P^{I}=1$ \\
$P^{I I}=2$ \\
$\phi=1$ \\
$Y_{h}=1$ \\
$Y_{f}=1$
\end{tabular}
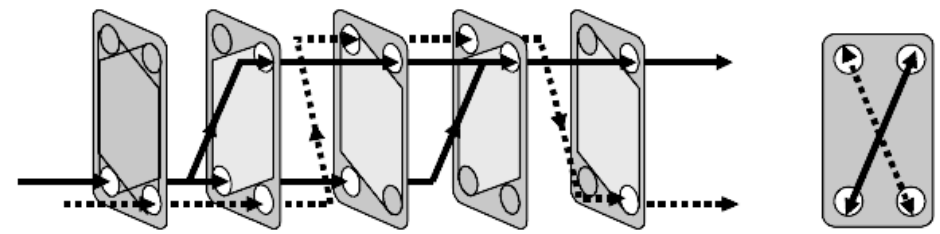

fluxo diagonal

Figura 3.9 - Tipos de escoamento vertical e diagonal em um trocador de quatro canais (GUT, 2003).

Para facilitar a compreensão dos parâmetros de configuração, na Figura 3.10 é apresentado um exemplo de configuração para um trocador de calor com 8 placas, portanto, com 7 canais, indicando os valores e significado de cada parâmetro.

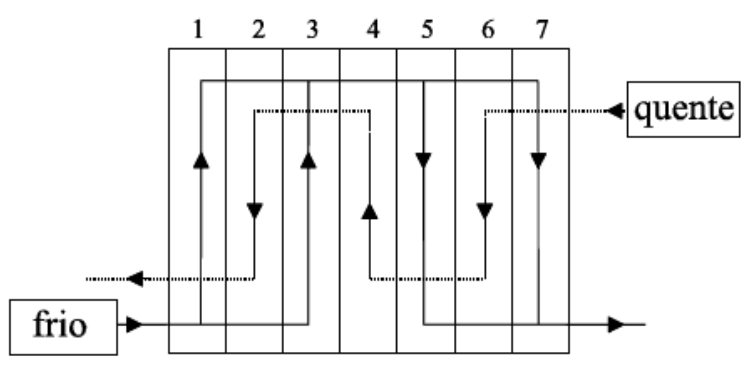

\begin{tabular}{clc}
\hline Parâmetro & Significado & Valor \\
\hline $\boldsymbol{N}_{\boldsymbol{c}}$ & Número total de canais & 7 \\
$\boldsymbol{P}^{\boldsymbol{I}}$ & Número de passes do lado $I$ & 2 \\
$\boldsymbol{P}^{I I}$ & Número de passes do lado $I I$ & 3 \\
$\varnothing$ & Posição da conexão de alimentação & 4 \\
$\boldsymbol{Y}_{\boldsymbol{h}}$ & Localização dos fluidos quente e frio & 0 \\
$\boldsymbol{Y}_{\boldsymbol{f}}$ & Tipo de fluxo nos canais & 1 \\
\hline
\end{tabular}

Figura 3.10 - Exemplo de configuração de um trocador de calor com 7 canais (GUT, 2003). 


\subsection{Modelos dinâmicos de trocadores de calor a placas}

Um modelo matemático pode ser definido como uma equação ou um conjunto de equações que representem de forma quantitativa um determinado sistema real. A obtenção de um modelo matemático aceitável é a parte mais importante na análise de um sistema, pois ele regerá o comportamento do sistema.

A modelagem matemática pode ser aplicada a uma infinidade de casos como projeto, otimização e descrição do comportamento de um processo e de suas unidades. O objetivo mais importante de um modelo matemático é que ele possa ser capaz de descrever o sistema de forma próxima ao real. Segundo Trystam (2012) a modelagem de processos será uma das principais áreas de pesquisa em engenharia de alimentos nos próximos anos.

Para obter um modelo matemático de um sistema dinâmico é preciso o conhecimento da relação entre as variáveis do sistema e a obtenção de equações que descrevam suas relações e comportamentos. Portanto, para o caso da pasteurização, o conhecimento das características do trocador de calor e dos outros componentes do pasteurizador é fundamental para o desenvolvimento do modelo matemático que represente o processo (MACHUDA; URRESTA, 2008).

A importância do uso dos modelos matemáticos reside na facilidade de obter e analisar informação com o objetivo de evitar acidentes, treinar pessoal, desenhar estratégias de controle e analisar paradas e partidas de equipamentos, entre outros. O comportamento dinâmico dos trocadores de calor a placas vem sendo estudado por muitos autores, em virtude da importância desse tipo de equipamento em processos de pasteurização.

Em estudo realizado por Masubuchi e to (1977), o comportamento dinâmico do PHE frente a mudanças de arranjo e tipo de escoamento foi comparado com resultados em estado estacionário. Os autores concluíram que a resposta dinâmica do processo estudado era muito dependente dos parâmetros de configuração utilizados no PHE. Para a resolução do modelo obtido, neste estudo, foram realizadas algumas considerações simplificadoras e o método numérico utilizado foi Runge-Kutta de $4^{\mathrm{a}}$ ordem. 
Lakshmanan e Potter (1990) realizaram um estudo de dois trocadores de calor a placas, de 6 e 8 canais, para escoamento em contracorrente. Com o fim de avaliar o desempenho dinâmico do trocador os autores desenvolveram um modelo matemático a partir de equações diferenciais ordinárias ao qual denominaram "modelo cinemático". Este modelo, segundo os autores, gera resultados precisos do perfil de temperatura, tanto no regime permanente quanto no transiente, com baixo esforço computacional.

Sharifi, Narandji e Mehravaran (1995) estudaram o comportamento de um trocador de calor de cinco placas com arranjo em paralelo e contracorrente frente a variações na temperatura de entrada da água quente. Utilizaram o "modelo cinemático" estendido baseado em diferenças finitas para a discretização de equações diferenciais parciais para simular o perfil de temperatura ao longo dos canais assim como nas saídas do trocador. Os resultados experimentais foram comparados com os resultados numéricos tanto do regime permanente quanto do transiente e apresentaram boa concordância. Os autores indicam que a metodologia obtida por eles é aplicável para qualquer tipo de arranjo e geometria de placas utilizados num trocador.

lbarrola et al. (1998) desenvolveram e validaram um modelo matemático não fenomenológico para um processo de pasteurização HTST a partir de dados de um processo de pasteurização existente. Cada parte física da planta foi identificada separadamente e o processo inteiro foi considerado como uma união de todas as partes. Este modelo foi capaz de trabalhar com diferentes pontos de operação dentro dos limites do hardware e conseguiu integrar a não-linearidade através de parâmetros variáveis. Os softwares utilizados foram o MATLAB e o Simulink para a análise e estimação de parâmetros. A validação dos resultados mostrou que o modelo reproduziu o comportamento do processo sendo adequado para avaliação do processo frente a mudanças de vazão.

Georgiadis e Macchietto (2000) apresentaram uma modelagem dinâmica fenomenológica de um trocador de calor a placas, de 6 canais, para um processo de aquecimento de leite. Baseado na cinética de desnaturação de proteínas, o modelo obtido em regime transitório permitiu analisar a queda do coeficiente global de troca térmica ao longo do tempo, providenciando critérios significativos sobre os fatores que influenciam o fenômeno de incrustação do leite sobre a superfície dos 
trocadores de calor a placas, assim como a identificação de possíveis formas de mitigação deste efeito. Baseados nos resultados dinâmicos, eles concluíram que, devido à turbulência nos canais do trocador de calor a placas, o efeito de incrustação não é tão severo quanto no caso do trocador de calor de tubos e argumentaram também que a incrustação não foi uniforme ao longo dos canais e foi sempre menor depois do primeiro tratamento térmico do leite. O software utilizado para a solução deste modelo foi gPROMS.

A distribuição de fluxo dentro do trocador de calor a placas é um fator importante a ser considerado. Estudos realizados por Rao, Kumar e Das (2002) mostraram que a má distribuição de fluxo dentro dos canais do trocador exerce um papel importante no desempenho térmico do trocador de calor, tanto no domínio transiente como no estacionário. Esta influência também foi corroborada por Thonon, Mercier e Feidt (1992). Outro estudo feito por Shihari et al. (2005) indica que a influência da má distribuição nos canais do trocador é sensível à dispersão axial (número de Peclet) e ao número de placas, e é quase independente do NTU (número de unidades de transferência) e da capacidade calorífica.

De acordo com Grijspeerdt et al. (2004), uma modelagem rigorosa do processo é necessária para que o tratamento térmico possa ser simulado e otimizado visando determinar condições ótimas de operação para minimizar os efeitos indesejáveis do aquecimento, garantir a qualidade e segurança microbiológica do alimento e reduzir os custos operacionais. Portanto, para uma correta modelagem do processo são fundamentais modelos térmicos e hidráulicos rigorosos do equipamento, dados de cinética de inativação térmica e de propriedades termofísicas confiáveis.

Um processo de pasteurização do leite HTST com trocador de calor a placas e fluxo contracorrente foi simulado e otimizado por Bom et al. (2010). Para a simulação, um fluxograma do processo foi desenvolvido usando um simulador geral de processos (ProSimPlus) e foi construída uma base de dados com valores e funções para a estimação das propriedades físicas do leite e água. Para a otimização do processo, foi criada uma função objetivo e foram também considerados custos de energia para a avaliação dos aspectos econômicos. $O$ fluxograma e as funções objetivo podem ser modificados, de acordo aos interesses, introduzindo valores de parâmetros como pressão, tamanho de trocador, superfície de troca térmica, coeficiente de transferência de calor e temperaturas. Este 
programa de simulação, segundo os autores, pode ser aplicado a outros tipos de alimentos com a introdução das propriedades físicas dos mesmos.

\subsection{Efeito da incrustação em trocadores de calor}

A formação de depósitos indesejáveis de materiais na superfície dos trocadores de calor aumenta a espessura da parede entre os fluidos provocando um aumento da resistência à transferência de energia e uma diminuição da eficiência na troca térmica, podendo até obstruir a passagem do fluido (BOTT, 1995).

Estudos realizados sobre incrustações concentram-se principalmente em equipamentos de troca térmica, como é o caso dos trocadores de calor instalados nas indústrias alimentícias e petroquímicas.

O processo de formação do depósito é em geral complexo e pode ser provocado por sedimentação, polimerização, cristalização, coqueamento, corrosão, ou causas de natureza orgânica. A taxa de formação deste depósito é afetada por condições de processo tais como natureza dos fluidos, velocidade de escoamento, temperatura dos fluidos, tipo de trocador de calor, desempenho hidrodinâmico e termodinâmico, material e condições de funcionamento, entre outros (JUN; PURI, 2005).

Uma quantidade considerável de trabalhos foi realizada sobre processos de incrustação do leite em trocadores de calor, pois o tratamento térmico do leite é a base para a indústria de laticínios onde a higienização e manutenção são fundamentais (CHANGANI et al., 1997). Contudo, os mecanismos da incrustação ainda não são totalmente compreendidos. Uma parte do problema é devido à natureza complexa do leite (BANSAL; CHEN, 2006).

Outros estudos relativos ao leite indicam que além da influência da composição do produto, $\mathrm{pH}$ e temperatura de processamento, outros aspectos como a geometria da placa e presença de bolhas de ar no processo também têm-se mostrado influentes sobre a taxa de incrustação (GRUSPEERDT et al., 2003). Segundo Jeurnink (1995), a presença de bolhas de ar no trocador pode gerar sobreaquecido da superfície, resultando no local, um lugar propício para a nucleação da incrustação. 
Um fator que reduz a formação de incrustação é a turbulência, pois mantém os sólidos em suspensão. O fator de incrustação para uma mesma velocidade média de escoamento é aproximadamente dez vezes menor para trocadores de calor a placas daquele valor adotado para os trocadores casco-e-tubos, esta diferença devido à turbulência induzida em baixa velocidade de fluxo pela corrugação das placas (GUT; PINTO, 2003b). Um estudo de Youcef et al. (2009), onde foi utilizado um modelo bidimensional para estudar a incrustação num trocador de calor a placas, reportou que entre muitos fatores que influenciam a incrustação, a velocidade de escoamento é um dos mais importantes, portanto, concluíram que o grau de incrustação é também relacionado com o número de Reynolds e é inversamente proporcional ao mesmo.

Nas indústrias de laticínios, o custo ocasionado pela interrupção da produção para limpeza do equipamento pode ser algumas vezes comparado com o custo ocasionado por diminuição da eficiência na troca térmica no processo (CHENG; FRISS, 2007). Por outro lado, segundo Georgiadis et al. (1998), junto com o custo,

problemas de qualidade e contaminação do produto são fatores muito mais importantes a serem avaliados no processamento de alimentos.

\subsubsection{Fator de incrustação}

Para quantificar o efeito de incrustação, costuma-se usar um parâmetro definido como fator de incrustação ou fator de sujeira ("fouling factor"). Este fator, dimensionalmente, é o inverso do coeficiente de transporte de energia por convecção e quanto maior é o fator de incrustação, maior é a quantidade de massa depositada, consequentemente, maior a resistência à troca térmica.

$\mathrm{Na}$ literatura podem ser encontradas faixas de valores típicos de fator de incrustação para operações comuns. Como o depósito é um processo complexo, que depende de uma série de variáveis, é difícil de ser previsto. Por essa razão, valores típicos de incrustação da literatura devem ser usados com reserva e cautela, pois dificilmente irão refletir a realidade específica de um processo. Os valores mais confiáveis são os obtidos experimentalmente para cada caso particular (BOTT, 1995). 
O fenômeno de incrustação tem sido reconhecido como um problema quase geral no processamento térmico de alimentos líquidos, tanto no projeto quanto na operação dos equipamentos. Um dos maiores problemas deve-se à baixa condutividade térmica que possui a camada incrustante que provoca o aumento da resistência térmica e a diminuição da transferência de calor, reduzindo assim a eficiência na troca térmica, entre outros problemas. Portanto, o fator de incrustação deve ser considerado a priori num projeto de troca térmica, pois a área de troca térmica calculada deve ser suficiente para cumprir as necessidades do processo quando o trocador está novo (limpo) e assim como quando o trocador está em operação há algum tempo (já com incrustação). Como o valor desse fator é difícil de ser previsto, essa deficiência constituirá uma das causas principais da imprecisão no projeto de um trocador de calor. A experiência profissional nesse aspecto é então fundamental.

O fator de incrustação em geral é influenciado por muitos fatores, como a natureza do fluido (relacionada com o mecanismo de incrustação), variáveis de operação do processo (velocidade de escoamento, temperatura e tempo de residência), efeito da estrutura do equipamento (tipo de material e superfície) e efeito da geometria do desenho do equipamento e sistema de circulação dos fluidos. Por esta razão, a utilização dos modelos matemáticos para descrever este efeito auxilia o entendimento (TIRUMALESH et al., 1997; JEURNINK et al., 1996; DELPLACE et al., 1997; VISSER et al., 1997; BELMAR-BEINY e FRYER, 1993).

O modelo genérico de incrustação apresentado na equação (3.8), proposto pela primeira vez por Kern e Seaton (1959) é um dos mais conhecidos e utilizados para a previsão da incrustação.

$$
\frac{d m_{f}}{d t}=\emptyset_{d}-\emptyset_{r}
$$

Sendo:

$m_{f}=$ Massa incrustada na área superficial de troca térmica $\left(\mathrm{kg} / \mathrm{m}^{2}\right)$ 
$\frac{d m_{f}}{d t}=$ Taxa de formação de incrustação na área superficial de troca térmica $\left(\mathrm{kg} / \mathrm{m}^{2} . \mathrm{s}\right)$

$\emptyset_{d}=$ Taxa de crescimento de massa incrustada na área superficial de troca térmica que depende do mecanismo de incrustação $\left(\mathrm{kg} / \mathrm{m}^{2} . \mathrm{s}\right)$

$\emptyset_{r}=$ Taxa de remoção de massa incrustada na área superficial de troca térmica que depende da forca de adesão do depósito e da tensão de cisalhamento $\left(\mathrm{kg} / \mathrm{m}^{2} . \mathrm{s}\right)$

$t \quad=$ Tempo $(\mathrm{s})$

A Figura 3.11 mostra uma forma idealizada de representar a evolução da incrustação no tempo.

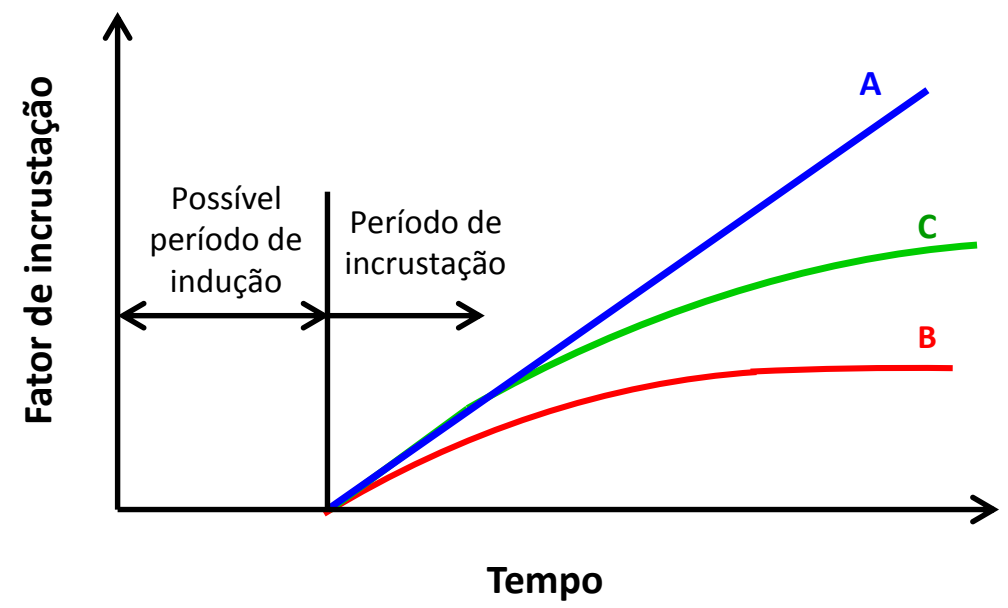

Figura 3.11 - Tendência do fator de incrustação em função do tempo.(A) Incrusração linear, (B) Incrustação assintótica e (C) Incrustação intermediária entre linear e assintótica (CHANGANI et al., 1997).

Na Figura 3.11, a curva A, chamada de "incrustação linear" ou incrustação constante, indica que a taxa de remoção é desprezível ou as taxas de remoção e deposição são constantes, sendo predominante a taxa de deposição. Os processos industriais que apresentam este comportamento podem ficar obstruídos após determinado tempo de operação, sendo necessária a parada do processo para a limpeza do equipamento.

A curva B, chamada de "incrustação assintótica", indica uma taxa de remoção crescente com aumento da camada incrustante até chegar num ponto onde são 
igualadas as taxas de deposição e remoção, sugerindo assim, que a força de coesão dos depósitos está decrescendo, ou que outro mecanismo está reduzindo a estabilidade da camada incrustante. Os sistemas industriais que apresentam esse comportamento podem trabalhar sem paradas obrigatórias para limpeza.

A curva "C" apresenta um comportamento intermediário entre as curvas " $\mathrm{A}$ " e "B", sendo quase constante no início da incrustação para depois apresentar uma queda na velocidade de incrustação.

O período de indução ou período de nucleação é o período de processamento térmico onde ainda não é efetivada a incrustação. Este tempo significa o período onde se dá início a formação de depósitos insolúveis na solução. Para qualquer tipo de incrustação, o período de indução diminui quando a superfície é rugosa, pois proporciona um lugar adicional para a nucleação e adsorção.

Nos processos industriais de transferência de calor a duração do período de indução é de grande importância, pois uma vez que o processo entra no período linear o equipamento se torna inoperante após certo tempo de operação. 


\section{MODELAGEM MATEMÁticA DO PROCESSO DE PASTEURIZAÇÃO}

Neste capítulo é desenvolvido um modelo matemático de base fenomenológica para a simulação de um processo contínuo de pasteurização em trocador de calor a placas.

A modelagem é apresentada em duas partes: modelagem de um trocador de calor a placas e modelagem do tubo de retenção e trechos de tubo, pois estes são os principais elementos presentes no pasteurizador.

As considerações que foram utilizadas para a modelagem do processo de pasteurização foram:

A1) Operação em regime transiente;

A2) Fluxo incompressível unidirecional (pistonado);

A3) Distribuição uniforme de fluxo, considerando mistura perfeita nas entradas e saídas dos passes do PHE;

A4) Temperatura do fluido uniforme na seção transversal dos canais;

A5) Temperatura uniforme na seção transversal das placas;

A6) Perdas de calor para o ambiente são consideradas no tubo de retenção e nos trechos de tubo;

A7) Perdas de calor para o ambiente são desprezíveis no PHE;

A8) No PHE, os fluidos trocam calor com as placas adjacentes por convecção e sem difusão axial de calor nos fluidos;

A9) No PHE, as placas trocam calor com os canais adjacentes por convecção e há difusão axial de calor por condução;

A10) Propriedades físicas dos fluidos são consideradas constantes em cada seção do processo;

A11) Sem mudanças de fase. 


\subsection{Modelagem de um trocador de calor a placas}

O equipamento de pasteurização possui três trocadores de calor a placas que são as três seções de troca térmica para os processos de aquecimento, regeneração e resfriamento. A modelagem matemática do trocador foi desenvolvida para uma seção genérica do trocador com configurações de arranjo definidas, sendo possível aplicar a mesma metodologia da modelagem para as outras seções.

Na modelagem do trocador é importante lembrar que a associação dos fluidos aos lados $I$ e $I I$ do trocador, assim como as propriedades e características de cada fluido, estão associadas ao valor do parâmetro $Y_{h}$.

A vazão mássica no lado $I$, para um valor de $Y_{h}=1$, poderá ser representada por $W^{I}$ ou $W_{h o t}$, consequentemente, a vazão mássica do lado II será representada por $W^{I I}$ ou $W_{\text {cold }}$. Da mesma forma, se o valor do parâmetro é $Y_{h}=0$, a representação da vazão do lado I será de $W^{I}$ ou $W_{\text {cold }}$ e do lado $I I$ de $W^{I I}$ ou $W_{\text {hot }}$.

As características que devem ser conhecidas para a avaliação do trocador de calor são:

- Parâmetros de configuração do pacote de placas: $N_{C}, P^{I}, P^{I I}, \emptyset, Y_{h}$ e $Y_{f}$.

- Características da placa e do canal: $L$ (comprimento do canal), $w$ (largura do canal), $b$ (espessura do canal), $D_{p}$ (diâmetro do orifício da placa), $e_{p}$ (espessura da placa), $\Phi$ (fator de alargamento da área de troca da placa), $k_{p}$ (condutividade térmica da placa).

- Correlações de troca térmica para obter o coeficiente convectivo referente ao fluido escoando no canal.

Para o fluido quente e fluido frio, devem ser conhecidos:

- Temperaturas de entrada: $T_{\text {hot,in }}$ e $T_{\text {cold,in }}$

- Vazões mássicas: $W_{\text {hot }}$ e $W_{\text {cold }}$

- Equações das propriedades termo-físicas dos fluidos em função da temperatura (densidade $\rho$, viscosidade $\mu$, calor específico $C p$ e condutividade térmica $k$ ).

- Coeficientes de resistência térmica de incrustação (fator de incrustação, $R_{f}$ ). 
Nos dois lados do trocador de calor, o fluido de alimentação que entra preenche inicialmente os canais (ou canal) que formam o primeiro passe, ou seja, o fluido de alimentação que entra é dividido ou repartido uniformemente em todos os canais que conformam o primeiro passe. Na saída de cada passe ocorre uma mistura perfeita dos fluxos, para logo continuar preenchendo da mesma maneira os próximos passes até preencher todos os canais do trocador.

Para calcular a vazão mássica por canal do fluido $W_{i}$, com a consideração de distribuição uniforme de fluxo e mistura perfeita nos canais (A3), é utilizada a equação (4.1):

$$
W_{i}= \begin{cases}\frac{W^{I}}{N^{I}} & \text { se } i \text { é ímpar (canal pertence ao lado } I \text { ) } \\ \frac{W^{I I}}{N^{I I}} & \text { se é par (canal pertence ao lado } I I \text { ) }\end{cases}
$$

A consideração A8 da troca de calor no sentido do escoamento pode ser ignorada na modelagem dos trocadores de calor se a condição de $\operatorname{Re} \operatorname{Pr}>10$ for cumprida (SHAH, 1983; GUT; PINTO, 2003a), condição que geralmente é bem cumprida nos trocadores de calor a placas.

Com esta consideração, o balanço global de energia é descrito pela equação (4.2) onde a taxa de calor trocado, $Q$, pode ser descrita como a taxa de calor liberado pela corrente quente, $Q_{\text {hot }}$, e recebido pela corrente fria, $Q_{\text {cold }}$.

$$
Q=\left\{\begin{array}{l}
Q_{\text {hot }}=W_{\text {hot }} \cdot \overline{C p}_{\text {hot }} \cdot\left(T_{\text {hot }, \text { in }}-T_{\text {hot }, \text { out }}\right) \\
Q_{\text {cold }}=W_{\text {cold }} \cdot \overline{C p}_{\text {cold }} \cdot\left(T_{\text {cold }, \text { in }}-T_{\text {cold }, \text { out }}\right)
\end{array}\right.
$$

Assumindo que os fluidos quente e frio escoem do lado $I$ e lado $I I$ do trocador de calor a equação (4.2) pode ser também apresentada da forma da equação(4.3). 


$$
Q=\left\{\begin{array}{l}
Q^{I}=W^{I} \cdot \overline{C p}^{I} \cdot\left|T_{\text {in }}^{I}-T_{\text {out }}^{I}\right| \\
Q^{I I}=W^{I I} \cdot \overline{C p^{I I}} \cdot\left|T_{\text {in }}^{I I}-T_{\text {out }}^{I I}\right|
\end{array}\right.
$$

Para calcular o calor trocado são usados os valores médios dos calores específicos $\overline{C_{P}}$ para cada fluido.

$$
\overline{C p}_{i}=\frac{C p_{T_{i, \text { in }}}+C p_{T_{i, \text { out }}}}{2}
$$

A equação (4.5) define o coeficiente global de troca térmica, que relaciona a convecção, a condução e a incrustação. Os parâmetros $h_{\text {hot }}$ e $h_{\text {cold }}$ são os coeficientes convectivos de troca térmica e os parâmetros $R_{f, h o t}$ e $R_{f, \text { cold }}$ são os fatores de incrustação dos fluidos quente e frio do trocador de calor. Os parâmetros $e_{p}$ e $k_{p}$ são a espessura e a condutividade térmica das placas.

$$
\frac{1}{U}=\frac{1}{h_{\text {hot }}}+\frac{1}{h_{\text {cold }}}+\frac{e_{p}}{k_{p}}+R_{f, \text { hot }}+R_{f, \text { cold }}
$$

Os coeficientes convectivos de troca térmica estão relacionados com os parâmetros de configuração do trocador, propriedades físicas dos fluidos, vazão e geometria do canal e são geralmente calculados a partir da seguinte correlação (GUT; PINTO, 2009):

$$
N u=a_{1} \cdot \operatorname{Re}^{a_{2}} \cdot \operatorname{Pr}^{a_{3}}
$$


Os números adimensionais de Reynolds $(R e)$, que é a relação entre as forças de inércia e as forças viscosas, Prandtl $(P r)$, que é a relação entre a difusividade de momento e a difusividade térmica e que relaciona a distribuição de temperatura à distribuição de velocidade e Nusselt $(N u)$, que é o gradiente de temperatura adimensional na interface fluido-superfície, são expressos na equação (4.7) (BIRD; STEWART; LIGHTFOOT, 2001).

$$
R e=\frac{G_{C} \cdot D_{e}}{\mu} \quad ; \quad \operatorname{Pr}=\frac{C p \cdot \mu}{k} \quad ; \quad N u=\frac{h \cdot D_{e}}{k}
$$

Os valores dos parâmetros $a_{1}, a_{2}$ e $a_{3}$ da equação (4.6) podem ser obtidos experimentalmente através do ajuste de parâmetros (GALEAZZO et al., 2006).

O diâmetro equivalente do canal, $D_{e}$, é considerado igual ao diâmetro hidráulico que é definido como o quádruplo da razão entre a área de escoamento, $A_{e}$, e o perímetro molhado, $P_{W}$. Nos canais do trocador de calor a placas, como o valor da espessura do canal, $b$, é muito pequena comparada com o valor da largura da parte úmida da placa, $w$, o cálculo do valor do diâmetro equivalente da placa pode ser feita com a seguinte aproximação (KAKAÇ; LIU, 2002):

$$
D_{e}=\frac{4 \cdot A_{e}}{P_{W}}=\frac{4 \cdot(b \cdot w)}{2 \cdot(b+w \cdot \Phi)} \cong \frac{2 \cdot b}{\Phi}
$$

Os fluxos mássicos dos canais dos lados $I$ e $I I$ do trocador, $G_{C}^{I}$ e $G_{C}^{I I}$, podem ser calculados com as equações (4.9) e (4.10), que relacionam a vazão mássica por canal $W_{i}$ e a área transversal do escoamento do canal $b . w$. 


$$
\begin{aligned}
& G_{C}^{I}=\frac{W^{I}}{N^{I} \cdot b \cdot w} \\
& G_{C}^{I I}=\frac{W^{I I}}{N^{I I} \cdot b \cdot w}
\end{aligned}
$$

O número de unidades de transferência de calor expressado como NTU, também denominado como "comprimento térmico", é uma variável importante para a avaliação do desempenho térmico do trocador que considera tanto a condutância térmica total do equipamento quanto as propriedades físicas do fluido e a vazão. A equação (4.11) representa o número de unidades de transferência de calor, NTU.

$$
N T U=\frac{U \cdot A}{\min \left(W^{I} \cdot \overline{C p}^{I}, W^{I I} \cdot \overline{C p}^{I I}\right)}=\max \left(N T U^{I}, N T U^{I I}\right)
$$

Sendo $A=\left(N_{C}-1\right) \cdot A_{P}$ a área de troca térmica do PHE e $A_{P}$ a área de troca térmica de uma placa.

Expressando esta equação para os dois lados do trocador de calor obtêm-se as equações:

$$
\begin{aligned}
& N T U^{I}=\frac{U^{I} \cdot A}{W^{I} \cdot \overline{C p}} \\
& N T U^{I I}=\frac{U^{I I} \cdot A}{W^{I I} \cdot \overline{C p}^{I I}}
\end{aligned}
$$

A eficiência $E$ do trocador de calor, equação (4.14) é definida como a razão entre a taxa de transferência de calor $Q$ e o valor máximo da taxa de transferência de calor que poderia ocorrer, $Q_{\max }$. 


$$
E=\frac{Q}{Q_{\max }}
$$

Em que:

$$
Q_{\text {max }}=\min \left(W_{\text {hot }} \cdot C p_{\text {hot }}, W_{\text {cold }} \cdot C p_{\text {cold }}\right) \cdot\left(T_{\text {hot }, \text { in }}-T_{\text {cold.in }}\right)
$$

As propriedades termo-físicas da água, como densidade, viscosidade, calor específico e condutividade térmica foram calculadas a partir das equações (4.16), (4.17), (4.18) e (4.19) compiladas por (GUT; PINTO, 2003a). As unidades para estas equações estão dadas em ${ }^{\circ} \mathrm{C}$ para a temperatura, $\mathrm{kg} / \mathrm{m}^{3}$ para a densidade, Pa.s para a viscosidade e J/kg.K para o calor específico.

$$
\begin{aligned}
& \rho=2,080 \times 10^{-5} \cdot T^{3}-6,668 \times 10^{-3} \cdot T^{2}+0,04675 \cdot T+999,9 \\
& \text { (água, } 0 \leq T \leq 90^{\circ} \mathrm{C} \text { ) } \\
& \frac{1}{\mu}=21,482\left[(T-8,435)+\sqrt{8078,4+(T-8,435)^{2}}\right]-1200 \\
& \text { (água, } 0 \leq T \leq 100^{\circ} \mathrm{C} \text { ) } \\
& C p=5,2013 \times 10^{-7} \cdot T^{4}-2,1528 \times 10^{-4} \cdot T^{3}+4,1758 \times 10^{-2} \cdot T^{2}- \\
& 2,6171 \cdot T+4226,1 \quad \text { (água, } 0 \leq T \leq 260^{\circ} \mathrm{C} \text { ) } \\
& k=0,5692+\frac{T}{538}-\frac{T^{2}}{1,333 \times 10^{5}} \quad \text { (água, } 0 \leq T \leq 90{ }^{\circ} \mathrm{C} \text { ) }
\end{aligned}
$$

A Figura 4.1 representa o volume de controle do fluido escoando dentro de um canal genérico $i$ do PHE e trocando calor com as placas adjacentes e da mesma 
forma, representa também a troca de calor das placas com os fluidos que atravessam os canais vizinhos. Como a capacidade calorifica das placas pode ser relevante, o modelo deve contemplar seu aquecimento e resfriamento e não só a resistência térmica.

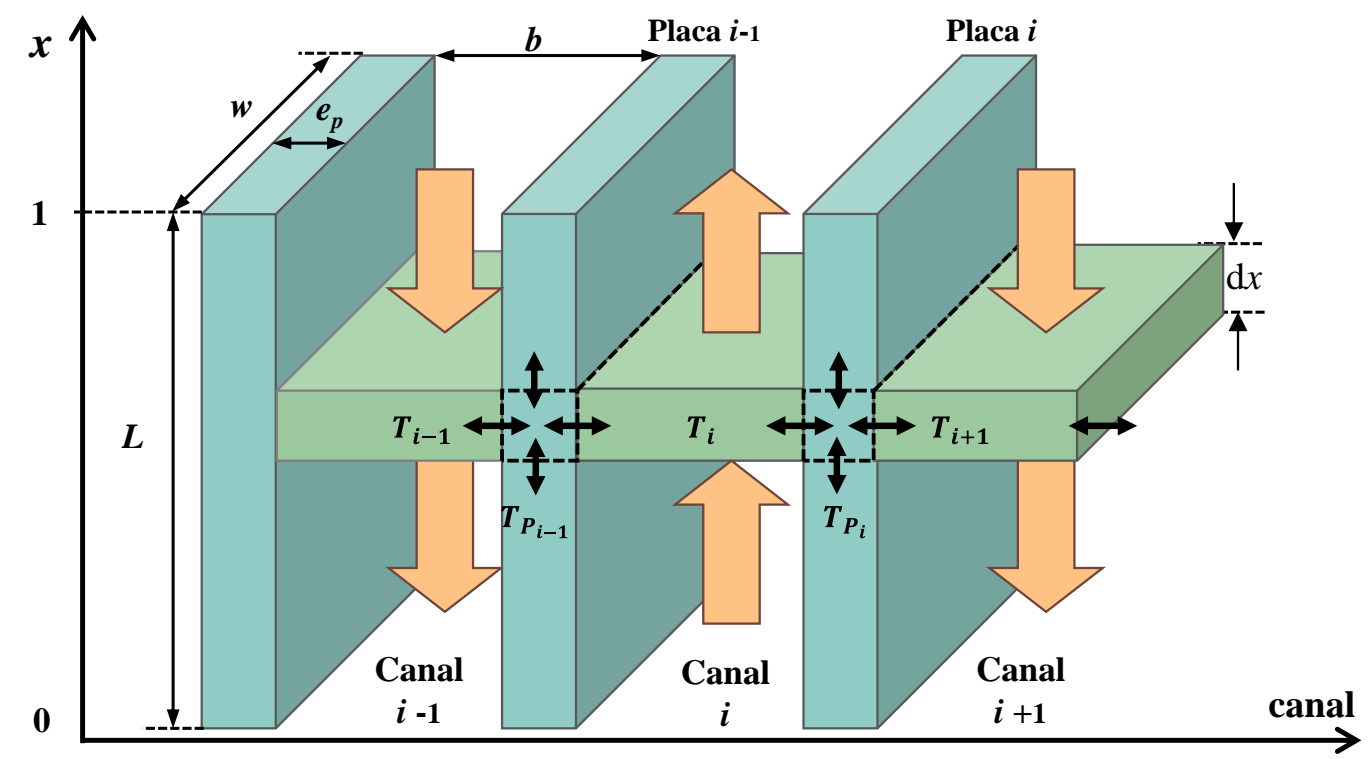

Figura 4.1 - Volume de controle para o balanço diferencial de energia num canal e numa placa genérica $\boldsymbol{i}$ do trocador de calor a placas.

O balanço diferencial de energia em regime transiente para um canal genérico $i$ do PHE, em função do volume de controle da Figura 4.1, onde o fluido que escoa pelo canal $i$ e troca calor com as placas adjacentes $P_{i}$ e $P_{i-1}$ é descrito pela equação (4.20). Nesta equação, os termos de $T_{P_{i}}$ e $T_{P_{i-1}}$ são as temperaturas das placas adjacentes ao canal $i$.

$$
\begin{aligned}
\mathrm{d} V_{c} \cdot \rho_{i} \cdot C p_{i} \cdot \frac{\partial T_{i}}{\partial t}= & W_{i} \cdot C p_{i} \cdot T_{i}(x)-W_{i} \cdot C p_{i} \cdot T_{i}(x+\mathrm{d} x)+\cdots \\
& \mathrm{d} A_{P} \cdot U_{i} \cdot\left[T_{P_{i}}(x)-T_{i}(x)\right]+\mathrm{d} A_{P} \cdot U_{i} \cdot\left[T_{P_{i-1}}(x)-T_{i}(x)\right]
\end{aligned}
$$


A área infinitesimal da placa é igual a $\mathrm{d} A_{p}=\Phi . w . \mathrm{d} x$, e o volume infinitesimal do canal é igual a $\mathrm{d} V_{c}=b \cdot w \cdot \mathrm{d} x$.

Para fins de cálculo, a variável de comprimento $L$ é adimensionalizada segundo a equação (4.21):

$$
\eta(x)=\frac{x}{L} \quad, \quad 0 \leq \eta \leq 1
$$

Utilizando a relação:

$$
\frac{\mathrm{d} V_{C}}{\mathrm{~d} A_{p}}=\frac{b \cdot w \cdot \mathrm{d} x}{\Phi \cdot w \cdot \mathrm{d} x}=\frac{b}{\Phi}
$$

e fazendo uso da adimensionalização axial da equação (4.21), a equação (4.20) pode ser reescrita com introdução do parâmetro $s_{i}$ que descreve a direção do escoamento dentro do canal, sendo que seu valor é +1 se o escoamento no canal $i$ é no sentido da direção $x$, ou -1 se o escoamento é no sentido contrário.

$$
\begin{aligned}
& \frac{b \cdot L \cdot w \cdot \rho_{i} \cdot N_{i}}{W} \cdot \frac{\partial T_{i}}{\partial t}+s_{i} \cdot \frac{\partial T_{i}}{\partial \eta}= \\
& \frac{L \cdot \Phi \cdot w \cdot N_{i} \cdot U_{i}}{C p_{i} \cdot W} \cdot\left(T_{P_{i}}(\eta)-2 \cdot T_{i}(\eta)+T_{P_{i-1}}(\eta)\right)
\end{aligned}
$$

A equação (4.23) de balanço de energia num canal $i$ do PHE pode ser expressa da seguinte forma:

$$
\tau_{i} \cdot \frac{\partial T_{i}}{\partial t}+s_{i} \cdot \frac{\partial T_{i}}{\partial \eta}=\alpha_{i} \cdot U_{i}\left(T_{P_{i-1}}(\eta)-2 \cdot T_{i}(\eta)+T_{P_{i}}(\eta)\right)
$$


onde o termo $\tau_{i}$ é o tempo espacial do fluido no canal $i$ (razão entre volume e vazão volumétrica) e o termo $\alpha_{i}$ é um parâmetro adotado na modelagem. Os termos $\tau_{i}$ e $\alpha_{i}$ são descritos pelas equações (4.25) e (4.26).

$$
\begin{aligned}
\tau_{i} & =\frac{b \cdot L \cdot w \cdot \rho_{i} \cdot N_{i}}{W} \\
\alpha_{i} & =\frac{L \cdot \Phi \cdot w \cdot N_{i}}{C p_{i} \cdot W}
\end{aligned}
$$

O termo $\alpha_{i}$ para os lados I e II do PHE é calculado como:

$$
\alpha^{I}=\frac{N^{I} \cdot \Phi \cdot w \cdot L}{C p^{I} \cdot W^{I}} \quad ; \quad \alpha^{I I}=\frac{N^{I I} \cdot \Phi \cdot w \cdot L}{C p^{I I} \cdot W^{I}}
$$

O balanço de energia nos canais do PHE, especificando a posição do canal, é representado pelas seguintes equações:

Para o primeiro canal:

$$
\tau_{1} \cdot \frac{\partial T_{1}}{\partial t}+s_{1} \cdot \frac{\partial T_{1}}{\partial \eta}=\alpha^{I} \cdot U^{I}\left(T_{P_{1}}(\eta)-T_{1}(\eta)\right)
$$

Para um canal interno $i$, com a condição: $1<i<N_{C}$

Se o canal $i$ é ímpar:

$$
\tau_{i} \cdot \frac{\partial T_{i}}{\partial t}+s_{i} \cdot \frac{\partial T_{i}}{\partial \eta}=\alpha^{I} \cdot U^{I}\left(T_{P_{i-1}}(\eta)-2 \cdot T_{i}(\eta)+T_{P_{i}}(\eta)\right)
$$


Se o canal $i$ é par:

$$
\tau_{i} \cdot \frac{\partial T_{i}}{\partial t}+s_{i} \cdot \frac{\partial T_{i}}{\partial \eta}=\alpha^{I I} \cdot U^{I I}\left(T_{P_{i-1}}(\eta)-2 \cdot T_{i}(\eta)+T_{P_{i}}(\eta)\right)
$$

Para o último canal:

Se $N_{C}$ é ímpar:

$$
\tau_{N_{C}} \cdot \frac{\partial T_{N_{C}}}{\partial t}+s_{N_{C}} \cdot \frac{\partial T_{N_{C}}}{\partial \eta}=\alpha^{I} \cdot U^{I}\left(T_{P_{N_{C-1}}}(\eta)-T_{N_{C}}(\eta)\right)
$$

Se $N_{C}$ é par:

$$
\tau_{N_{C}} \cdot \frac{\partial T_{N_{C}}}{\partial t}+s_{N_{C}} \cdot \frac{\partial T_{N_{C}}}{\partial \eta}=\alpha^{I I} \cdot U^{I I}\left(T_{P_{N_{C-1}}}(\eta)-T_{N_{C}}(\eta)\right)
$$

O coeficiente de transferência de calor entre o centro de um canal e o centro da placa adjacente é calculado com a equação (4.33):

$$
\frac{1}{U_{i}}=\frac{1}{h_{i}}+\frac{e_{p}}{2 \cdot k_{P}}+R_{f, i}
$$

O coeficiente convectivo $h_{i}$ da equação (4.33) pode ser calculado a partir das equações (4.6), (4.7) e (4.8) descritas no texto para o fluido que ocupa o canal $i$.

A eficiência de troca térmica $E$ e o número de unidades de transferência de calor para cada lado do trocador de calor em função dos parâmetros $\alpha^{I}$ e $\alpha^{I I}$ da equação (4.27) podem ser calculados com as equações (4.34) e (4.35) respetivamente (GUT, 2003). 


$$
E=\left\{\begin{array}{l}
E^{I}=\frac{N^{I}}{\alpha^{I} \cdot U^{I}} \cdot \max \left(\frac{\alpha^{I} \cdot U^{I}}{N^{I}}, \frac{\alpha^{I I} \cdot U^{I I}}{N^{I I}}\right) \cdot\left|\frac{T_{\text {in }}-T_{\text {out }}}{T_{\text {in }}}\right|^{I} \\
E^{I I}=\frac{N^{I I}}{\alpha^{I I} \cdot U^{I I}} \cdot \max \left(\frac{\alpha^{I} \cdot U^{I}}{N^{I}}, \frac{\alpha^{I I} \cdot U^{I I}}{N^{I I}}\right) \cdot\left|\frac{T_{\text {in }}-T_{\text {out }}}{T_{\text {in }}}\right|^{I I} \\
N T U^{I}=\left(N_{C}-1\right) \cdot\left(\frac{\alpha^{I} \cdot U^{I}}{N^{I}}\right) ; \quad N T U^{I I}=\left(N_{C}-1\right) \cdot\left(\frac{\alpha^{I I} \cdot U^{I I}}{N^{I I}}\right)
\end{array}\right.
$$

O balanço diferencial de energia em regime transiente para uma placa genérica $i$ do PHE, em função do volume de controle da Figura 4.1, é descrita na equação (4.36). Nesta equação, consideram-se os efeitos de condução e convecção sobre as placas com os fluidos que atravessam os canais adjacentes.

$$
\begin{gathered}
\rho_{P} \cdot C p_{P} \cdot \mathrm{d} V_{P} \cdot \frac{\partial T_{P_{i}}}{\partial t}=U_{i} \cdot \mathrm{d} A_{P} \cdot\left[T_{i}(x)-T_{P_{i}}(x)\right]+\cdots \\
U_{i+1} \cdot \mathrm{d} A_{P} \cdot\left[T_{i+1}(x)-T_{P_{i}}(x)\right]+\left.K_{P} \cdot A_{C} \cdot \frac{\partial T_{P_{i}}}{\partial x}\right|_{x+\mathrm{d} x}-\left.K_{P} \cdot A_{C} \cdot \frac{\partial T_{P_{i}}}{\partial x}\right|_{x}
\end{gathered}
$$

Lembrando que a área da seção transversal do canal é $A_{c}=w . e_{p}$, a área infinitesimal de troca térmica da placa é $\mathrm{d} A_{P}=\Phi . w . \mathrm{d} x$, o volume infinitesimal da placa é $\mathrm{d} V_{P}=e_{p} . w . \mathrm{d} x$ e fazendo uso da equação (4.21) de adimensionalização do comprimento $L$, a equação (4.36) pode ser escrita como: 


$$
\begin{aligned}
& \frac{\rho_{P} \cdot C p_{P} \cdot L^{2}}{k_{P}} \cdot \frac{\partial T_{P_{i}}}{\partial t}-\frac{\partial^{2} T_{P_{i}}}{\partial \eta^{2}}= \\
& \frac{L^{2} \cdot \Phi}{k_{P} \cdot e_{p}} \cdot U_{i} \cdot\left[T_{i}(\eta)-T_{P_{i}}(\eta)\right]+U_{i+1} \cdot\left[T_{i+1}(\eta)-T_{P_{i}}(\eta)\right]
\end{aligned}
$$

Como os fluidos em cada lado adjacente das placas são fluidos distintos, os coeficientes de troca térmica $U_{i}$ e $U_{i+1}$ do balanço de energia das placas do PHE são considerados diferentes, portanto $U_{i} \neq U_{i+1}$.

A difusividade térmica de um material representa a capacidade do material de conduzir a energia térmica em relação à sua capacidade de armazená-la. A difusividade térmica da placa, representada pelo termo $\alpha_{P}$, é descrita na equação (4.38), onde $k_{P}$ é a condutividade térmica da placa, $C p_{P}$ é o calor específico da placa e $\rho_{P}$ é a densidade da placa.

$$
\alpha_{P}=\frac{k_{P}}{\rho_{P} \cdot C_{P_{P}}}
$$

Substituindo a equação (4.38) na equação (4.37), pode ser escrita a equação (4.39) que representa o balanço de energia numa placa genérica $i$ do PHE:

$$
J_{P} \cdot \frac{\partial T_{P_{i}}}{\partial t}-\frac{\partial^{2} T_{P_{i}}}{\partial \eta^{2}}=\beta \cdot\left\{U_{i} \cdot\left[T_{i}(\eta)-T_{P_{i}}(\eta)\right]+U_{i+1} \cdot\left[T_{i+1}(\eta)-T_{P_{i}}(\eta)\right]\right\}
$$

sendo que $J_{\mathrm{P}}$ e $\beta$ são variáveis auxiliares: 


$$
\begin{aligned}
& J_{P}=\frac{L^{2}}{\alpha_{P}} \\
& \beta=\frac{L^{2} \cdot \Phi}{k_{P} \cdot e_{P}}
\end{aligned}
$$

A equação (4.39) do balanço de energia numa placa $i$ pode ser expressa na forma das equações (4.42) e (4.43) segundo a posição da placa no PHE:

Se $i$ é ímpar:

$$
J_{P} \cdot \frac{\partial T_{P_{i}}}{\partial t}-\frac{\partial^{2} T_{P_{i}}}{\partial \eta^{2}}=\beta \cdot\left\{U^{I} \cdot\left[T_{i}(\eta)-T_{p_{i}}(\eta)\right]+U^{I I} \cdot\left[T_{i+1}(\eta)-T_{p_{i}}(\eta)\right]\right\}
$$

Se $i$ é par:

$$
J_{P} \cdot \frac{\partial T_{P_{i}}}{\partial t}-\frac{\partial^{2} T_{P_{i}}}{\partial \eta^{2}}=\beta \cdot\left\{U^{I I} \cdot\left[T_{i}(\eta)-T_{p_{i}}(\eta)\right]+U^{I} \cdot\left[T_{i+1}(\eta)-T_{p_{i}}(\eta)\right]\right\}
$$

\subsection{Modelagem do tubo de retenção e trechos de tubo}

As considerações adotadas para a modelagem matemática do tubo de retenção e trechos de tubo são $A 2, A 6, A 8, A 10$ e $A 11$ mencionadas no início do Capítulo. A modelagem é desenvolvida para um tubo genérico, sendo aplicável tanto para o tubo de retenção quanto nos trechos de tubo adjacentes.

A Figura 4.2 representa o volume de controle para o balanço de energia num tubo genérico indicando a direção de escoamento do fluido quente e a perda de calor para o ambiente. 

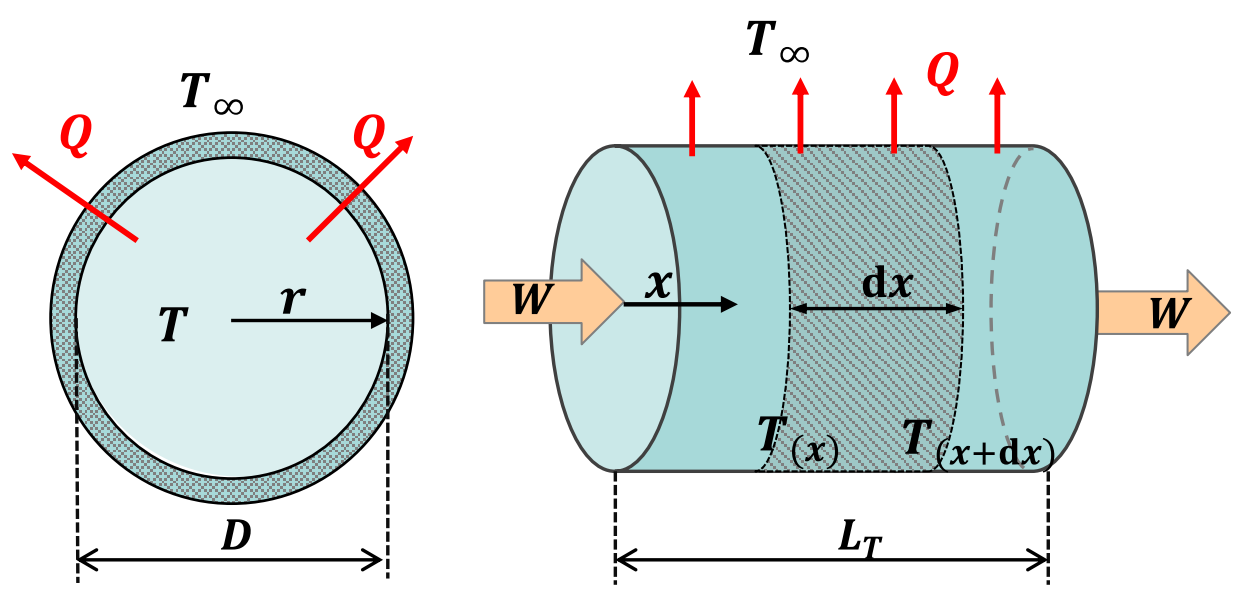

Figura 4.2 - Volume de controle para o balanço de energia no tubo de retenção e trechos de tubo.

A equação (4.44) descreve a perda de calor do fluido para o ambiente:

$$
\mathrm{d} Q=\mathrm{d} A_{T} \cdot U \cdot\left(T_{x}-T_{\infty}\right)
$$

onde $\mathrm{d} A_{T}=\pi . D . \mathrm{d} x$ é a área de troca térmica infinitesimal do tubo, $D$ o diâmetro interno do tubo, $T_{\infty}$ a temperatura do ambiente e $U$ o coeficiente global de troca térmica entre o centro do tubo e o ambiente.

Adotando o volume de controle infinitesimal da Figura 4.2, o balanço de energia na fatia $d x$ de fluido é representado pela equação (4.45):

$$
\rho \cdot \mathrm{d} V_{T} \cdot C p \cdot \frac{\partial T}{\partial t}=W \cdot C p \cdot\left(T_{x}-T_{x+d x}\right)-\mathrm{d} Q
$$

onde $W$ é a vazão mássica e $\mathrm{d} V_{T}$ é o volume infinitesimal do fluido, que pode ser calculado com a equação (4.46): 


$$
\mathrm{d} V_{T}=\frac{\pi \cdot D^{2}}{4} \cdot \mathrm{d} x
$$

Substituindo as equações (4.44) e (4.46) na equação (4.45) a equação do balanço de energia no tubo pode ser escrita como:

$$
\frac{\pi \cdot L_{T} \cdot \rho \cdot D^{2}}{4 \cdot W} \cdot \frac{\partial T_{T}}{\partial t}=-\frac{\partial T_{T}}{\partial \eta}-\frac{\pi \cdot L_{T} \cdot D \cdot U}{C p \cdot W} \cdot\left(T_{T}-T_{\infty}\right)
$$

Sendo que o comprimento do tubo é representado por $L_{T}$, o tempo espacial do fluido dentro o tubo, designado como $\tau_{T}$ é descrito na equação (4.48) e o parâmetro auxiliar $Z$ é descrito na equação (4.49):

$$
\begin{gathered}
\tau_{T}=\frac{\pi \cdot L_{T} \cdot \rho \cdot D^{2}}{4 \cdot W} \\
Z=\frac{\pi \cdot L_{T} \cdot D \cdot U}{W \cdot C p}
\end{gathered}
$$

Então, a equação do balanço de energia num tubo genérico do pasteurizador é representada pela equação (4.50).

$$
\tau_{T} \cdot \frac{\partial T_{T}}{\partial t}=-\frac{\partial T_{T}}{\partial \eta}-Z \cdot\left(T_{T}-T_{\infty}\right)
$$




\subsection{Condições de contorno}

Para a resolução das equações diferenciais do balanço de energia, é necessário especificar as condições de contorno para a temperatura $T_{i}(\eta)$ nos canais do trocador, $T_{P}$ nas placas do trocador e $T_{t}(\eta)$ no tubo de retenção $e$ conexões.

As condições de contorno para os canais são aplicadas na entrada e na saída de cada canal.

Condição de entrada do fluido: a temperatura do início do primeiro passe no trocador de calor é igual à temperatura de alimentação do fluido.

$$
T_{i}(\eta)=T_{\text {fluido, in }} \quad, \quad i \in \text { primeiro passe }
$$

Condição de mudança de passe: mistura perfeita no fluido que deixa um passe antes de entrar no próximo. A temperatura de saída do passe é igual à somatória das temperaturas de saída dos canais dividido pelo número de canais que conformam o passe. A equação (4.52) indica esta condição.

$$
T_{i}(\eta)=\frac{1}{N} \cdot \sum_{\substack{j \in \text { passe } \\ \text { anterior }}}^{N} T_{j}(\eta) \quad, \quad i \in \text { novo passe }
$$

Condição de saída do fluido: a temperatura de saída do fluido é a mistura perfeita do fluido que deixa o último passe.

$$
T_{\text {fluido,out }}=\frac{1}{N} \cdot \sum_{\substack{j \in \text { ultimo } \\ \text { passe }}}^{N} T_{j}(\eta)
$$


Para os casos em que o número de canais por passe é um, como é mostrado no exemplo na Figura 4.3, de um trocador de calor de 12 canais, onde o arranjo é de 6 passes de uma passagem para ambos os lados do PHE, para a condição de contorno de mudança de passe a temperatura de saída de um canal é a temperatura de entrada do próximo canal.

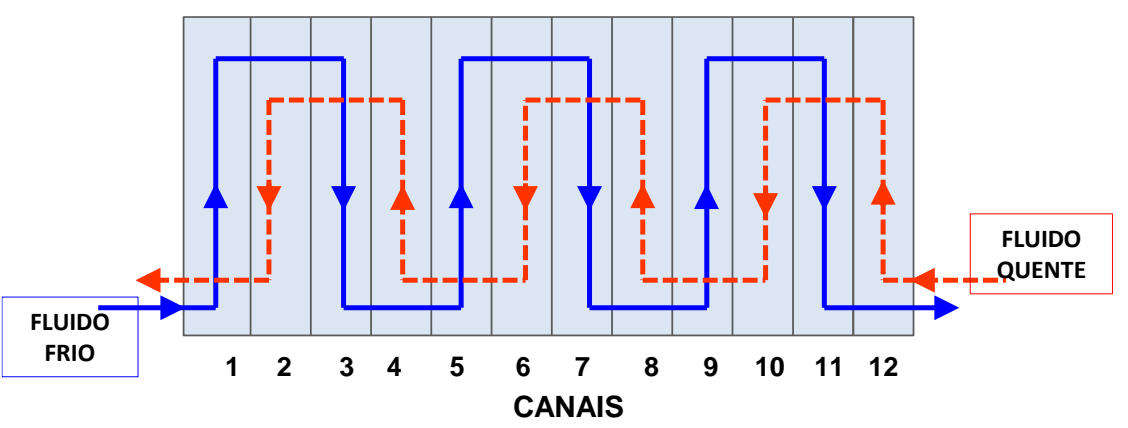

\begin{tabular}{cc}
\hline Parâmetro & Valor \\
\hline$N_{C}$ & 12 \\
$P^{I}$ & 6 \\
$P^{I I}$ & 6 \\
$\varnothing$ & 3 \\
$Y_{h}$ & 0 \\
$Y_{f}$ & 1 \\
\hline
\end{tabular}

Figura 4.3 - Exemplo de um arranjo em série de um PHE com 12 canais indicando a direção do fluido e os valores dos parâmetros de configuração.

Sendo as condições de contorno específicas para cada tipo de configuração de arranjo de trocador, segundo seus valores de configuração, para o exemplo da Figura 4.3, as equações de condição de contorno nos canais são apresentadas a seguir:

$$
\begin{aligned}
& \text { Lado } I \text { (Frio): } \\
& T_{1}(\eta=0)=T_{\text {frio,entrada }} \\
& T_{3}(\eta=1)=T_{1}(\eta=1) \\
& T_{5}(\eta=0)=T_{3}(\eta=0) \\
& T_{7}(\eta=1)=T_{5}(\eta=1) \\
& T_{9}(\eta=0)=T_{7}(\eta=0) \\
& T_{11}(\eta=1)=T_{9}(\eta=1) \\
& T_{\text {frio,saída }}=T_{11}(\eta=0)
\end{aligned}
$$


Lado II (Quente):

$$
\begin{aligned}
& T_{\text {quente,saída }}=T_{2}(\eta=0) \\
& T_{2}(\eta=1)=T_{4}(\eta=1) \\
& T_{4}(\eta=0)=T_{6}(\eta=0) \\
& T_{6}(\eta=1)=T_{8}(\eta=1) \\
& T_{8}(\eta=0)=T_{10}(\eta=0) \\
& T_{10}(\eta=1)=T_{12}(\eta=1) \\
& T_{12}(\eta=0)=T_{\text {quente,entrada }}
\end{aligned}
$$

As condições de contorno nas placas do PHE são baseadas na consideração A7, onde as perdas de calor para o ambiente são desprezíveis no PHE. Esta condição expressa na equação (4.56), descreve que não há troca de calor nas extremidades das placas onde os valores de $\eta$ são 0 ou 1.

$$
\left.\frac{\partial T_{P_{i}}}{\partial \eta}\right|_{\eta=0, \eta=1}=0 \quad i=1,2 \ldots\left(N_{C}-1\right)
$$

As condições de contorno para o pasteurizador são determinadas pelas ligações entre as diferentes seções do trocador de calor e as ligações entre os tubos e trechos de tubo. Seguindo o esquema na Figura 3.1, que mostra as conexões entre as diferentes partes do pasteurizador e o caminho que percorrem os fluidos no processo, as condições de contorno para a unidade de pasteurização são as seguintes: 


$$
\begin{aligned}
& T_{\text {entrada,produto cru }}=T_{\text {entrada, },}(\text { regeneração }) \\
& T_{\text {saída,I }}(\text { regeneração })=T_{\text {entrada }, I}(\text { aquecimento }) \\
& T_{\text {saída, } I} \text { (aquecimento) }=T_{\text {entrada }}(\text { Tubo 1) } \\
& T_{\text {saída }}\left(\text { Tubo 1) }=T_{\text {entrada }}(\text { Tubo 2) }\right. \\
& T_{\text {saída }}\left(\text { Tubo 2) }=T_{\text {entrada }}(\text { Tubo } 3)\right. \\
& T_{\text {saída }}\left(\text { Tubo 3) }=T_{\text {entrada,II }}(\text { regeneração })\right. \\
& T_{\text {saída, } I}(\text { regeneração })=T_{\text {entrada, } I}(\text { aquecimento }) \\
& T_{\text {saída,II }}(\text { regeneração })=T_{\text {entrada, } I}(\text { resfriamento }) \\
& T_{\text {saída,I }}(\text { resfriamento })=T_{\text {saída, produto pasteurizado }} \\
& T_{\text {entrada, fluido de aquecimento }}=T_{\text {entrada, }, I} \text { (aquecimento) } \\
& T_{\text {saída,II }} \text { (aquecimento) }=T_{\text {saída } \text {,fluido de aquecimento }} \\
& T_{\text {entrada, fluido de resfriamento }}=T_{\text {entrada,II }} \text { (resfriamento) } \\
& T_{\text {saída,II }}(\text { resfriamento })=T_{\text {saída,fluido de resfriamento }}
\end{aligned}
$$

sendo $I$ e $I I$ as especificações referentes aos lados frio e quente do PHE. A especificação Tubo 2 refere-se ao tubo de retenção, em quanto as especificações Tubo1 e Tubo 3 referem-se aos trechos de tubo ou conexões.

O valor de $Y_{h}$, que é o parâmetro binário que indica a localização do fluido quente no trocador, foi adotado conforme Gut e Pinto (2009) para maior efetividade na troca térmica, sendo para cada seção: $Y_{h}($ regeneração $)=0, Y_{h}$ (aquecimento) $=0$ e $Y_{h}($ resfriamento $)=0$.

\subsection{Condições iniciais do processo}

Para o processo de pasteurização podem ser utilizadas duas possibilidades para as condições iniciais. A primeira possibilidade de condição inicial é na qual o pasteurizador encontra-se operando em estado estacionário com troca de calor, permanecendo as temperaturas constantes em cada ponto de medição do 
pasteurizador ao longo do tempo. Esta condição é representada pela equação (4.58).

$$
\left.\frac{\partial T}{\partial t}\right|_{t=0}=\left.\frac{\partial T_{P}}{\partial t}\right|_{t=0}=\left.\frac{\partial T_{T}}{\partial t}\right|_{t=0}=0 \quad T(\text { canais }), T_{P} \text { (placas) e } T_{T} \text { (tubos) }
$$

A segunda possibilidade de condição inicial para o processo de pasteurização é a condição de partida, na qual todos os fluidos e materiais do pasteurizador estão a uma mesma temperatura inicial, por tanto, sem troca de calor no processo. A equação (4.59) representa esta condição.

$$
\left.T\right|_{t=0}=\left.T_{P}\right|_{t=0}=\left.T_{T}\right|_{t=0}=T_{\text {inicial }} \quad T \text { (canais), } T_{P} \text { (placas) e } T_{T} \text { (tubos) }
$$

\subsection{Modelagem da incrustação no trocador de calor a placas}

A equação (4.5), que define o coeficiente global de troca térmica, é influenciada pelos fatores de incrustação dos fluidos do lado quente e frio do trocador de calor, representados por $R_{f, \text { hot }}$ e $R_{f, \text { cold }}$ na equação.

$\mathrm{Na}$ engenharia prática, distingue-se o coeficiente global de troca térmica do trocador limpo, e o coeficiente global de troca térmica do trocador depois da incrustação (CHANGANI et al., 1997):

$$
\frac{1}{U_{f}}=\frac{1}{U_{c}}+R_{f, \text { hot }}+R_{f, \text { cold }}
$$

Sendo:

$$
\begin{aligned}
R_{f, h o t}= & \text { Resistência térmica da incrustação ou fator de incrustação do lado } \\
& \text { quente }\left(\mathrm{m}^{2} . \mathrm{K} / \mathrm{W}\right)
\end{aligned}
$$


$R_{f, c o l d}=$ Resistência térmica da incrustação ou fator de incrustação do lado frio $\left(\mathrm{m}^{2} \cdot \mathrm{K} / \mathrm{W}\right)$

$U_{c} \quad=$ Coeficiente global de transferência de calor do trocador limpo $\left(\mathrm{W} / \mathrm{m}^{2} . \mathrm{K}\right)$

$U_{f} \quad=$ Coeficiente global de transferência de calor do trocador depois da incrustação $\left(\mathrm{W} / \mathrm{m}^{2} . \mathrm{K}\right)$

O pasteurizador deste estudo é composto por um trocador de calor a placas com três seções de troca térmica (aquecimento, regeneração e resfriamento). Levando em consideração que o efeito de incrustação é mais acentuado na seção de aquecimento, onde são registradas as temperaturas mais elevadas do processo, a modelagem da incrustação será desenvolvida para esta seção de troca térmica, ressaltando que a mesma metodologia utilizada nesta seção do trocador também é aplicável às outras seções do trocador de calor utilizadas.

Vale lembrar que na modelagem do trocador de calor a placas, na seção de aquecimento, o lado I refere-se ao produto que está sendo pasteurizado (ou fluido frio) e o lado II refere-se ao fluido de aquecimento (ou fluido quente). A influência da incrustação sobre o coeficiente global de troca térmica é considerada no lado $I$ do trocador, já que no lado II circula água limpa.

Para a incorporação do efeito da incrustação na modelagem dinâmica do pasteurizador, foram consideradas duas tendências de incrustação ao longo do tempo: incrustação linear e incrustação assintótica, ambas apresentadas na Figura 3.11 pelas curvas "A" e "B", respectivamente.

As duas tendências de incrustação são modeladas separadamente. A modelagem do trocador que considera o fator de incrustação com tendência linear é denominada como modelagem de incrustação 1, e a modelagem com tendência assintótica, é denominada como modelagem de incrustação 2. As duas modelagens utilizam como base o termo $R_{\max }$, que representa o valor máximo de incrustação para o tempo do processo. 


\subsubsection{Modelo de incrustação 1}

Para a modelagem de incrustação 1, com crescimento linear do fator de incrustação ao longo do processo, foi utilizada e equação (4.61).

$$
\frac{R_{f}}{R_{\max }}=\alpha_{f} \cdot\left(t-t_{f_{0}}\right) \quad \text { para } t \geq t_{f_{0}}
$$

Sendo:

$$
t_{f}=t-t_{f_{0}}
$$

Onde:

$$
\begin{aligned}
& R_{f} \quad=\text { Fator de incrustação }\left(\mathrm{m}^{2} \mathrm{~K} / \mathrm{W}\right) \\
& R_{\text {max }}=\text { Valor máximo de incrustação para operação do processo }\left(\mathrm{m}^{2} \mathrm{~K} / \mathrm{W}\right) \\
& \alpha_{f} \quad=\text { Constante de velocidade cinética da incrustação }\left(\mathrm{s}^{-1}\right) \\
& t_{f_{0}} \quad=\text { Período de indução }(\mathrm{s}) \\
& t_{f} \quad=\text { Período de incrustação }(\mathrm{s}) \\
& t \quad=\text { Tempo de operação do processo }(\mathrm{s})
\end{aligned}
$$

\subsubsection{Modelo de incrustação 2}

$\mathrm{Na}$ modelagem de incrustação 2, com tendência de incrustação assintótica, 0 ajuste do parâmetro $\alpha_{f}$ é realizado utilizando a equação (4.63).

$$
\frac{R_{f}}{R_{\text {Max }}}=\frac{\left(t-t_{f_{0}}\right)}{\alpha_{f}+\left(t-t_{f_{0}}\right)} \quad \text { para } t \geq t_{f_{0}}
$$


Para as duas modelagens de incrustação apresentadas, os valores dos parâmetros $\alpha_{f}$ e $t_{f_{0}}$ são muito importantes, pois $t_{f_{0}}$ determinará o tempo em que se inicia a incrustação e $\alpha_{f}$ influenciará na taxa de incrustação o que irá refletir nos valores de incrustação do processo ao longo do tempo.

\subsection{Simulação}

Para a simulação do modelo matemático desenvolvido para o processo de pasteurização contínua com trocador de calor a placas foi usado o gPROMS (Process System Enterprise, versão 3.2).

O processo de pasteurização, dependendo da configuração do PHE, é descrito pelas equações (4.24), (4.28), (4.29), (4.30), (4.31), (4.32), (4.42), (4.43) e (4.50) apresentadas no texto.

A escolha dos métodos de discretização para a simulação do processo foi adotada de acordo com os testes de simulação dinâmica de um PHE para eliminar problemas de estabilidade numérica apresentados no trabalho de Gut (2003). Os métodos de discretização utilizados na simulação foram: Centered Finite Difference Method (CFDM) para a temperatura nas placas do PHE, Backward Finite Difference Method (BFDM) para a temperatura nos canais em que a direção do escoamento é positiva no sentido $\eta$ e o método Forward Finite Difference Method (FFDM) para a temperatura nos canais em que a direção do fluido é negativa no sentido $\eta$. Para o tubo de retenção e trechos do tubo, o método utilizado foi BFDM.

Os pontos de discretização utilizados na simulação foram de 30 pontos para canais e placas do trocador de calor e 200 pontos para o tubo de retenção e trechos de tubo. Estes valores foram adotados tendo em vista que foram realizadas experiências com maior quantidade de pontos de discretização e foi constatado que não houve variação nos resultados e apenas um aumento do tempo computacional, por esta razão, foi considerado desnecessário o aumento de pontos de discretização. 


\section{MATERIAIS E MÉTODOS}

Neste capítulo se descreve o equipamento utilizado para o estudo experimental de pasteurização junto com as metodologias empregadas para a determinação dos coeficientes de transferência térmica do trocador de calor, tubo de retenção e trechos de tubo e a determinação da constante de tempo do termopar. Em seguida são descritos os ensaios experimentais da partida e de perturbação do processo de pasteurização, assim como os ensaios experimentais e de simulação da incrustação do processo.

\subsection{Equipamento utilizado}

O equipamento utilizado para a pesquisa foi o pasteurizador de laboratório Armfield modelo FT-43A com trocador de calor a placas. Na Figura 5.1 é apresentada uma imagem do pasteurizador e das placas do trocador de calor.

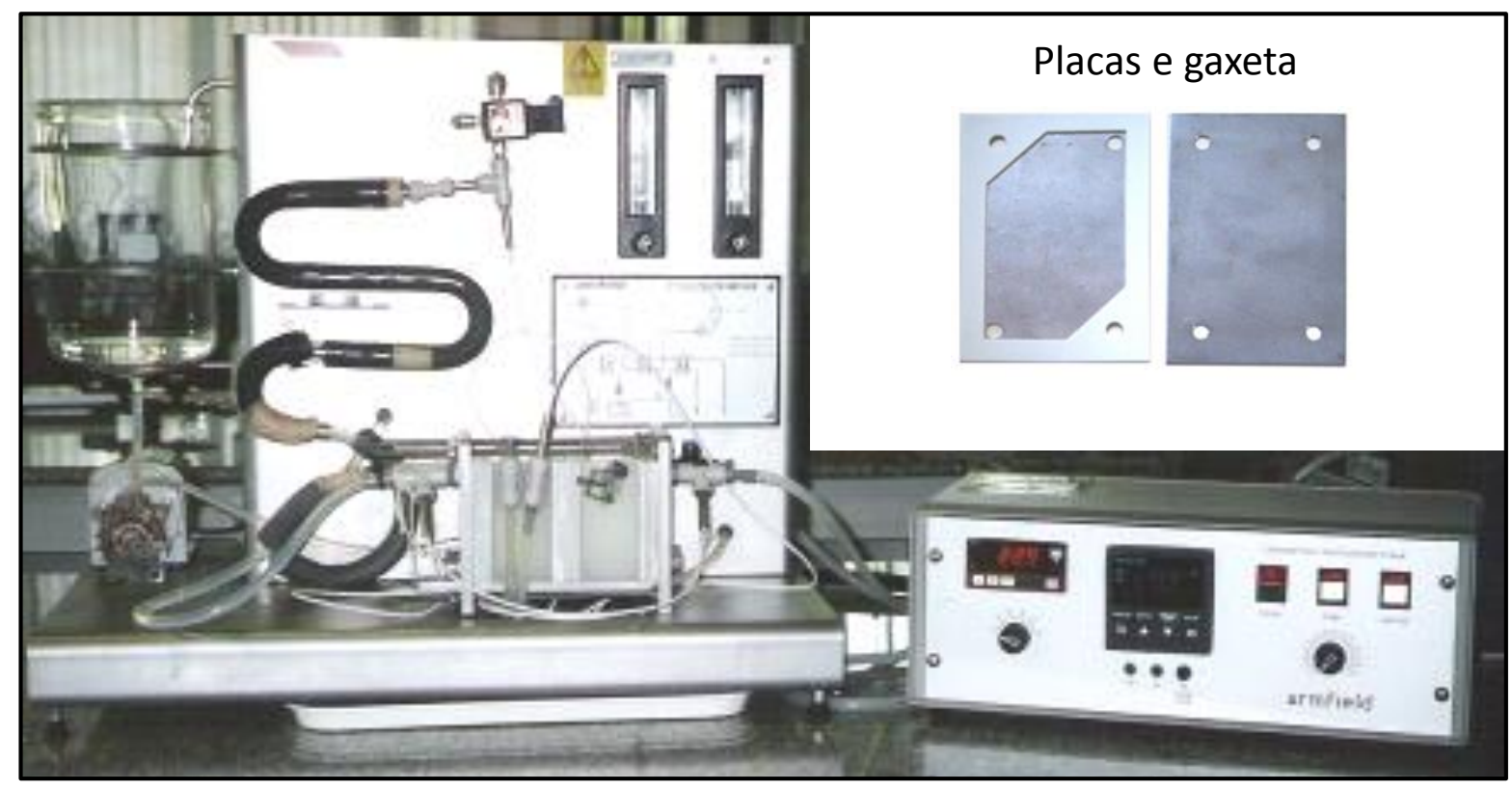

Figura 5.1 - Pasteurizador de laboratório ARMFIELD modelo FT-43A e placas do trocador de calor.

Os acessórios e componentes deste pasteurizador são: unidade processadora de pasteurização, console de controle, unidade de refrigeração modelo FT61-B e 
interface de aquisição de dados modelo FT43 A-90 IFD. As especificações deste equipamento são as seguintes:

- Bomba de alimentação: peristáltica marca MASTERFLEX, capacidade máxima 200L/h. Capacidade nominal de operação do pasteurizador: 20 L/h.

- Controlador de temperatura de pasteurização: microprocessador com ação PID para o aquecedor da água, faixa de 0 a $100^{\circ} \mathrm{C}$;

- Placas lisas de aço inoxidável AISI 316, com gaxetas em silicone grau sanitário; área de troca térmica unitária $50,1 \mathrm{~cm}^{2}$;

- Sistema de aquecimento: bomba centrífuga de circulação de água quente aquecida por uma resistência elétrica de capacidade 1,5 kW. A vazão de água quente é variável através da válvula agulha do rotâmetro até 1,5 L/min;

- Tanque de alimentação de produto com capacidade de 4 litros;

- Tubos de retenção: "S" com volume aproximado de $89 \mathrm{~cm}^{3}$ e helicoidal de 200 $\mathrm{cm}^{3}$;

- Sistema de resfriamento ARMFIELD modelo FT-61 com bomba centrifuga interna que resfria até $4{ }^{\circ} \mathrm{C}$. A vazão de água fria é variável através da válvula agulha do rotâmetro até $1,5 \mathrm{~L} / \mathrm{min}$;

O equipamento e software adicional utilizado para a aquisição de dados foi:

- Equipamento de aquisição de dados Compact DAQ-9172 (National Instruments, Estados Unidos da América) com três módulos NI-9211 para termopares;

- Software LabView 8.6 (National Instruments, Estados Unidos da América);

- Conjunto de 12 termopares de junta exposta com cabo 24AWG (IOPE, Brasil), adaptados a conectores PI0812S 3/8" (John Guest, Reino Unido).

A Figura 5.2 mostra a foto e o esquema do pasteurizador indicando a posição dos 12 sensores de temperatura que foram inseridos ao longo do processo no meio das tubulações, de acordo com as indicações T1 a T12 da figura. Os sensores foram termopares com junta exposta, para reduzir a inércia no registro da temperatura em ensaios dinâmicos. Todos os termopares utilizados foram previamente calibrados para a faixa de 0 a $90^{\circ} \mathrm{C}$.

O tubo de retenção está ligado ao equipamento por duas mangueiras de silicone, a perda térmica nestes trechos foi monitorada pelos sensores T3 a T6. Os trechos entre T3 e T4 e entre T4 a T5 têm uma camada de isolamento térmico. 
Os 12 pontos de controle de temperatura foram registrados continuamente ao longo do processo para obtenção do histórico de temperatura do produto. A Tabela 5.1 especifica os pontos de medição de temperatura do fluido ao longo do pasteurizador.
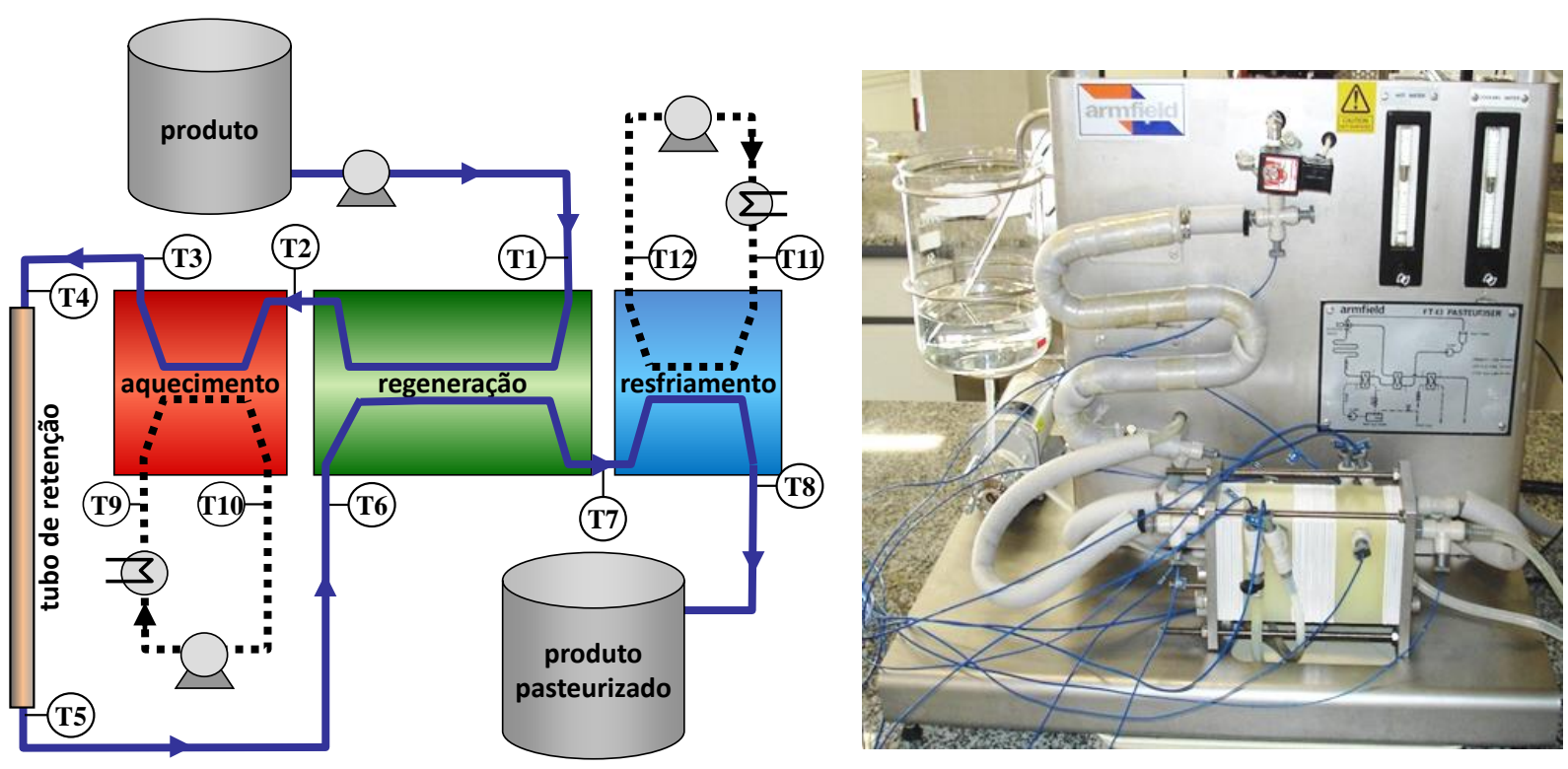

Figura 5.2 - Esquema e foto do pasteurizador com indicação dos 12 pontos de medição de temperatura.

Tabela 5.1 - Pontos de medição da temperatura do fluido no pasteurizador.

\begin{tabular}{cl}
\hline Ponto & \multicolumn{1}{c}{ Localização } \\
\hline T1 & Entrada no processo \\
T2 & Saída da regeneração e entrada para aquecimento \\
T3 & Saída do aquecimento e entrada para tubo de retenção \\
T4 & Localizado entre o tubo de retenção e sua conexão anterior \\
T5 & Localizado entre o tubo de retenção e a próxima conexão \\
T6 & Saída do tubo de retenção e entrada para regeneração \\
T7 & Saída da regeneração e entrada para resfriamento \\
T8 & Saída do processo \\
T9 & Entrada do fluido de aquecimento \\
T10 & Saída do fluido de aquecimento. \\
T11 & Entrada do fluido de resfriamento \\
T12 & Saída do fluido de resfriamento \\
\hline
\end{tabular}


As características das placas do trocador são apresentadas na Tabela 5.2 e as principais dimensões das gaxetas são mostradas na Figura 5.3.

Tabela 5.2 - Características das placas do trocador de calor do pasteurizador ARMFIELD FT-43A (GUT; PINTO, 2004).

\begin{tabular}{llc}
\hline Característica & Valor & Unidade \\
\hline Comprimento da parte úmida, $L$ & $8,35 \times 10^{-2}$ & $\mathrm{~m}$ \\
Largura da parte úmida, $w$ & $6,00 \times 10^{-2}$ & $\mathrm{~m}$ \\
Espessura do canal, $b$ & $1,50 \times 10^{-3}$ & $\mathrm{~m}$ \\
Diâmetro do orifício, $D_{P}$ & $8,00 \times 10^{-3}$ & $\mathrm{~m}$ \\
Espessura da placa, $e_{P}$ & $1,00 \times 10^{-3}$ & $\mathrm{~m}$ \\
Fator de alargamento, $\Phi$ & 1,00 & - \\
Condutividade térmica, $k_{p}$ & $1,34 \times 10^{1}$ & $\mathrm{~W} / \mathrm{m} . \mathrm{K}$ \\
Densidade da placa, $\rho_{P}$ & 8238 & $\mathrm{~kg} / \mathrm{m}^{3}$ \\
Capacidade calorífica da placa, $C p$ & 468 & $\mathrm{~J} / \mathrm{kg} \cdot \mathrm{K}$ \\
\hline
\end{tabular}

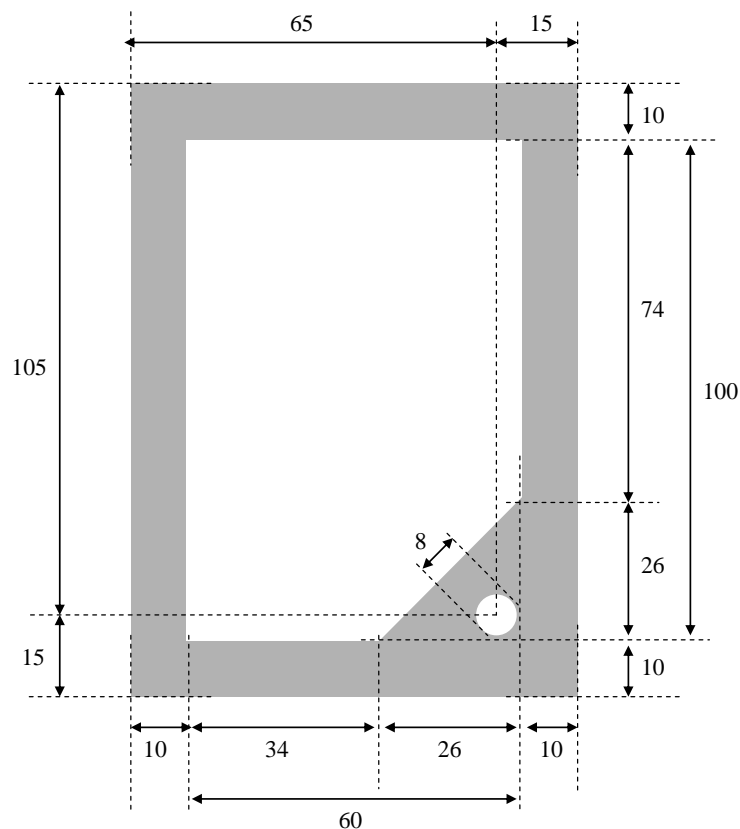

Figura 5.3 - Dimensões da gaxeta do trocador de calor a placas do pasteurizador ARMFIELD FT-43A, valores em milímetros (GUTIERREZ, 2008). 
Na Tabela 5.3 são mostrados valores dos parâmetros de configuração para as três seções de troca térmica do PHE (aquecimento, regeneração e resfriamento). Os trocadores de calor mantiveram a configuração padrão do equipamento, arranjo em série contracorrente (um canal por passe).

Tabela 5.3 - Parâmetros de configuração das três seções do trocador de calor a placas.

\begin{tabular}{lccc}
\hline \multicolumn{1}{c}{ Parâmetros } & Aquecimento & Regeneração & Resfriamento \\
\hline Número de canais, $N_{C}$ & 12 & 20 & 8 \\
Número de Passes (lado $I$ ), $P^{I}$ & 6 & 10 & 4 \\
Número de Passes (lado $I I), P^{I I}$ & 6 & 10 & 4 \\
Posição relativa da conexão de & 3 & 3 & 3 \\
alimentação do lado $I I, \varnothing$ & 0 & 0 & 1 \\
Localização do fluido quente, $Y_{h}$ & 1 & 1 & 1 \\
Tipo de escoamento nos canais, $Y_{f}$ & & & \\
\hline
\end{tabular}

Observando a Figura 5.2, o produto a ser pasteurizado entra pela seção de regeneração, formada por 20 canais, trocando calor com o fluido já pasteurizado. Passa pela seção de aquecimento, formada por 12 canais, onde indiretamente água quente aquece o fluido. Atravessa então um tubo de retenção e entra na seção de regeneração novamente, trocando calor com o fluido que está entrando no processo, e passa por ultimo para a seção de resfriamento, formada por 8 canais, trocando calor com água gelada.

O pasteurizador de laboratório possui dois tubos de retenção, o tubo (1) com formato em "S" com volume interno aproximado de $89 \mathrm{~cm}^{3}$ e o tubo (2) com formato em espiral e volume interno de $200 \mathrm{~cm}^{3}$ mostrados na Figura 5.4. 

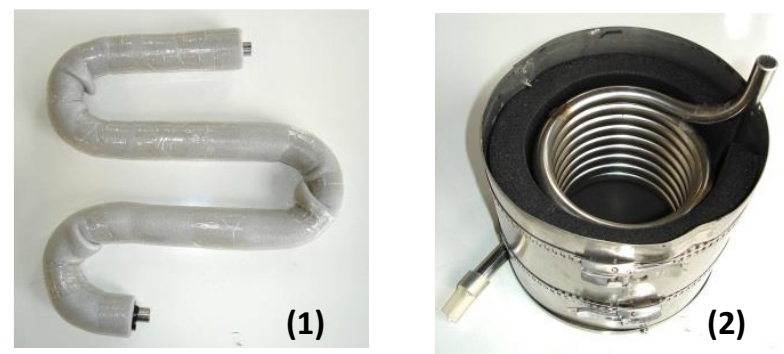

Figura 5.4 - Tubos de retenção (1) e (2) do pasteurizador ARMFIELD FT-43A.

O tubo de retenção utilizado nos ensaios experimentais foi o tubo de retenção (1), aquele que apresenta o formato de " $S$ " devido a que foi dimensionado especificamente para o processo de pasteurização do leite. O material do tubo é aço inoxidável e esta recoberto com material isolante térmico. O diâmetro interno do tubo de retenção utilizado é $10,7 \mathrm{~mm}$ e é designado como $D$. O comprimento é de 990 $\mathrm{mm}$ e é designado como $L_{T}$.

O tubo de retenção contém duas conexões tubulares com o trocador de calor, as mesmas que no trabalho estão sendo denominadas como trechos de tubo. A Tabela 5.4 apresenta as dimensões do tubo de retenção e dos trechos de tubo utilizados, onde a indicação "Tubo 1" representa o trecho de tubo inicial que conecta a saída do aquecimento com a entrada no tubo de retenção, já a denominação "Tubo 2" representa o tubo de retenção do pasteurizador e por ultimo a denominação "Tubo 3" representa o trecho de tubo que conecta saída do tubo de retenção com a entrada na seção de regeneração.

Tabela 5.4 - Identificação e dimensões do tubo de retenção e trechos de tubo do pasterizador.

\begin{tabular}{cccc}
\hline Parte & Tubo 1 & Tubo 2 & Tubo 3 \\
\hline Comprimento $(\mathrm{m})$ & 0,42 & 0,99 & 1,06 \\
Diâmetro interno $(\mathrm{m})$ & 0,0095 & 0,0107 & 0,0080 \\
Volume interno $(\mathrm{mL})$ & 29,8 & 89,0 & 53,3 \\
\hline
\end{tabular}




\subsection{Determinação experimental dos coeficientes de troca térmica}

Os coeficientes de transferência de calor foram determinados experimentalmente. Para o trocador de calor foram determinados os coeficientes convectivos de transferência de calor e para o tubo de retenção e trechos de tubo foram determinados os coeficientes globais de troca térmica com o ambiente.

\subsubsection{Determinação dos coeficientes de troca térmica no PHE}

O método que foi seguido para o ajuste dos parâmetros $a_{1}, a_{2}$ e $a_{3}$ da correlação de Nusselt, equação (4.6), utilizada para a determinação dos coeficientes convectivos de troca térmica do trocador de calor a placas é apresentado por Gut et al. (2004) e Galeazzo et al. (2006). Os métodos utilizam valores experimentais de vazão, temperaturas de entrada e saída dos fluidos e parâmetros de configuração do trocador.

As equações utilizadas para esta metodologia foram (4.1), (4.2), (4.5), (4.6), (4.7), (4.9), (4.10), (4.12), (4.13), (4.14), (4.16), (4.17), (4.18) e (4.19) descritas no texto, assim como os parâmetros de configuração do PHE indicados na Tabela 5.3.

Os ensaios experimentais para a determinação destes parâmetros foram realizados com vazões de produto de 10, 20, 30 e $40 \mathrm{~L} / \mathrm{h}$ e vazão dos fluidos de serviço (fluidos de aquecimento e resfriamento) de 24, 36, 48 e $60 \mathrm{~L} / \mathrm{h}$.

As temperaturas de entrada e saída dos fluidos foram medidas com os termopares inseridos nas conexões do PHE e continuamente monitoradas e registradas pelo sistema de aquisição de dados.

As vazões volumétricas dos fluidos de serviço foram medidas com os rotâmetros presentes nos circuitos fechados do pasteurizador. A vazão mássica do produto foi determinada por medição direta de massa e tempo na saída do pasteurizador. O produto utilizado para os ensaios experimentais foi água filtrada.

Nos ensaios experimentais, uma vez identificada a condição de estado estacionário de operação, o registro de temperaturas foi realizado durante 2 min. Os valores da média e desvio padrão da temperatura foram levados em consideração. 
As propriedades físicas dos fluidos foram calculadas com as equações (4.16), (4.17), (4.18) e (4.19) levando em conta a consideração A10 da modelagem matemática do processo.

O ajuste dos parâmetros $a_{1}$ e $a_{2}$ e a fixação do parâmetro $a_{3}$ em 1/3, seguiram o critério utilizado por Gut et al. (2004). Os valores foram estimados por minimização do erro quadrático entre o valor do coeficiente global de troca térmica experimental e o valor do coeficiente de troca térmica calculado.

\subsubsection{Determinação dos coeficientes de troca térmica no tubo de retenção e trechos de tubo}

Para a determinação experimental dos coeficientes globais de troca térmica dos tubos com o ar ambiente foram realizados ensaios experimentais em estado estacionário utilizando água filtrada com vazões de entrada do produto de 10, 20, 30 e $40 \mathrm{~L} / \mathrm{h}$.

A medição das temperaturas de entrada e saída do tubo de retenção e trechos de tubo foi realizada por meio dos termopares inseridos na entrada e saída de cada tubo. O registro de temperaturas foi feito pelo sistema de aquisição de dados.

Para cada ensaio foi registrada a temperatura ambiente. $O$ valor do calor específico do fluido $C p$ foi calculado com a equação (4.18).

Baseados no volume de contorno para o tubo de retenção apresentado na Figura 4.2, as equação utilizadas para o ajuste dos coeficientes globais de troca térmica do tubo de retenção e trechos de tubo são descritas a seguir.

A troca de calor através do tubo para o ambiente pode ser representado pela equação (5.1):

$$
Q=U \cdot A_{T} \cdot \Delta T_{l m}
$$

sendo $A_{T}$ a área de referência para troca térmica entre o produto e o ambiente igual a $A_{T}=\pi . D . L_{T}$, sendo $D$ o diâmetro interno do tubo e $L_{T}$ o comprimento. O termo 
$\Delta T_{l m}$ representa a média logarítmica da diferença de temperatura mostrada na equação (5.2). O termo $T_{\infty}$ representa a temperatura do ar ambiente e os termos $T_{e}$ e $T_{s}$ representam as temperaturas do fluido de entrada e saída do tubo respectivamente.

$$
\Delta T_{l m}=\frac{\left(T_{e}-T_{\infty}\right)-\left(T_{s}-T_{\infty}\right)}{\ln \left[\frac{\left(T_{e}-T_{\infty}\right)}{\left(T_{s}-T_{\infty}\right)}\right]}
$$

A equação de balanço de energia no tubo, em estado estacionário, é representada pela equação (5.3), onde a vazão, assim como o calor específico do fluido tanto na entrada como na saída do tubo são consideradas constantes e foram calculados na temperatura média aritmética.

$$
Q=W \cdot C p \cdot\left(T_{e}-T_{s}\right)
$$

Fazendo a substituição entre as equações (5.1) e (5.3), é possível calcular o coeficiente global de troca térmica do tubo com o ar ambiente por meio da equação (5.4).

$$
U=\frac{W \cdot C p \cdot\left(T_{e}-T_{S}\right)}{\pi \cdot D \cdot L_{T} \cdot \Delta T_{l m}}
$$

\subsection{Determinação da constante de tempo do termopar}

A constante de tempo do termopar, definida como o tempo necessário para atingir $63,2 \%$ do valor da temperatura real do meio, foi determinada para um dos termopares utilizados no registro das temperaturas do processo. 
Para conhecer a resposta de um termopar ou influência do efeito da inércia térmica do sensor foram realizados ensaios experimentais, onde o termopar foi exposto a mudanças instantâneas de temperaturas (termopar imerso em água nas temperaturas de $0{ }^{\circ} \mathrm{C}$ e $90^{\circ} \mathrm{C}$ ).

No início de cada teste, o termopar foi imerso em um banho de água gelada durante um determinado tempo até verificar registro constante de temperatura. Transcorridos 30 segundos do registro, o termopar foi transferido imediatamente para 0 banho de água quente deixando que passem 2 minutos para novamente transferi-lo para o banho de água gelada.

O registro das temperaturas foi realizado com a ajuda do sistema de aquisição de dados e foram realizados dez testes.

\subsection{Ensaios dinâmicos}

Para estudar a dinâmica do processo de pasteurização e validar o modelo matemático de simulação desenvolvido no Capítulo 4, foram realizados ensaios experimentais com perturbações impostas durante 0 processo. Os resultados experimentais foram comparados com resultados simulados.

Os ensaios foram realizados em malha aberta no pasteurizador, sem controle da temperatura na saída do tubo de retenção e a válvula diversora de fluxo do equipamento permaneceu fechada. A temperatura de alimentação da água quente $\left(90^{\circ} \mathrm{C}\right)$ foi controlada.

O fluido utilizado como produto durante os ensaios dinâmicos de perturbação foi água filtrada. Para os fluidos de serviço quente e gelado foi utilizada água destilada.

No início de cada ensaio experimental foi importante realizar uma inspeção prévia do processo. Os pontos verificados foram: montagem correta do equipamento, alinhamento adequado entre placas e gaxetas, arranjo de configuração utilizado nos trocadores de calor a placas e eliminação de bolhas de ar dentro dos canais e tubulações, aspectos que podem influenciar no desempenho térmico do pasteurizador. Para a realização dos ensaios experimentais o pasteurizador permaneceu previamente em funcionamento durante 30 minutos, para 
garantir desta forma o estado estacionário, a eliminação das bolhas e a estabilidade da temperatura de alimentação dos fluidos de aquecimento e resfriamento. Todos os ensaios experimentais tiveram início a partir de um estado estacionário.

Para a simulação das perturbações no processo usando o modelo desenvolvido, as temperaturas e vazões de alimentação do produto e dos fluidos de aquecimento e resfriamento, foram especificadas de acordo com os valores experimentais.

A seguir são descritos os ensaios experimentais de perturbação realizados no pasteurizador de laboratório.

\subsubsection{Partida do processo}

Os ensaios de partida do processo de pasteurização foram realizados para analisar o comportamento do sistema em uma situação de partida com 0 equipamento e o produto na temperatura ambiente e os fluidos de utilidade em condições operacionais.

Para este ensaio experimental, inicialmente todas as tubulações do pasteurizador foram preenchidas pelos fluidos na temperatura ambiente. A vazão de alimentação do produto foi mantida ligada e as vazões de aquecimento e resfriamento foram desconectadas e mantidas circulando separadamente. No painel de controle das temperaturas foi verificado o estado estacionário sem troca de calor para dar início ao ensaio de partida do processo. Foi acionado o registro de temperaturas. Transcorrido um tempo determinado nessa condição (95 segundos), foram imediatamente conectadas as mangueiras dos fluidos de aquecimento e resfriamento e religadas as bombas de recirculação. As mudanças de temperatura do processo foram acompanhadas até que o estado estacionário fosse verificado.

Procurou-se manter constante a temperatura (T1) e a vazão de alimentação ao longo do processo, assim como as temperaturas de alimentação e vazões dos fluidos de aquecimento (T9) e resfriamento (T11) assim que foram acionados.

Para o ensaio da partida do processo de pasteurização os parâmetros de tempo e vazões de operação do processo estão especificados na Tabela 5.5. 
Tabela 5.5 - Parâmetros de tempo e vazão utilizados no ensaio da partida do pasteurizador.

\begin{tabular}{lccc}
\hline Tempo $(\mathbf{s})$ & $\boldsymbol{q}_{\text {prod }}(\mathrm{L} / \mathbf{h})$ & $\boldsymbol{q}_{\boldsymbol{q} \boldsymbol{q}}(\mathrm{L} / \mathbf{h})$ & $\boldsymbol{q}_{\text {res }}(\mathrm{L} / \mathbf{h})$ \\
\hline $0-95$ & 20 & 0 & 0 \\
$95-750$ & 20 & 60 & 60 \\
\hline
\end{tabular}

O histórico de temperatura de operação do processo, nos 12 pontos de medição de temperatura mostrados na Figura 5.2 e especificados na Tabela 5.1 do texto, foram continuamente monitorados e registrados pelo sistema de aquisição de dados.

\subsubsection{Ensaios com perturbações}

Para todos os ensaios dinâmicos de perturbação do processo de pasteurização foi utilizada uma mesma metodologia, com a diferença dos valores nos parâmetros de operação entre um ensaio e outro.

No início dos ensaios, o pasteurizador encontrava-se operando em estado estacionário com determinadas vazões de produto, vazões de fluido de aquecimento e resfriamento. Neste estado de operação, foi imposta uma perturbação em degrau no processo com a mudança instantânea da vazão de um ou mais fluidos. Uma vez comprovado que o processo perturbado atingiu um novo estado estacionário, foi imposta uma segunda perturbação para voltar às condições de operação originais. Os ensaios foram concluídos quando o processo atingia o estado estacionário original.

Durante os ensaios todas as temperaturas do processo nos 12 pontos de medição foram acompanhadas e registradas pelo sistema de aquisição de dados.

Em cada etapa dos ensaios, a vazão do produto foi determinada por medição direta de massa e tempo na saída do pasteurizador. As vazões dos fluidos de aquecimento e resfriamento foram medidas com os rotâmetros dos circuitos fechados, próprios do equipamento. Procurou-se manter constantes estas vazões para cada etapa do processo.

Os parâmetros de operação para os exemplos de ensaios dinâmicos com perturbação, denominados como ensaios A, B, C, D, E e F são apresentados nas 
Tabelas 5.6, 5.7, 5.8, 5.9, 5.10 e 5.11. No ensaio A, a perturbação imposta no processo foi a variação simultânea de três vazões: vazão de entrada do produto, vazão do fluido de aquecimento e vazão do fluido de resfriamento.

Tabela 5.6 - Parâmetros de tempo e vazões de operação para o ensaio dinâmico de perturbação A com variação simultânea de três vazões.

\begin{tabular}{cccc}
\hline Tempo (s) & $\boldsymbol{q}_{\text {prod }}(\mathrm{L} / \mathbf{h})$ & $\boldsymbol{q}_{\boldsymbol{a q}}(\mathrm{L} / \mathbf{h})$ & $\boldsymbol{q}_{\text {res }}(\mathrm{L} / \mathbf{h})$ \\
\hline $0-50$ & 20 & 60 & 60 \\
$50-240$ & 40 & 24 & 24 \\
$240-477$ & 20 & 60 & 60 \\
\hline
\end{tabular}

Nos ensaios B, C e D foram realizadas perturbações no processo com a variação simultânea de duas vazões: vazão de entrada do produto e vazão do fluido de aquecimento. A vazão do fluido de resfriamento foi mantida constante durante os três ensaios no valor de $60 \mathrm{~L} / \mathrm{h}$. Como esta vazão afeta apenas a temperatura de saída do produto, não foi explorado seu efeito nos ensaios dinâmicos.

Tabela 5.7 - Parâmetros de tempo e vazões de operação para o ensaio dinâmico de perturbação B com variação simultânea de duas vazões.

\begin{tabular}{ccc}
\hline Tempo (s) & $\boldsymbol{q}_{\text {prod }}(\mathbf{L} / \mathbf{h})$ & $\boldsymbol{q}_{\boldsymbol{a q}}(\mathbf{L} / \mathbf{h})$ \\
\hline $0-35$ & 9,9 & 60 \\
$35-300$ & 38,2 & 24 \\
$300-629$ & 9,7 & 60 \\
\hline
\end{tabular}

Tabela 5.8 - Parâmetros de tempo e vazões de operação para o ensaio dinâmico de perturbação C com variação simultânea de duas vazões.

\begin{tabular}{ccc}
\hline Tempo (s) & $\boldsymbol{q}_{\text {prod }}(\mathbf{L} / \mathbf{h})$ & $\boldsymbol{q}_{\boldsymbol{a q}}(\mathrm{L} / \mathbf{h})$ \\
\hline $0-40$ & 20,3 & 60 \\
$40-270$ & 37,5 & 24 \\
$270-510$ & 19,3 & 60 \\
\hline
\end{tabular}


Tabela 5.9 - Parâmetros de tempo e vazões de operação para o ensaio dinâmico de perturbação $D$ com variação simultânea de duas vazões.

\begin{tabular}{ccc}
\hline Tempo $(\mathbf{s})$ & $\boldsymbol{q}_{\text {prod }}(\mathbf{L} / \mathbf{h})$ & $\boldsymbol{q}_{\boldsymbol{a q}}(\mathrm{L} / \mathbf{h})$ \\
\hline $0-30$ & 20 & 60 \\
$30-270$ & 10 & 24 \\
$270-450$ & 20 & 60 \\
\hline
\end{tabular}

Para os ensaios E e F, a perturbação imposta foi a mudança de uma variável de processo. O ensaio $\mathrm{E}$ apresenta a mudança da vazão de alimentação do produto. As vazões dos fluidos de aquecimento e resfriamento foram mantidas constantes em $60 \mathrm{~L} / \mathrm{h}$ durante todo o ensaio.

Tabela 5.10 - Parâmetros de tempo e vazões de operação para o ensaio dinâmico de perturbação $E$ com variação de uma vazão.

\begin{tabular}{cc}
\hline Tempo (s) & $\boldsymbol{q}_{\text {prod }}(\mathrm{L} / \mathrm{h})$ \\
\hline $0-60$ & 10,3 \\
$60-360$ & 40,8 \\
$360-660$ & 10,6 \\
\hline
\end{tabular}

No ensaio $F$ a perturbação imposta foi a variação na vazão do fluido de aquecimento. Foram mantidas constantes no processo a vazão de alimentação do produto $(20 \mathrm{~L} / \mathrm{h}$ e a vazão do fluido de resfriamento $(60 \mathrm{~L} / \mathrm{h})$.

Tabela 5.11 - Parâmetros de tempo e vazões de operação para o ensaio dinâmico de perturbação $F$ com variação de uma vazão.

\begin{tabular}{cc}
\hline Tempo (s) & $\boldsymbol{q}_{\boldsymbol{a q}}(\mathrm{L} / \mathbf{h})$ \\
\hline $0-60$ & 60 \\
$60-300$ & 24 \\
$300-540$ & 60 \\
\hline
\end{tabular}

Para a simulação dos ensaios dinâmicos, foi utilizada a modelagem matemática do pasteurizador desenvolvida no Capítulo 4, respeitando a configuração de arranjo do trocador de calor a placas e dimensões do equipamento. 
As propriedades físicas dos fluidos foram calculadas levando em conta a consideração A10 da modelagem matemática (propriedades físicas dos fluidos consideradas constantes em cada seção). As equações de correlações de temperatura utilizadas para o cálculo das propriedades físicas da água foram: para a densidade (4.16), viscosidade (4.17), calor específico (4.18) e condutividade térmica da água (4.19). As temperaturas utilizadas para o cálculo das propriedades físicas dos fluidos foram as médias entre a temperatura de entrada e a temperatura de saída de cada seção do pasteurizador. As temperaturas foram obtidas dos dados experimentais do processo para cada uma das etapas.

Para cada seção do trocador de calor a placas (seção de aquecimento, regeneração e resfriamento), foram calculados os parâmetros da modelagem de troca térmica nos canais $\tau_{i}$ e $\alpha_{i}$ da equação (4.24) e os parâmetros $J_{P}$ e $\beta$ da equação (4.39) da modelagem das placas do trocador de calor.

Os parâmetros da modelagem do tubo de retenção e trechos de tubo $\tau_{T}$ e $Z$ da equação (4.47), assim como todos os outros parâmetros da modelagem da troca de calor no pasteurizador foram calculados para cada uma das etapas do ensaio, ou seja, para cada mudança de parâmetro de operação imposta no processo.

Para a simulação, além das temperaturas e os parâmetros de operação do processo, foram também utilizados os valores ajustados para os parâmetros $a_{1}, a_{2} \mathrm{e}$ $a_{3}$ da correlação de Nusselt da equação (4.6) para o cálculo dos coeficientes convectivos de troca térmica do PHE, assim como os valores ajustados dos coeficientes globais de transferência de calor com o ambiente para o tubo de retenção e trechos de tubo.

\subsection{Estudo experimental do efeito da incrustação}

Para o estudo do efeito de incrustação no desempenho térmico do trocador a placas durante o processo de pasteurização, foram realizados ensaios experimentais com utilização do leite.

Com o objetivo de obter baixa e alta incrustação, foram utilizados dois tipos de leite: 
- Leite pasteurizado - UHT integral marca PARMALAT (16 L)

- Leite cru - Procedência Lorena - São Paulo (30 L)

O leite cru foi previamente homogeneizado utilizando o homogeneizador de laboratório GAULIN modelo 15M-8TBA. Os parâmetros de homogeneização foram: temperatura de entrada do leite $65^{\circ} \mathrm{C}$, pressão de $20 \mathrm{MPa}$ no primeiro estágio e 4,8 MPa no segundo estágio (BYLUND, 1995).

Os fluidos de aquecimento e resfriamento foram água destilada. Os parâmetros de operação do processo para os dois ensaios experimentais com leite foram:

- Vazão do produto 20 L/h

- Vazão do fluido de aquecimento $60 \mathrm{~L} / \mathrm{h}$

- Vazão do fluido de resfriamento $60 \mathrm{~L} / \mathrm{h}$

- Temperatura de entrada do fluido de aquecimento $90^{\circ} \mathrm{C}$

- Temperatura de entrada do fluido de resfriamento entre $4^{\circ} \mathrm{C}$ e $7^{\circ} \mathrm{C}$

Para investigar o efeito de incrustação no processo em malha aberta, em lugar de controlar a temperatura de saída do produto do tubo de retenção, foi controlada a temperatura de entrada do fluido de aquecimento a $90{ }^{\circ} \mathrm{C}$.

O sistema de refrigeração do pasteurizador não possui controle de temperatura. É por essa razão que, durante a operação do pasteurizador, são registradas variações de temperatura na entrada de água gelada na seção de resfriamento do pasteurizador.

As placas do trocador de calor foram devidamente identificadas, pesadas e fotografadas antes e depois do ensaio de pasteurização de leite.

Procurou-se manter constantes durante todo o processo a vazão e a temperatura de alimentação do produto. As temperaturas foram registradas nos 12 pontos de medição da Figura 5.2. Na Figura 5.5 são mostradas fotografias do processamento do leite no pasteurizador de laboratório e do trocador de calor com as placas devidamente identificadas para o processo. 

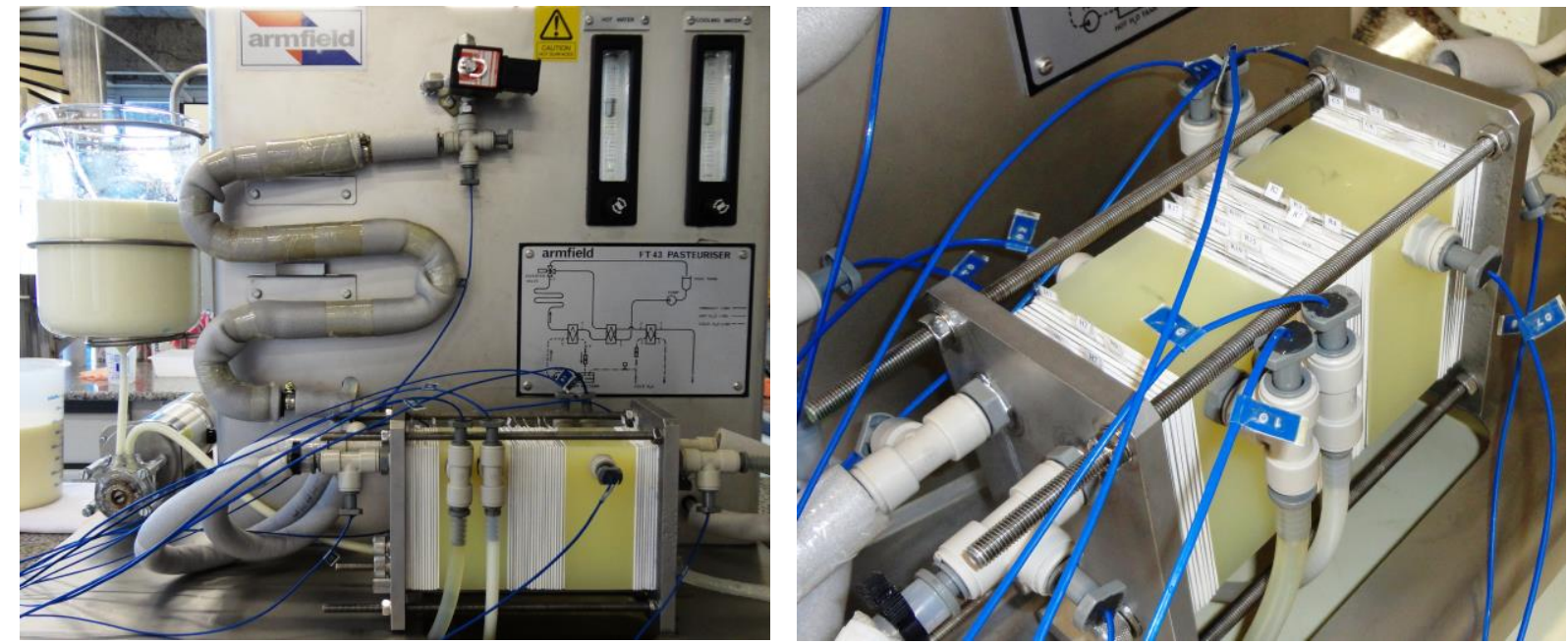

Figura 5.5 - Processamento do leite no pasteurizador de laboratorio ARMFIELD FT-43A e identificação de placas do trocador de calor.

Uma vez finalizado o ensaio experimental de pasteurização, com o trocador de calor resfriado, as placas e grades conectoras foram cuidadosamente desmontadas, escorridas e pesadas para posteriormente serem introduzidas numa estufa a uma temperatura de $105{ }^{\circ} \mathrm{C}$ durante 10 horas, para a determinação da massa seca incrustada na superfície das placas do trocador. As placas secas uma vez resfriadas, foram novamente pesadas.

Para cada lote de leite, foi determinado o extrato seco total seguindo a metodologia usada para alimentos como leite e derivados (Instituto Adolfo Lutz, 1985).

O valor da fração mássica de gordura para o leite UHT de 0,030 foi obtido da informação da embalagem do produto. Para o caso do leite cru foi assumido o valor médio dos valores encontrados na literatura (BEHMER, 1999; TORRES et al., 2000) e o valor foi de 0,038 .

As propriedades termo-físicas do leite, como densidade, viscosidade, calor específico e condutividade térmica foram calculadas a partir das equações (5.5), (5.6) e (5.8) (CHENG; FRIIS, 2007) e equação (5.7) (CHOl; OKOS, 1986). As denominações de $x_{w}$ e $x_{f}$ são referidas aos valores de fração mássica de água e fração mássica de gordura presente no leite, respectivamente. Estas equações são calculadas com temperaturas em ${ }^{\circ} \mathrm{C}$, densidade em $\mathrm{kg} / \mathrm{m}^{3}$, viscosidade em Pa.s e calor específico em J/kg.K. 


$$
\begin{aligned}
\rho= & \left(1040,7-0,2665 \cdot T-0,0023 \cdot T^{2}\right)-x_{f}(1,011+0,00976 \cdot T- \\
& \left.4,81 \times 10^{-5} \cdot T^{2}\right) \\
\mu= & \left(0,9565-1,3004 \times 10^{-3} \cdot T+1,958 \times 10^{-4} \cdot T^{2}\right)+x_{f}(0,4766- \\
& \left.\left.0,0114 \cdot T+7,264210^{-5} \cdot T^{2}\right)\right] \times 10^{-3} \\
C p= & 1275+2512 \cdot x_{w} \\
k= & \left(0.528+0,00123 \cdot T-0,732 \times 10^{-5} \cdot T^{2}\right)\left(1-x_{f}(0,843+\right. \\
& 0,0019 \cdot T)
\end{aligned}
$$

O tempo de operação para o ensaio utilizando leite UHT foi 6 horas e para 0 ensaio do leite cru previamente homogeneizado foi de 3 horas.

Durante o estudo experimental de incrustação com o leite UHT, o leite pasteurizado foi recirculado continuamente durante o processo, já no ensaio com leite cru, a recirculação foi realizada uma vez a partir do instante $1,45 \mathrm{~h}$ depois do início do processo.

\subsection{Simulação do processo de pasteurização com influência da incrustação}

Para a simulação do processo de pasteurização com influência da incrustação, a seção de aquecimento do trocador, onde são registradas as temperaturas mais elevadas do processo, é considerada como a única seção do trocador afetada pela incrustação. Sendo que um dos maiores problemas da incrustação num processo térmico é a influência da baixa condutividade térmica do material incrustado na superfície de troca térmica, assim como o aumento da espessura da parede entre o 
fluido e a fonte de calor, este efeito é refletido no valor do coeficiente global de troca térmica $U$ ao longo do processo, especificamente no valor do $U^{I}$ que é o coeficiente de troca térmica global do lado $I$ da seção de aquecimento, que é o lado onde o fluido é o produto a ser pasteurizado. Lembrando que no lado II o fluido é água, portanto, sem efeitos considerados de incrustação.

Os parâmetros de operação utilizados para a simulação do processo de pasteurização com a incorporação do efeito de incrustação foram:

- Vazão do produto 20 L/h

- Vazão do fluido de aquecimento 60 L/h

- Vazão do fluido de resfriamento $60 \mathrm{~L} / \mathrm{h}$

- Temperatura de entrada do produto $19^{\circ} \mathrm{C}$

- Temperatura de entrada do fluido de aquecimento $90^{\circ} \mathrm{C}$

- Temperatura de entrada do fluido de resfriamento $2{ }^{\circ} \mathrm{C}$

- Temperatura ambiente $23^{\circ} \mathrm{C}$

- Tempo total de operação 4 horas

- Período de indução 30 minutos

- Fator de incrustação máximo no processo $2,8 \times 10^{-4} \mathrm{~m}^{2} \mathrm{~K} / \mathrm{W}$

O valor máximo do fator de incrustação adotado para a simulação do processo com incrustação foi obtido a partir do trabalho de Tejeda (2003), que obteve um valor de incrustação para o leite integral num trocador de calor a placas, com um período de indução de aproximadamente 30 minutos.

Para o modelo de incrustação 1, definido pela equação (4.61), o valor da constante de velocidade cinética $\alpha_{f}$ foi ajustado para que o processo de pasteurização, em 4 horas de operação, atinja o $90 \%$ do valor permitido de incrustação, levando em conta que os primeiros 30 minutos de operação, são considerados como período de indução, ou seja, sem presença de incrustação.

Na Figura 5.6 é apresentada a tendência linear de crescimento da incrustação utilizada para o modelo de incrustação 1 . O valor ajustado para o $\alpha_{f}$ foi de $7,2 \times 10^{-5}$ $\mathrm{s}^{-1}$. A linha pontilhada vermelha indica o fim do período de indução e o início da incrustação no processo. 


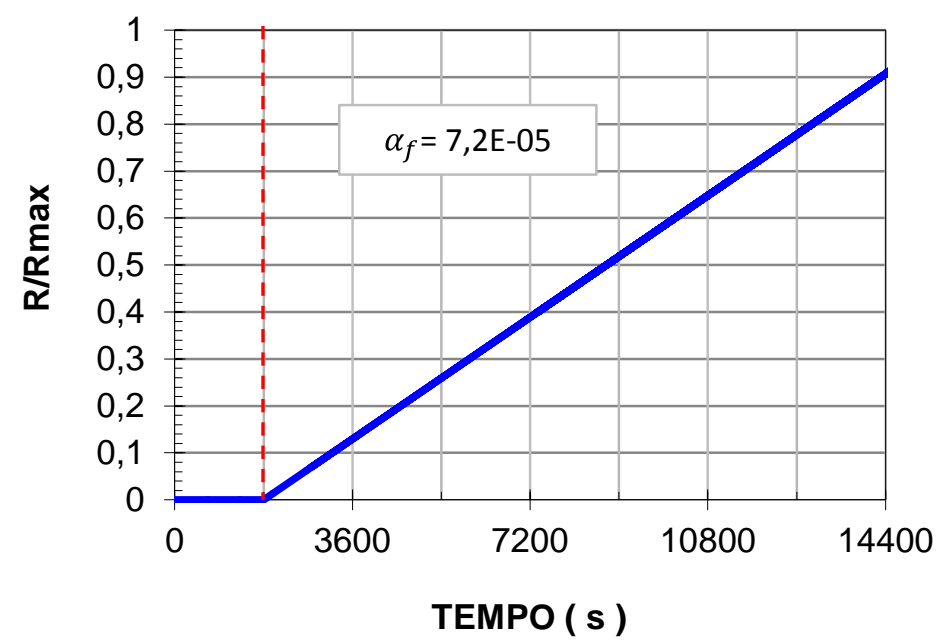

Figura 5.6 - Tendência da incrustação linear em função do tempo (modelo 1 de incrustação).

A influência do fenômeno de incrustação no coeficiente global de transferência de calor no trocador, para o modelo de incrustação 1, pode ser calculado com a equação (5.9). Vale salientar que o valor de $U_{c}$ é o valor do coeficiente global de troca térmica do trocador limpo (livre de incrustação).

$$
U_{\text {modelo } 1}=\frac{U_{c}}{1+\left(t-t_{f_{0}}\right) \cdot\left(\alpha_{f} \cdot R_{\max } \cdot U_{c}\right)} \quad \text { para } \quad t \geq t_{f_{0}}
$$

Para o caso do modelo de incrustação 2, descrito pela equação (4.63), o valor determinado para o parâmetro da constante de velocidade cinética da incrustação $\alpha_{f}$ foi $1380 \mathrm{~s}^{-1}$. Da mesma forma que no modelo de incrustação 1 , os primeiros 30 minutos de operação do processo foram considerados como período de indução, ou seja, sem incrustação. As próximas 3,5 horas de operação seguintes com a incorporação do efeito de incrustação atingiram $90 \%$ do valor máximo de incrustação do processo, fazendo um tempo total de 4 horas de operação.

A Figura 5.7 mostra o gráfico da tendência de incrustação para o modelo de incrustação 2. A linha pontilhada vermelha indica o momento de início da incrustação no processo. 


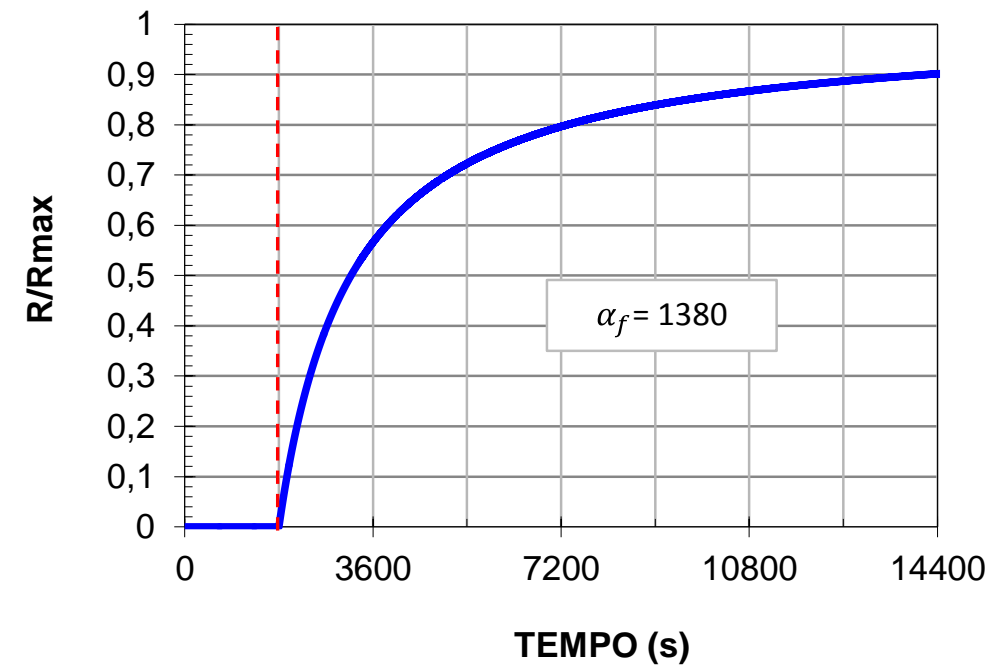

Figura 5.7 - Tendência da incrustação assintótica em função do tempo (modelo 2 de incrustação).

Para a modelagem de incrustação 2, a influência da incrustação no lado $I$ do trocador, pode ser calculada com a equação (5.10).

$$
U_{\text {modelo } 2}=\frac{U_{c} \cdot\left(\alpha_{f}+t\right)}{\alpha_{f}+\left(t-t_{f_{0}}\right) \cdot\left(U_{c} \cdot R_{\max }+1\right)} \quad \text { para } t \geq t_{f_{0}}
$$




\section{RESULTADOS E DISCUSSÃO}

Resultados ajustados para os coeficientes experimentais de troca térmica, validação de dados experimentais e simulados da partida do pasteurizador e ensaios de perturbação, assim como o resultado dos ensaios experimentais de incrustação do leite e das simulações do modelo de incrustação são apresentados neste capítulo.

\subsection{Coeficientes de troca térmica}

Nesta seção são apresentados os resultados do ajuste experimental dos coeficientes de troca térmica do trocador de calor a placas e os coeficientes globais de troca térmica com o ambiente do tubo de retenção e trechos de tubo.

\subsubsection{Coeficiente de troca térmica no trocador de calor a placas}

Os parâmetros de troca térmica $a_{1}$ e $a_{2}$ da equação de Nusselt, equação (4.6), utilizada para o cálculo do coeficiente convectivo de troca térmica no trocador de calor a placas, foram ajustados para 48 ensaios experimentais utilizando as seguintes condições de operação:

- Número de Reynolds: $82 \leq R e \leq 1666$;

- Número de Prandtl: $2,0 \leq \operatorname{Pr} \leq 11,2$;

- Temperatura em ${ }^{\circ} \mathrm{C}: 2,6 \leq T \leq 92$;

- Vazão do produto (água filtrada) em L/h: $10 \leq W \leq 40$;

- Vazão do fluido de serviço em L/h: $24 \leq W \leq 60$;

- Arranjo padrão do PHE (em série contracorrente, um canal por passe, sendo o número de canais por seção de 12 no aquecimento, 20 na regeneração e 8 no resfriamento).

Os valores ajustados para os parâmetros $a_{1}$ e $a_{2}$, nas condições de operação especificadas, são apresentados na Tabela 6.1. O gráfico de paridade entre o calor experimental e o calor calculado com a equação (6.1) é apresentado na Figura 6.1. 
O valor do coeficiente de correlação entre os valores do calor calculado e o calor experimental $\left(R^{2}\right)$ foi 0,868 .

Tabela 6.1 - Valores ajustados dos parâmetros de troca térmica no PHE para a equação de Nusselt.

\begin{tabular}{cc}
\hline Coeficiente & Valor \\
\hline$a_{1}$ & $9,02 \times 10^{-2}$ \\
$a_{2}$ & $6,63 \times 10^{-1}$ \\
\hline
\end{tabular}

$$
N u=9,02 \times 10^{-2} \cdot R e^{6,63 \times 10^{-1}} \cdot \operatorname{Pr}^{0,333}
$$

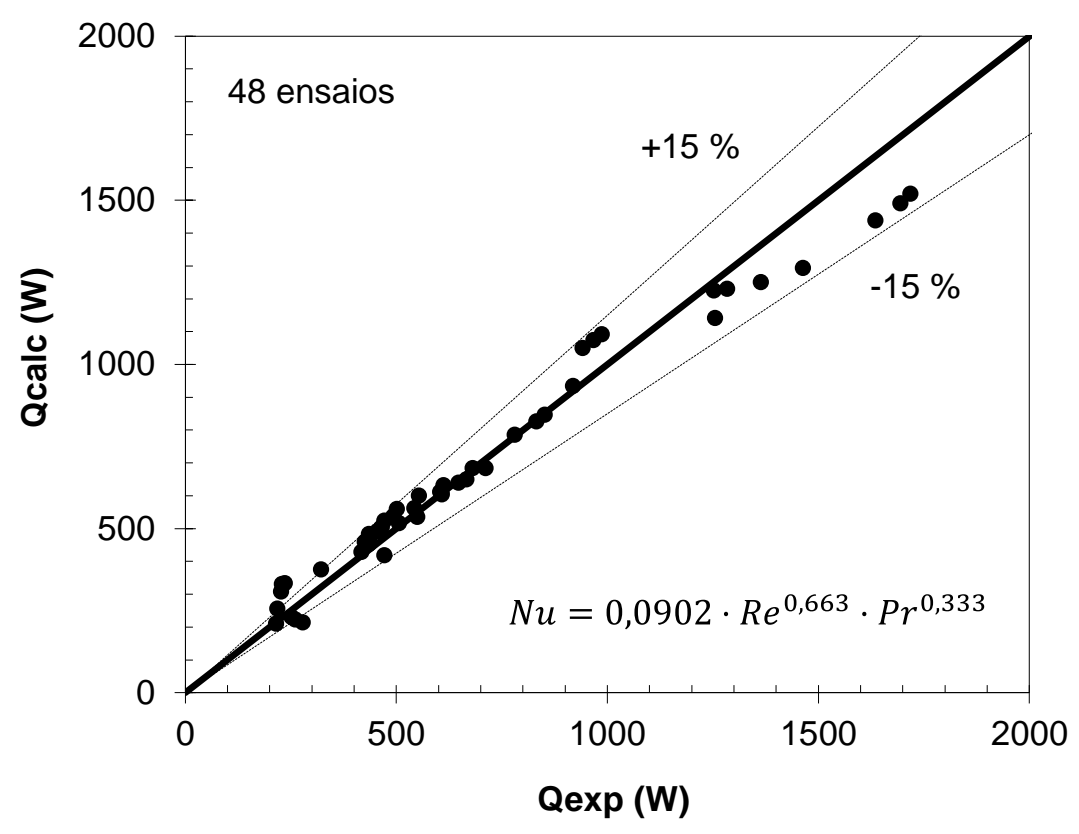

Figura 6.1 - Gráfico de paridade da taxa de troca de calor experimental com a troca de calor calculada no PHE.

Foi observado na Figura 6.1 que os pontos que estão fora ou aproximados do limite de $15 \%$ são referente aos ensaios experimentais onde a vazão de alimentação do produto foi a mais baixa $(10 \mathrm{~L} / \mathrm{h})$, independentemente das vazões dos fluidos de utilidade (aquecimento e resfriamento). Este comportamento pode ser relacionado ao efeito da troca térmica com o ambiente, pois quanto menor é a vazão do produto, 
a troca de calor com o ambiente é mais relevante. Por outro lado, em Reynolds baixos existe a possibilidade da formação de canais preferenciais de escoamento que propiciam o acumulo de bolhas de ar e diminuem a troca térmica o que poderia ter relação com os pontos obtidos nesta faixa de escoamento. Os ensaios com as outras vazões tiveram menor desvio.

$\mathrm{Na}$ literatura foram encontrados outros valores ajustados para os parâmetros $a_{1}$ e $a_{2}$ da equação (6.1) para o mesmo equipamento utilizando água como fluido de estudo. Valores de $a_{1}=0,0457$ e $a_{2}=0,771$ foram obtidos por Gut et al. (2004) para faixas de $R e$ mais amplas $10<R e<2400$, determinados a partir de 121 ensaios experimentais com vários arranjos de configuração e número de placas. Outros valores foram também apresentados por Miura et al. (2006), onde o ajuste dos parâmetros foi na faixa de $120 \leq R e \leq 1950$ utilizando um arranjo de configuração de trocador de $N=1$ em série; os valores obtidos para os parâmetros foram $a_{1}=0,0263$ e $a_{2}=0,867$.

O gráfico da Figura 6.2 apresenta a correlação ajustada experimentalmente e as correlações encontradas na literatura. Neste gráfico é possível observar que a correlação ajustada apresenta boa concordância com os dados da literatura, a pesar da considerável variação no valor dos parâmetros $a_{1}$ e $a_{2}$. 


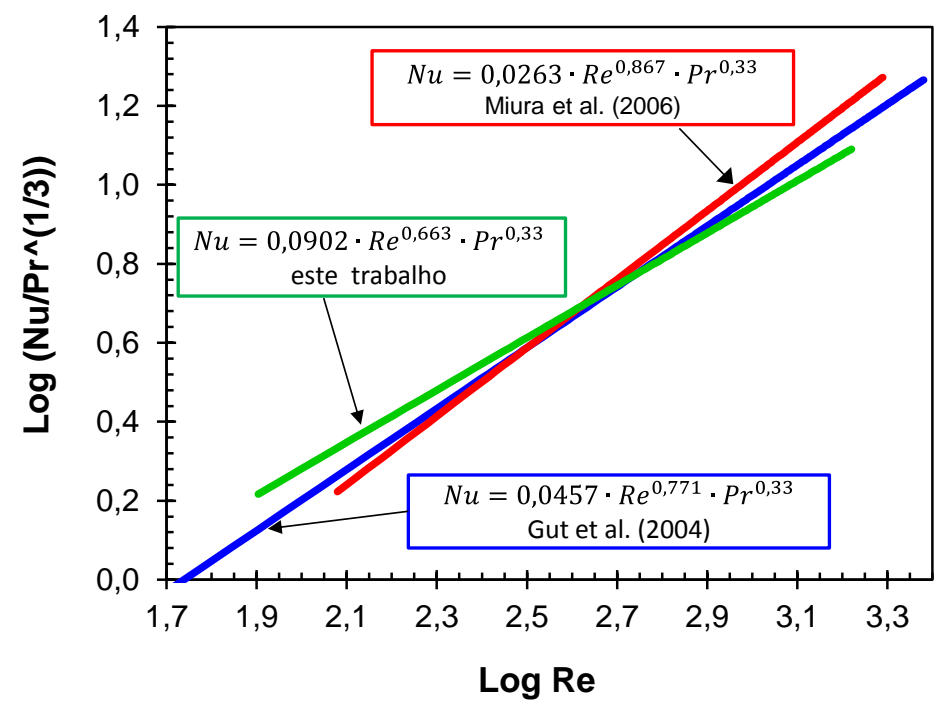

Figura 6.2 - Correlação dos valores ajustados experimentalmente e os valores encontrados na literatura para os parâmetros $a_{1}$.e $a_{2}$ da equação de Nusselt.

\subsubsection{Coeficiente global de troca térmica dos tubos}

$\mathrm{Na}$ determinação dos coeficientes globais de troca térmica do produto com o ambiente, para o tubo de retenção e trechos de tubo, devido à proximidade entre as temperaturas de entrada e saída dos tubos, o valor da diferença entre elas foi muito pequeno comparado com o erro de medição das temperaturas (erro do termopar: 0,5 ${ }^{\circ} \mathrm{C}$ ), fato que dificultou a obtenção destes coeficientes em função da vazão do fluido. Outro fator que também poderia ter influenciado à dispersão de pontos nos gráficos foi que os ensaios foram realizados a diferentes temperaturas de fluido assim como a diferentes temperaturas ambiente.

Nas Figuras 6.3, 6.4 e 6.5 são mostrados gráficos com os valores obtidos dos coeficientes globais de troca de calor com o ambiente para cada tubo em função da vazão. 
Tubo 1

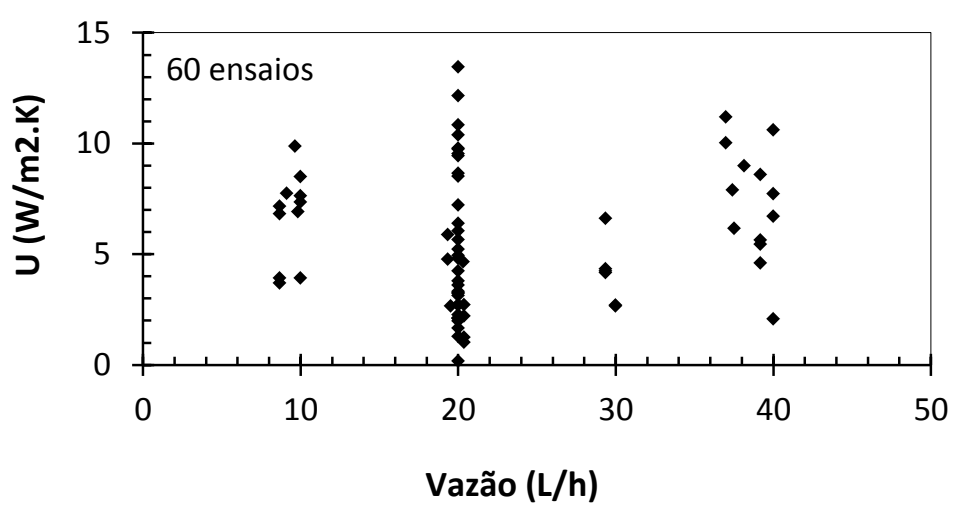

Figura 6.3 - Coeficiente global de troca térmica com o ambiente em função da vazão no Tubo 1.

Tubo 2

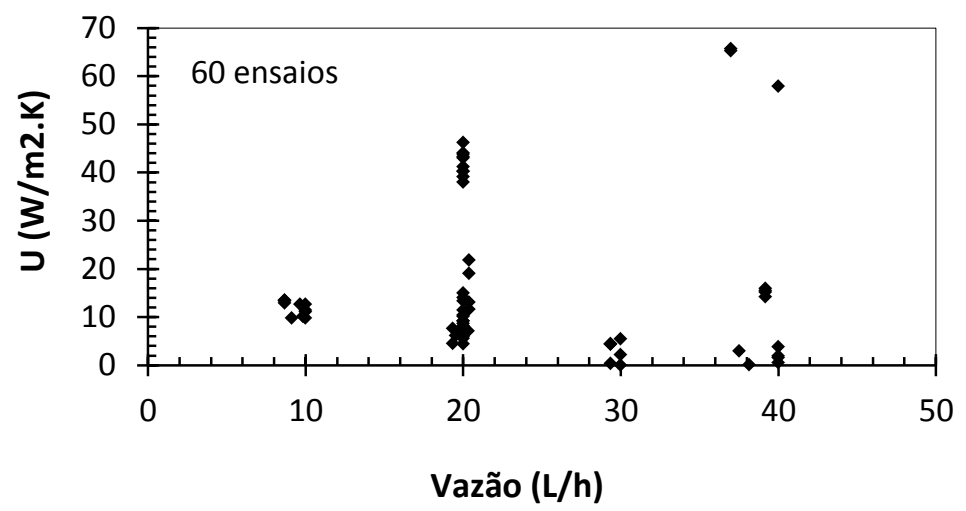

Figura 6.4 - Coeficiente global de troca térmica com o ambiente em função da vazão no Tubo 2.

Tubo 3

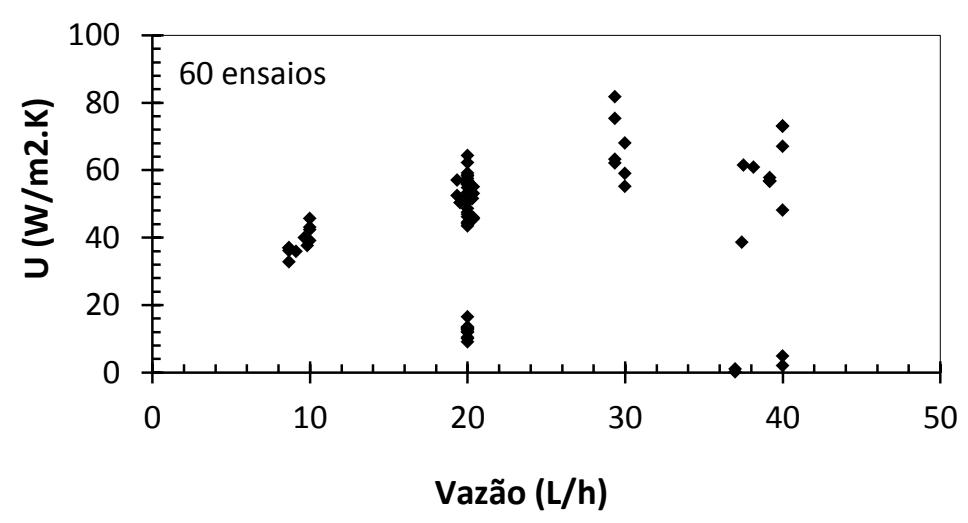

Figura 6.5 - Coeficiente global de troca térmica com o ambiente em função da vazão no Tubo 3. 
Devido ao espalhamento dos pontos, o valor adotado para o coeficiente global de troca térmica de cada tubo foi o valor da média de todos os ensaios experimentais realizados nas diferentes vazões estudadas (de 8,7 L/h até $40 \mathrm{~L} / \mathrm{h}$ ). A faixa de temperatura de fluido que atenderam estes ensaios foi de $60{ }^{\circ} \mathrm{C}$ até $90^{\circ} \mathrm{C}$.

Os valores experimentais médios dos coeficientes globais de troca térmica com o ambiente para o tubo de retenção e trechos de tubo são apresentados na Tabela 6.2. O trecho de tubo que conecta a seção de aquecimento com o tubo de retenção está indicado como "Tubo 1", o tubo de retenção indicado como "Tubo 2" e o trecho de tubo que conecta o tubo de retenção com a seção de regeneração está indicado como "Tubo 3".

Tabela 6.2 - Valores dos coeficientes globais médios de troca térmica dos trechos de tubo com o ambiente.

\begin{tabular}{ccc}
\hline Seção & $\boldsymbol{U}\left(\mathbf{W} / \mathbf{m}^{2} \cdot \mathbf{K}\right)$ & $\boldsymbol{R}$ \\
\hline Tubo 1 & $6,1 \pm 3,1$ & $947 \leq R e \leq 4143$ \\
Tubo 2 & $16 \pm 15$ & $826 \leq R e \leq 3677$ \\
Tubo 3 & $47 \pm 18$ & $1052 \leq R e \leq 4848$ \\
\hline
\end{tabular}

Os valores obtidos dos coeficientes globais de troca térmica com o ambiente foram coerentes, pois o tubo de retenção (Tubo 2), assim como o trecho inicial do tubo (Tubo 1) possuem uma camada de isolante térmico, portanto, apresentam menor troca de calor com o ambiente comparado com o trecho de tubo que não possui isolante térmico (Tubo 3).

Os valores elevados do desvio padrão nos resultados da Tabela 6.2, foram atribuídos ao erro de medição das temperaturas usando termopares, devido à pequena diferença entre as temperaturas de entrada e saída dos tubos.

\subsection{Resultado da constante de tempo do termopar}

O gráfico da Figura 6.6 mostra a velocidade de resposta de um termopar diante de variações instantâneas de temperatura. 


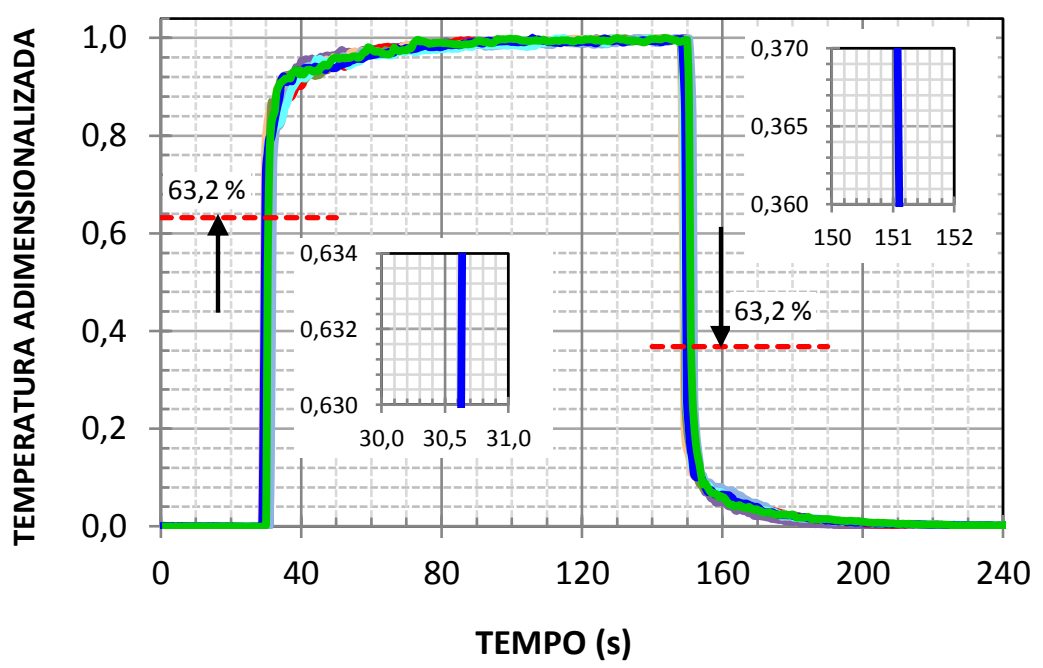

Figura 6.6 - Determinação da constante de tempo do termopar.

O valor da constante de tempo do termopar é de aproximadamente 1 segundo, conforme indicado no gráfico da Figura 6.6. Mesmo que o valor da constante de tempo do termopar demostre uma grande velocidade de resposta diante de degraus de temperatura, pode ser também observado, que o tempo que demora o termopar para atingir a temperatura real do meio, com precisão de $0,2^{\circ} \mathrm{C}$, é aproximadamente 50 segundos. Este comportamento pode influir de certa forma no registro de temperaturas nos ensaios dinâmicos.

\subsection{Resultado da partida do processo}

Os valores experimentais e simulados da partida do pasteurizador são apresentados na Figura 6.7. As linhas verdes no gráfico representam valores experimentais, as linhas azuis representam valores simulados e a linha pontilhada vermelha indica o instante em que foi iniciada a partida do processo.

As indicações de temperatura T2 (saída regeneração lado frio), T5 (saída tubo de retenção), T7 (saída regeneração lado quente) e T8 (fim do processo) correspondem aos pontos de medição mais representativos do processo de pasteurização, estes pontos foram mostrados na Figura 5.2 e descritos na Tabela 5.1 . 


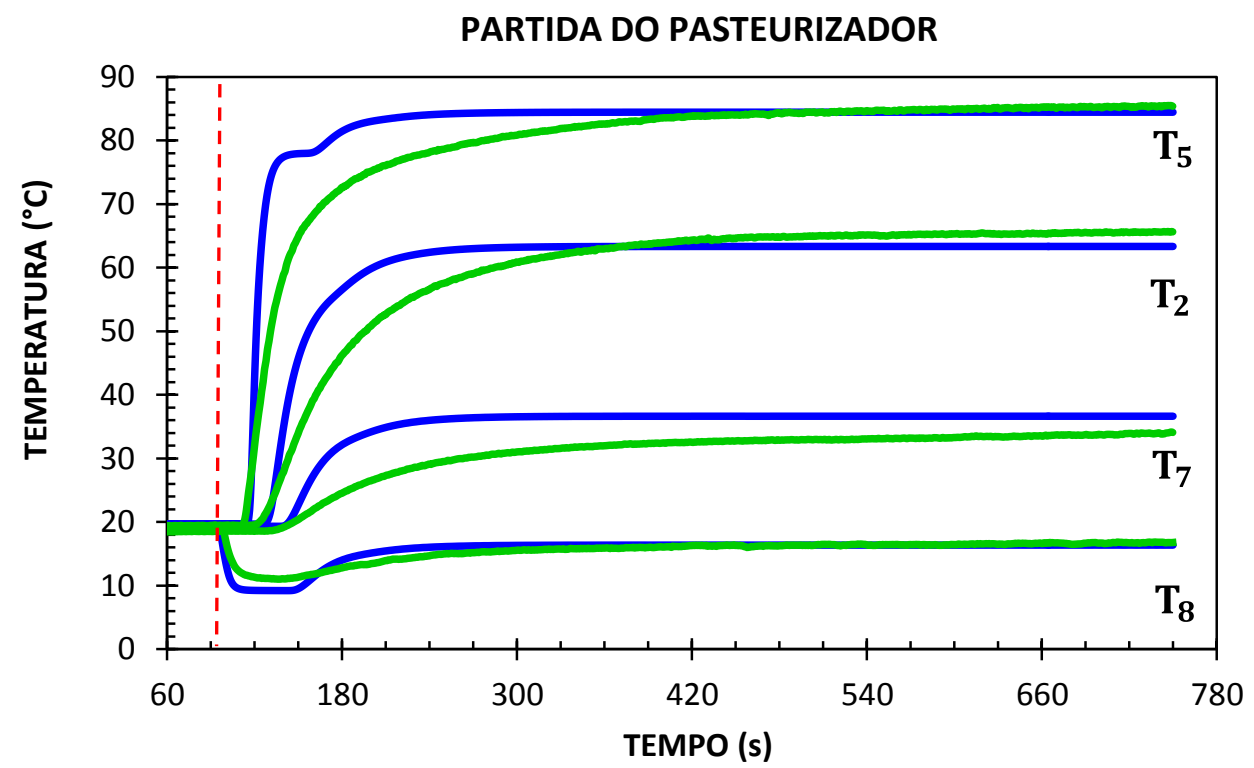

Figura 6.7 - Dados experimentais e simulados de temperatura da partida do pasteurizador. Linhas verdes representam dados experimentais e linhas azuis dados simulados.

Entre as temperaturas mostradas no gráfico da Figura 5.2, a primeira mudança de temperatura após o início da partida do processo de pasteurização (95 s) é a temperatura de saída do produto da seção de resfriamento (T8). Esta mudança foi quase imediata (96 s) devido à troca de calor da água gelada com a saída do produto na seção de resfriamento. A próxima mudança foi o aumento da temperatura na seção de aquecimento identificada no aumento da temperatura na saída do tubo de retenção T5 (116 s) o que nos próximos instantes ocasionou o aumento das temperaturas na seção de aquecimento T2 (130 s) e T7 (143s) e como consequência uma elevação das temperaturas T8 (150 s) e T5 (164 s) no processo.

A variação entre as curvas experimental e simulada da temperatura T5 manifesta que possivelmente o escoamento do fluido nos canais do trocador de calor, tubo de retenção e trechos de tubo, não seja puramente pistonado como é assumido pelo modelo matemático simulado. No Apêndice $A$, são mostrados os gráficos das temperaturas experimentais e simuladas nos 12 pontos de medição de temperatura para o ensaio da partida do pasteurizador, onde é possível identificar nas temperaturas experimentais o registro de uma leve mudança na curva da temperatura T3, sendo esta pouco perceptível na temperatura T4, e acabando de desaparecer na temperatura T5 a diferença das temperaturas determinadas pela 
simulação, comportamento que possivelmente poderia ser atribuído ao tipo de escoamento assumido na modelagem do pasteurizador.

Em geral, pode-se observar que a resposta da simulação do modelo da partida do pasteurizador foi mais rápida do que a resposta experimental. Este fato pode ser associado à inércia dos termopares em registrar as mudanças de temperatura, assim como à inércia térmica do equipamento que não foi contabilizada na modelagem do processo (apenas as placas metálicas foram consideradas). As diferenças entre a temperatura experimental e simulada, no segundo estado estacionário do processo, especificamente nas temperaturas $T 2$ e $T 7$, possivelmente sejam relacionadas com os coeficientes globais de troca térmica nos canais e tubos. Ainda assim, verifica-se que 0 modelo representa de forma satisfatória 0 comportamento dinâmico.

\subsection{Resultado dos ensaios com perturbação}

Nos gráficos seguintes são apresentados os valores experimentais e simulados dos ensaios dinâmicos com perturbações no processo denominados como ensaio $A$, B, C, D, E e F. Nas Tabelas 5.6, 5.7, 5.8, 5.9, 5.10 e 5.11 foram apresentados os parâmetros de operação para cada um dos ensaios.

Linhas azuis nos gráficos representam valores simulados, linhas verdes representam valores experimentais e linhas pontilhadas vermelhas indicam os instantes em que foram impostas as perturbações no processo. As indicações de temperatura nos pontos de medição T2, T5, T7 e T8 correspondentes aos pontos de medição mais representativos do processo.

A Figura 6.8 mostra as temperaturas experimentais e simuladas registradas no ensaio dinâmico de perturbação $A$, correspondente à variação simultânea de três variáveis: vazão de alimentação do produto, vazão de entrada de água quente e vazão de entrada de água gelada. 


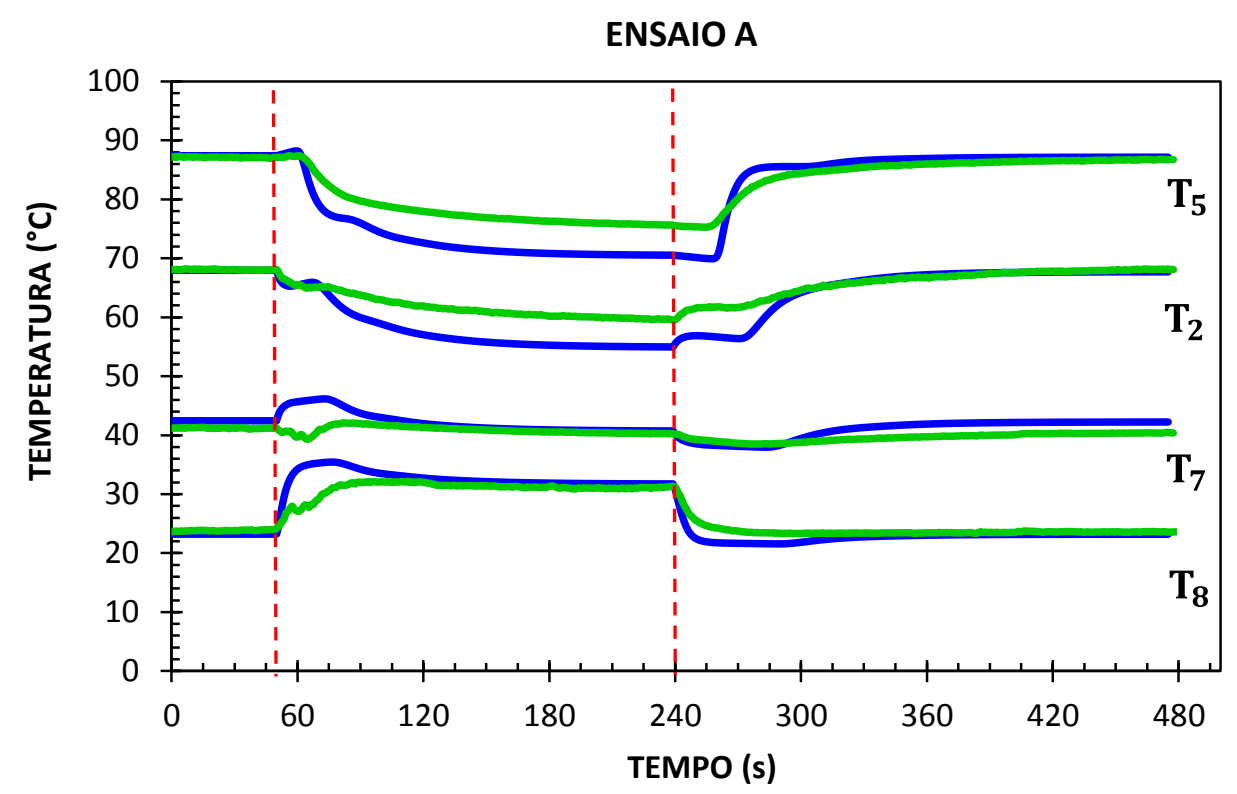

Figura 6.8 - Dados experimentais e simulados de temperatura para o ensaio dinâmico de perturbação A. Linhas verdes representam dados experimentais e linhas azuis dados simulados.

No ensaio $A$, a diminuição da vazão de entrada de água quente provocou a redução da troca térmica na seção de aquecimento do trocador, causando uma redução na temperatura do produto na saída do aquecimento, refletindo este comportamento na temperatura de saída do tubo de retenção T5 e, por conseguinte, nas temperaturas da seção de regeneração T2 e T7. Outro fator que também contribuiu com esse comportamento foi o aumento da vazão de alimentação do produto, que provocou a diminuição do tempo de residência do produto, prejudicando a troca térmica.

O aumento da temperatura T8, além de ter a influência do aumento da vazão do produto também tem relação direta com a diminuição da vazão de entrada de água gelada, o que provocou a diminuição de troca térmica na seção de resfriamento do trocador, aumentando a temperatura de saída do produto.

As Figuras 6.9, 6.10 e 6.11 apresentam os resultados dos ensaios dinâmicos de perturbação do processo $B, C$ e $D$ com variação de dois parâmetros de operação: vazão de alimentação do produto e vazão de entrada de água quente. A vazão de água gelada nestes ensaios foi mantida constante, já que a mudança desta vazão só influi na temperatura de saída do produto. 


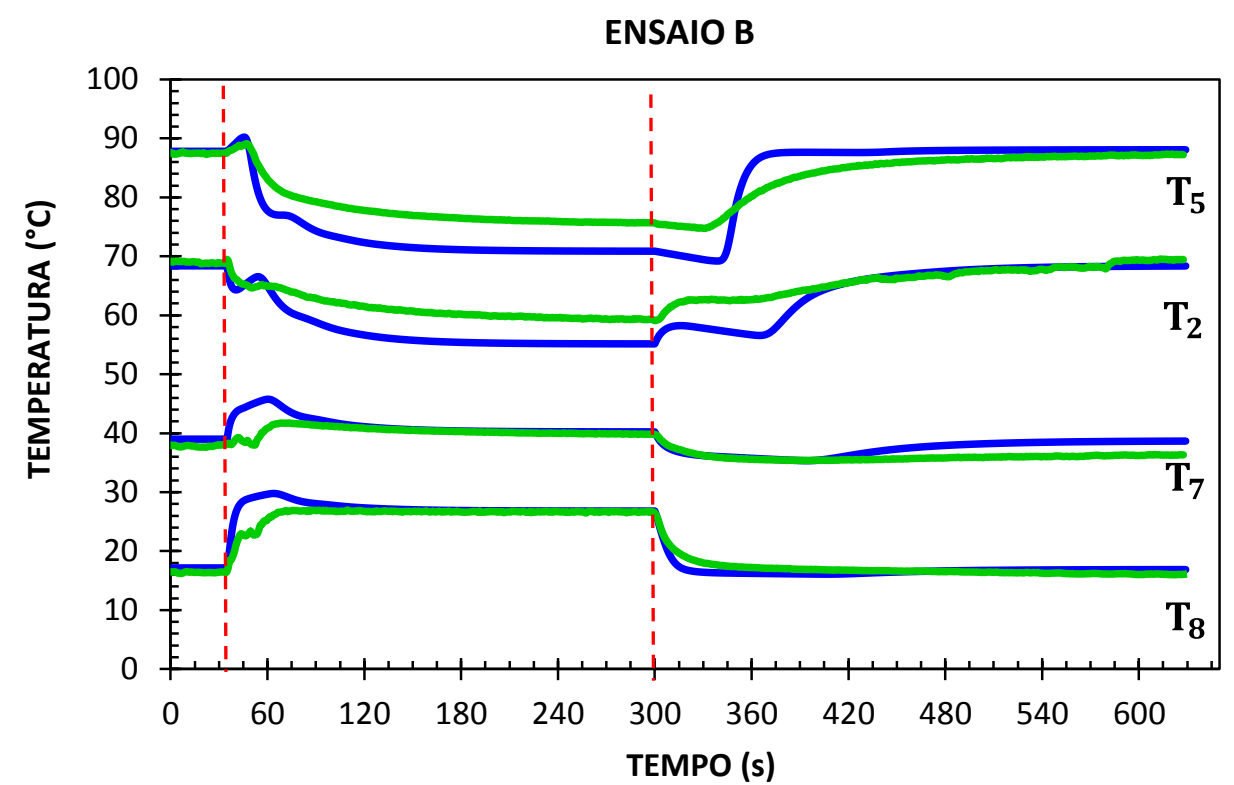

Figura 6.9 - Dados experimentais e simulados de temperatura para o ensaio dinâmico de perturbação B. Linhas verdes representam dados experimentais e linhas azuis dados simulados.

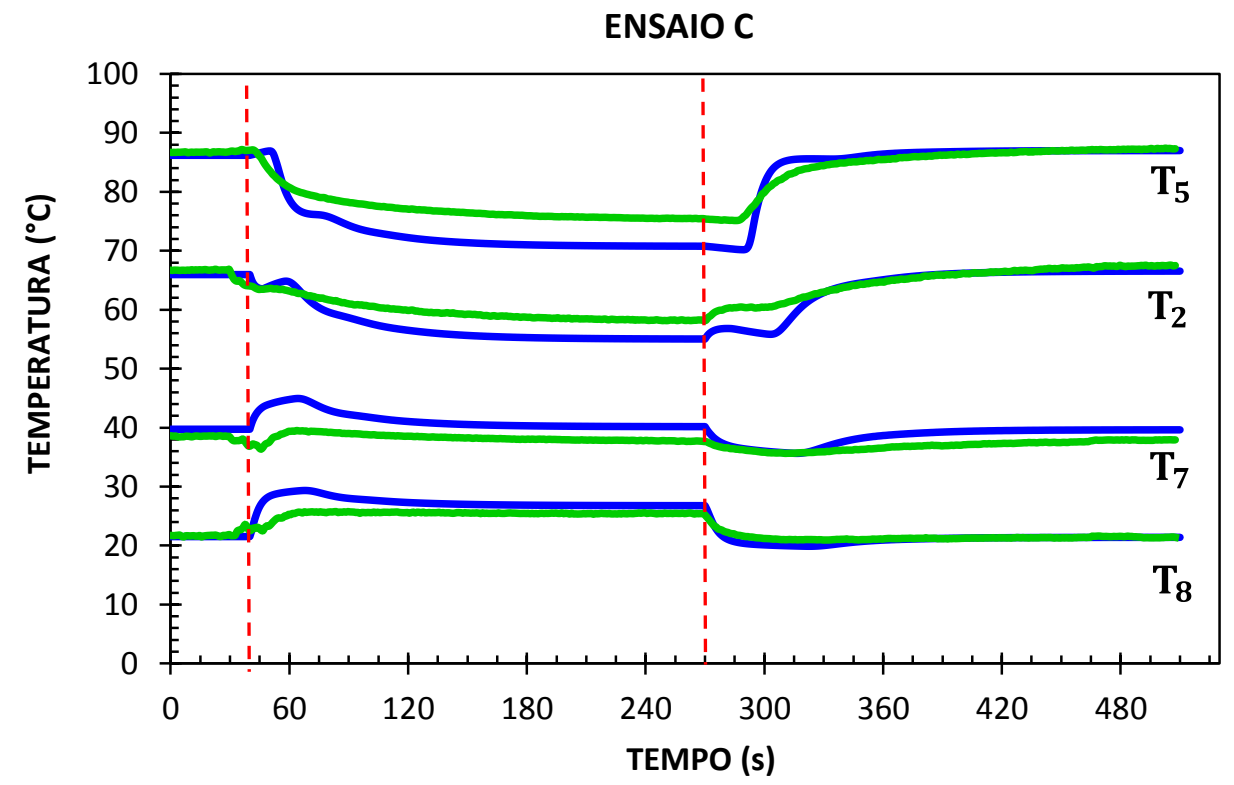

Figura 6.10 - Dados experimentais e simulados de temperatura para o ensaio dinâmico de perturbação C. Linhas verdes representam dados experimentais e linhas azuis dados simulados. 


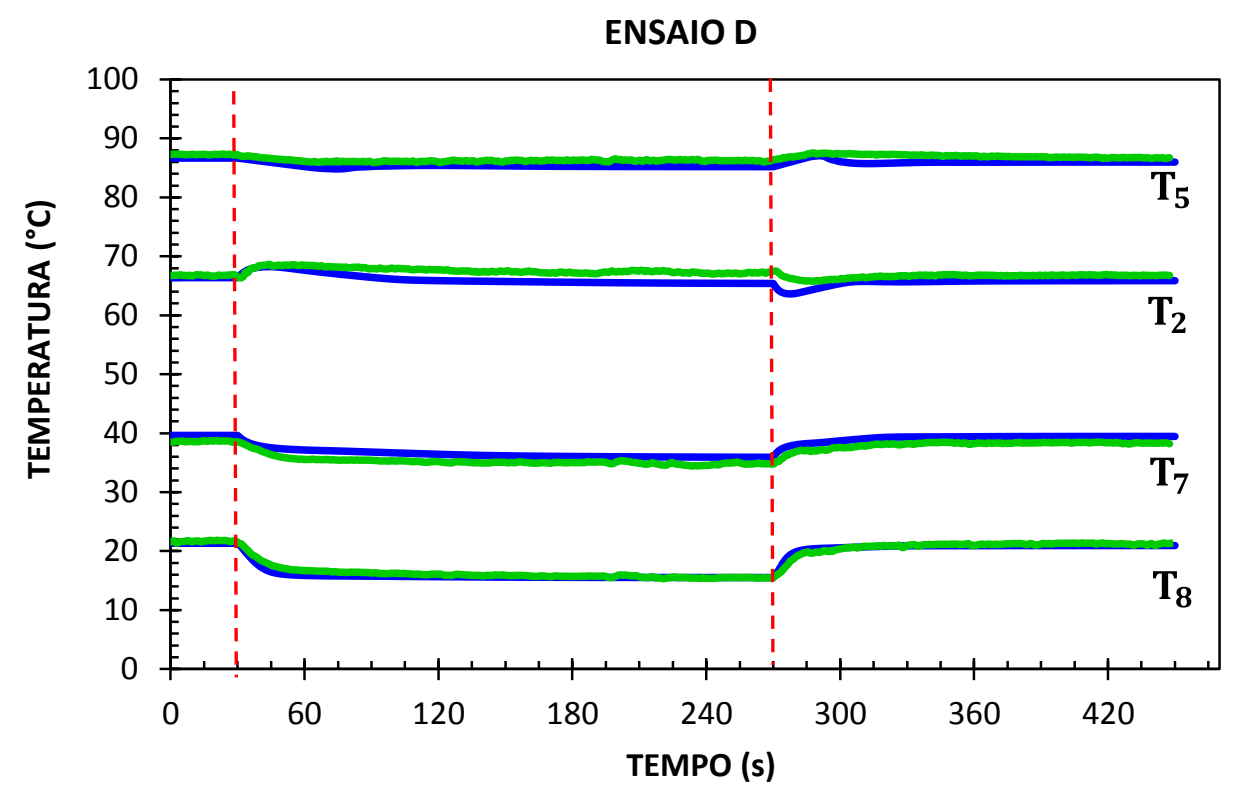

Figura 6.11 - Dados experimentais e simulados de temperatura para o ensaio dinâmico de perturbação $D$. Linhas verdes representam dados experimentais e linhas azuis dados simulados.

Os ensaios B e C apresentaram grandes mudanças de temperatura e basicamente tiveram a mesma tendência já que nos dois ensaios a perturbação do processo foi muito parecida, sendo um aumento na vazão de alimentação do produto e uma diminuição da vazão de entrada de água quente. No caso do ensaio $B$, a variação das temperaturas foi maior que no ensaio $C$ devido a uma mudança maior na vazão de alimentação do produto.

No ensaio $D$, como a perturbação imposta foi a diminuição das vazões de alimentação do produto e da entrada de água quente não foram observadas grandes mudanças. Se bem, a diminuição da vazão do produto gera um aumento no tempo de residência o que melhora a transferência de calor, por outro lado, a diminuição da vazão de entrada de água quente reduz a carga térmica na seção de aquecimento, dando como resultado uma atenuação da perturbação imposta no processo.

Os resultados dos ensaios de perturbação com a mudança de uma variável, ensaio $\mathrm{E}$ : vazão de alimentação do produto e ensaio $\mathrm{F}$ : vazão de entrada de água quente, são apresentados na Figura 6.12 e Figura 6.13 respectivamente. 


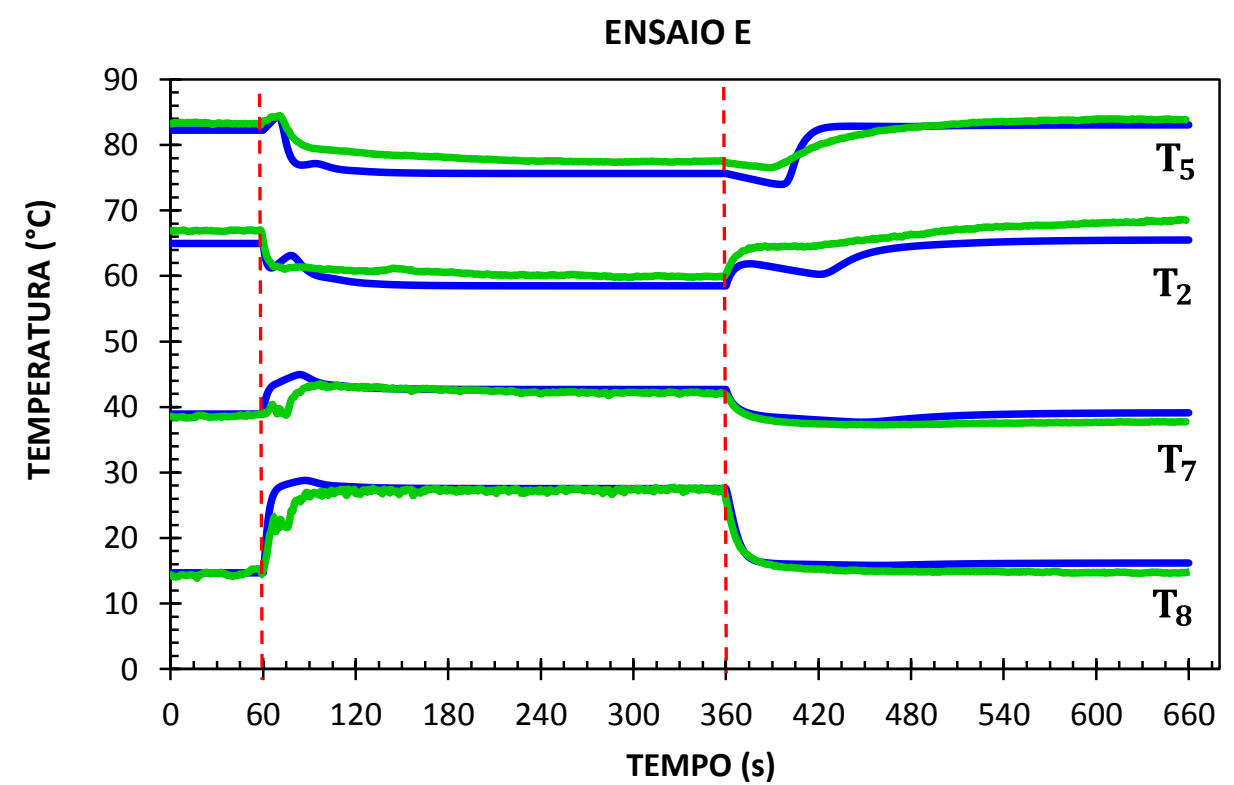

Figura 6.12 - Dados experimentais e simulados de temperatura para o ensaio dinâmico de perturbação E. Linhas verdes representam dados experimentais e linhas azuis dados simulados.

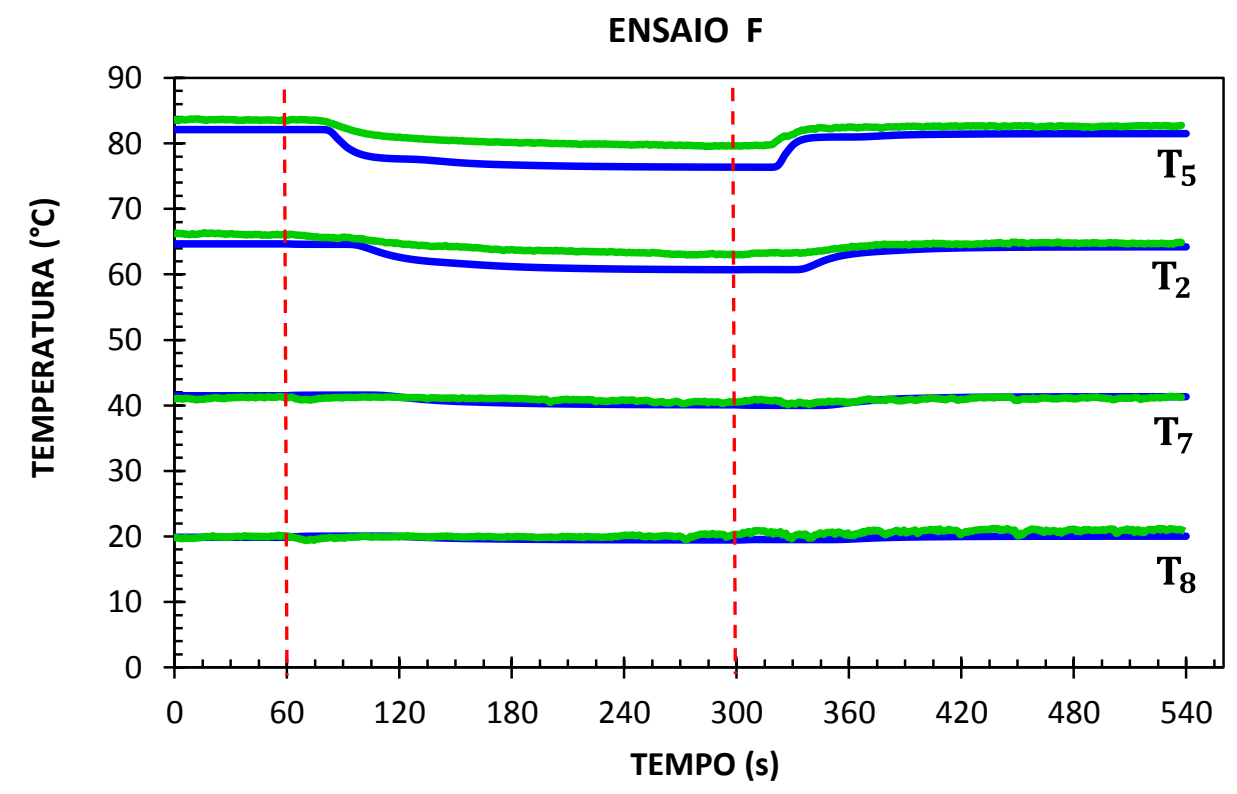

Figura 6.13 - Dados experimentais e simulados de temperatura para o ensaio dinâmico de perturbação F. Linhas verdes representam dados experimentais e linhas azuis dados simulados.

De uma forma geral, pode-se notar que os comportamentos experimentais e de simulação das temperaturas nos ensaios de perturbação foram muito próximos. 
Levando em consideração a presença de 3 estados estacionários durante os ensaios de perturbação, os maiores desvios de temperatura entre os valores experimentais e simulados nos ensaios $A, B, C$ e $E$ foram identificados nas temperaturas T2 e T5 no $2^{\circ}$ estado estacionário. Entre estes ensaios, um dos parâmetros em comum, nesse estagio, foi o valor extremo da vazão de alimentação do produto, comportamento que poderia estar refletindo o gráfico de paridade da troca de calor experimental com a troca de calor calculada na determinação dos coeficientes de troca térmica do PHE na Figura 6.1.

Nos ensaios A, B, C e E, o aumento na vazão de alimentação do produto provocou o aumento no coeficiente convectivo de troca térmica (o que melhora a taxa de transferência de calor) e por outro lado, provocou também uma diminuição no tempo de residência no trocador (o que reduz a variação de temperatura). Consequentemente, houve uma diminuição na temperatura de saída da seção de aquecimento que gerou a diminuição da temperatura na saída do tubo de retenção (T5) e, por conseguinte, uma variação na temperatura T2 relacionada com a seção de regeneração. A elevação da temperatura $T 7$ nestes ensaios foi amplificada na seção de resfriamento com a piora na troca térmica, refletida na elevação de T8. Outro fator que também influiu no comportamento dos ensaios $A, B, C, D$ e no ensaio $F$ foi a diminuição da vazão do fluido de aquecimento que provocou uma diminuição da carga térmica na seção de aquecimento que contribuiu na redução das temperaturas T2 e T5 no processo.

Nos ensaios D e F, a diferença dos outros ensaios o grau de perturbação imposto foi menor, fato que contribuiu para que as temperaturas não apresentassem grandes mudanças durante o processo.

Os desvios apresentados entre os valores experimentais e simulados, nos primeiros instantes das perturbações, podem estar associados à influência da inércia térmica do sensor de registro de temperatura, como foi verificado na Figura 6.6, assim como à influência da inércia térmica do tubo de retenção, trechos de tubo, grades conectoras, pedestal e outras partes do pasteurizador que não foram considerados na modelagem. Outro fator que pode também ter influenciado nestes desvios, foi que as perturbações nos ensaios experimentais foram realizadas manualmente, portanto, os degraus experimentais não foram exatamente 
instantâneos, fato que poderia influenciar no comportamento das temperaturas experimentais nos primeiros instantes após a perturbação do processo.

Contudo, de forma geral os resultados dos testes dinâmicos foram bons. $O$ modelo consegue representar de forma satisfatória o comportamento experimental.

\subsection{Resultado do estudo experimental do efeito da incrustação}

Os valores determinados da fração mássica de gordura $\left(x_{f}\right)$ e fração mássica de água $\left(x_{w}\right)$ seguindo a metodologia indicada na Seção 5.5 foram de 0,030 e 0,870 para o leite UHT e valores de 0,038 e 0,865 para o leite cru, respectivamente.

Os resultados dos ensaios experimentais de incrustação foram focados na seção de aquecimento do trocador de calor, onde são reportadas as temperaturas mais elevadas do processo, consequentemente, as maiores taxas de incrustação de leite.

A Figura 6.14 e a Figura 6.15 mostram o comportamento dos coeficientes globais de troca térmica experimental e da Média Logarítmica da Diferença de Temperatura (MLDT) ao longo do processo para os ensaios de incrustação com leite UHT e leite cru. Os valores nos gráficos mostrados correspondem à média dos valores registrados durante 15 minutos para o ensaio com leite UHT e 12 minutos para o caso do ensaio com o leite cru. 


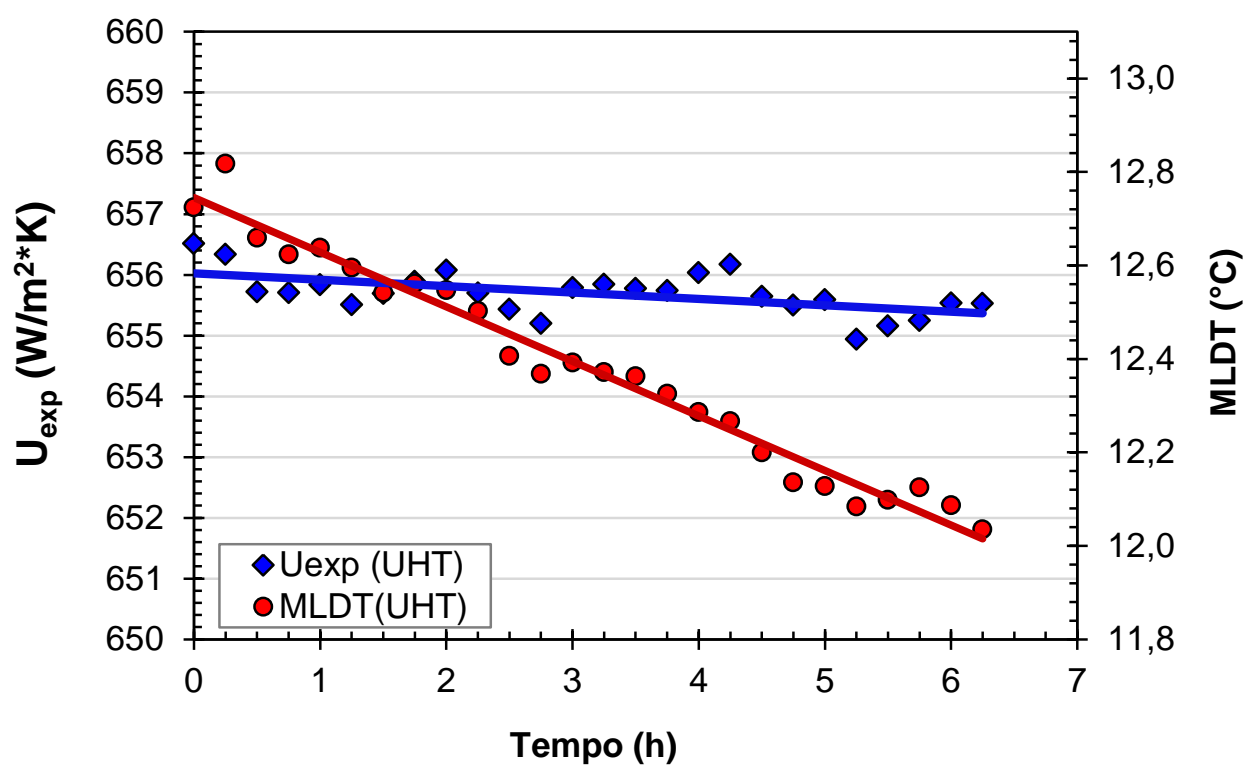

Figura 6.14 - Coeficiente global de troca térmica experimental e MLDT da seção de aquecimento para o ensaio de incrustação com leite UHT.

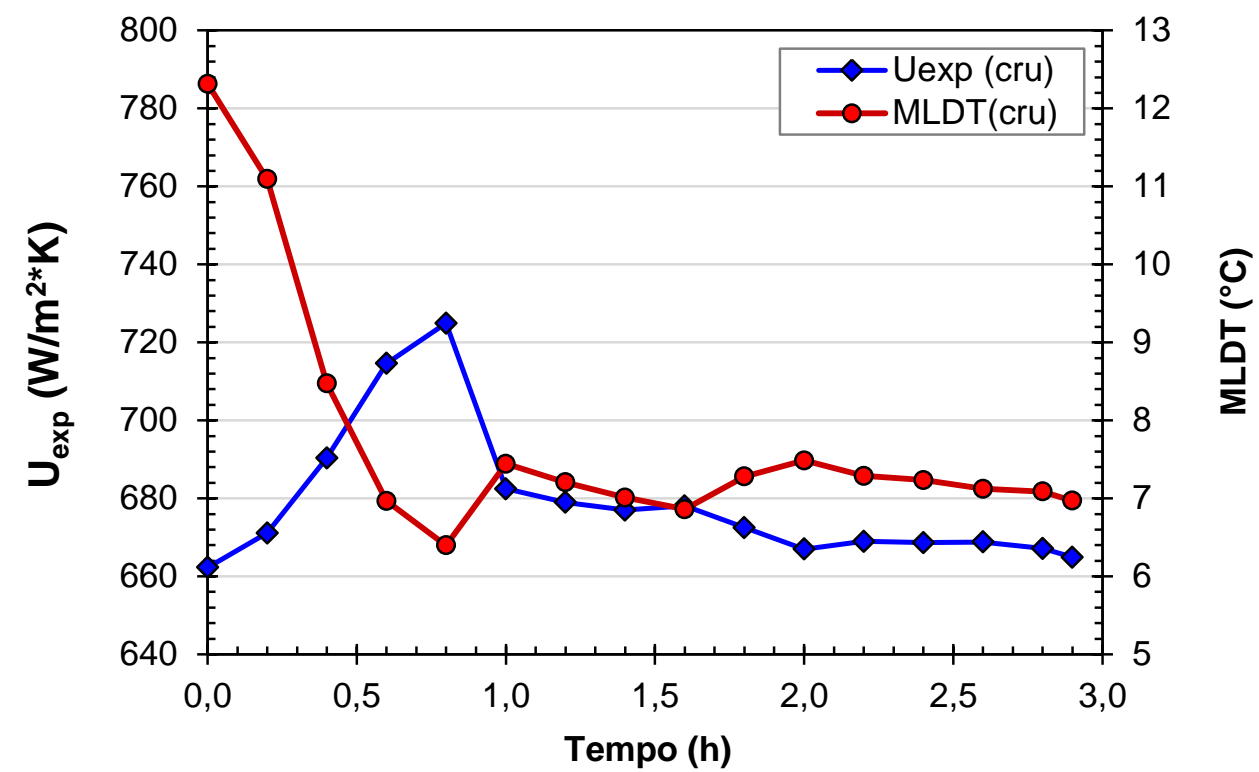

Figura 6.15 - Coeficiente global de troca térmica experimental e MLDT da seção de aquecimento para o ensaio de incrustação com leite cru.

A redução da carga térmica na seção de aquecimento durante o processo de pasteurização do leite foi mais nítida no ensaio com o leite cru, apresentando uma redução de aproximadamente $38 \%$ na temperatura de saída do produto na primeira 
hora de operação. Já no ensaio com o leite UHT, esta redução foi aproximadamente $6 \%$ nas 6 horas de operação.

Como a formação de depósitos sobre a superfície de troca térmica é relacionada com o decrescimento do coeficiente global de troca térmica, mediante os gráficos da Figura 6.14 e Figura 6.15 é possível observar que o ensaio de incrustação com o leite cru apresentou maior incrustação em comparação com o ensaio com o leite UHT.

Por outro lado, como as vazões e as temperaturas de entrada e saída das diferentes seções do pasteurizador são monitoradas durante o processo, levando em consideração, que na seção de aquecimento a vazão e a temperatura de entrada da água quente são mantidas constantes, a formação de depósitos sobre a superfície de troca térmica reduz a transferência de calor, por essa razão, a temperatura de saída do fluido de aquecimento é incrementada, enquanto a temperatura de saída do produto sofre uma queda.

A Figura 6.16 e a Figura 6.17 mostram as temperaturas registradas ao longo do processo de pasteurização do leite UHT e leite cru na seção de aquecimento, onde a diferença de temperatura T3-T2 representa a elevação de temperatura do produto (fluido frio) e a diferença de temperatura T9-T10 representa a queda de temperatura do fluido de aquecimento. 


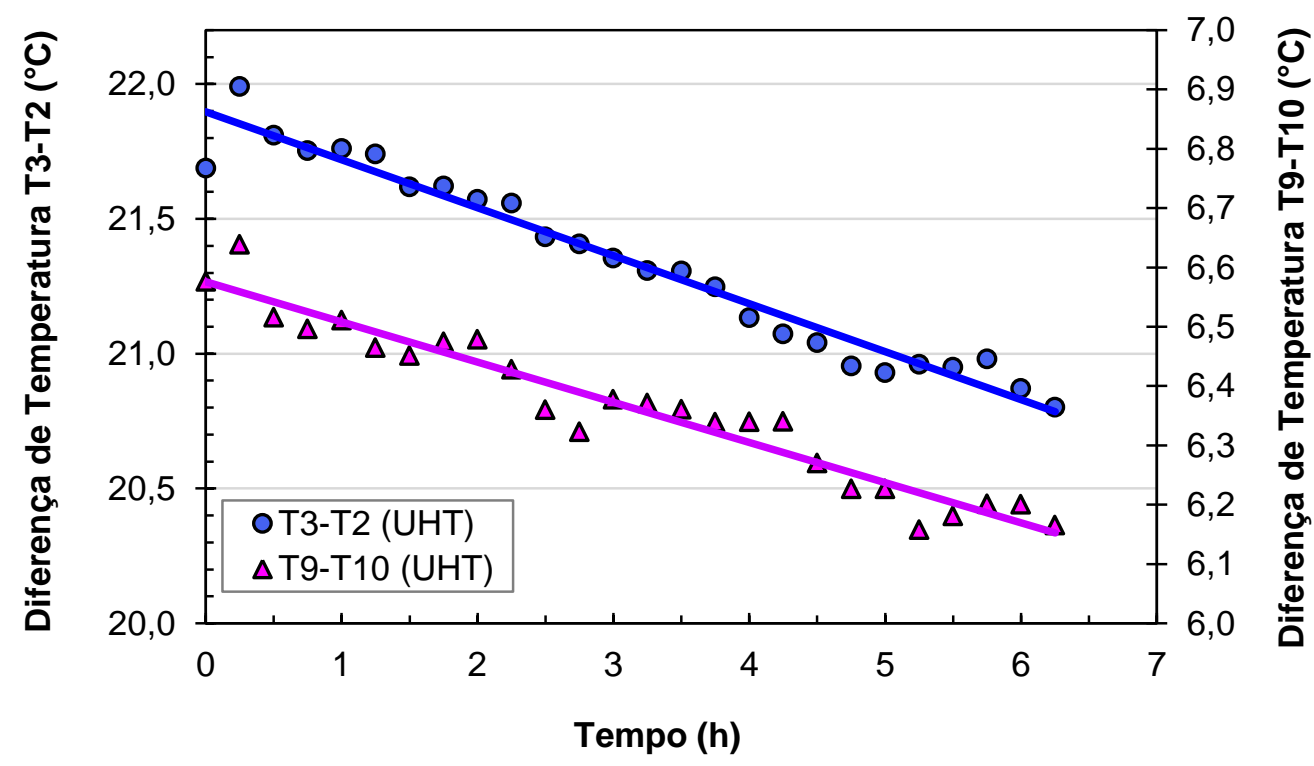

Figura 6.16 - Diferença de temperaturas do produto e do fluido de serviço na seção de aquecimento para o ensaio de incrustação com leite UHT.

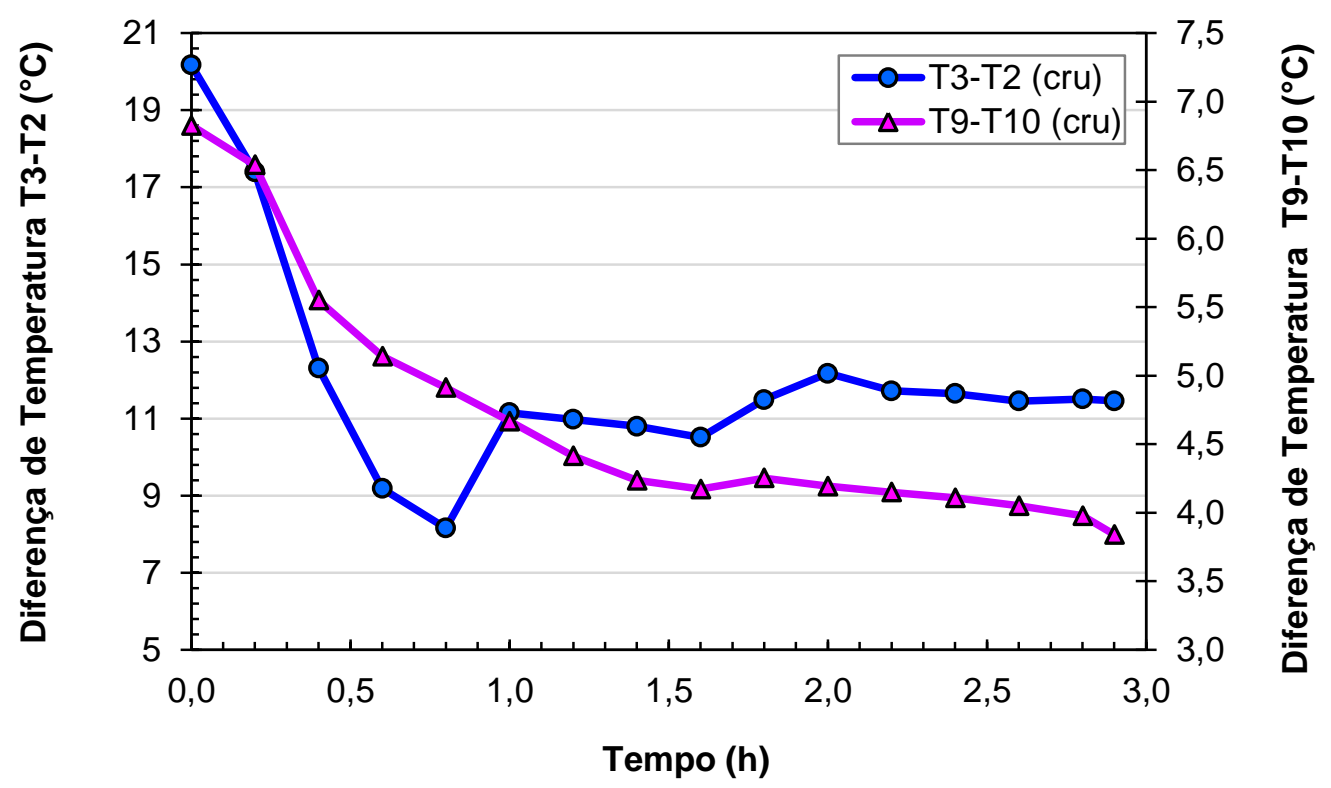

Figura 6.17 - Diferença de temperaturas do produto e do fluido de serviço na seção de aquecimento para o ensaio de incrustação com leite cru.

Entre os gráficos das diferenças de temperatura do produto e do fluido de serviço mostradas para os ensaios com leite UHT e leite cru na Figura 6.16 e Figura 6.17 , as maiores mudanças foram registradas no ensaio com leite cru. 
Devido à diferença substancial de vazões de operação na seção de aquecimento entre o produto $(20 \mathrm{~L} / \mathrm{h})$ e o fluido de aquecimento $(60 \mathrm{~L} / \mathrm{h})$ nos ensaios de incrustação com o leite, o incremento na temperatura de saída do meio de aquecimento foi muito menor que o decrescimento de temperatura na saída do produto. A Figura 6.17 mostra este comportamento no ensaio com o leite cru, indicando uma mudança de aproximadamente $9^{\circ} \mathrm{C}$ na diferença de temperatura no fluido de aquecimento e uma mudança de aproximadamente $3{ }^{\circ} \mathrm{C}$ na diferença de temperatura do produto. Para o caso do ensaio com o leite UHT na Figura 6.16, estas mudanças foram menos perceptíveis sendo aproximadamente $0,5{ }^{\circ} \mathrm{C}$ na diferença de temperatura de água quente e aproximadamente $0,47^{\circ} \mathrm{C}$ na diferença de temperatura do produto.

Durante o processamento do leite cru, foi possível observar a influência da recirculação do leite no efeito de incrustação. A Figura 6.18 apresenta 0 calor fornecido pelo fluido de aquecimento para a absorção do produto na seção de aquecimento do pasteurizador ao longo do processo. A linha pontilhada vermelha indica o instante em que o leite começou a ser recirculado no processo.

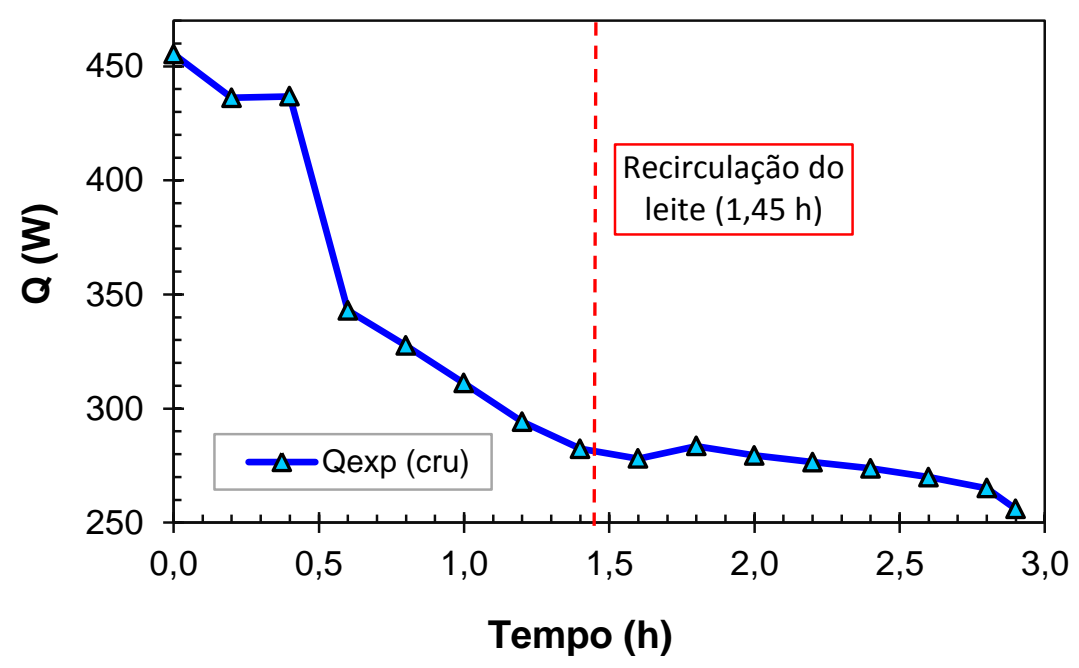

Figura 6.18 - Influência da recirculação do leite cru na incrustação.

No início do processo, o leite cru foi pasteurizado por primeira vez e é observada uma diminuição de calor absorvido pelo produto muito mais acentuada 
que a diminuição de calor após o leite ter sido recirculado, a partir do tempo de 1,45 horas de operação como indica o gráfico da Figura 6.18. Este comportamento pode estar associado à taxa de incrustação, sendo maior no início do processo com o leite cru, devido a que o produto cru contém uma determinada composição e quantidade de proteínas. No momento em que o leite cru é pasteurizado, a composição do produto sofre algumas alterações, entre elas a desnaturação de certa quantidade de proteínas, alterando assim a composição original do leite. No momento em que o leite foi recirculado, a taxa de incrustação do processo mostrou um menor decrescimento comparado com o leite cru sem recircular no início do processo. Este comportamento pode também indicar a influência da composição do produto no efeito de incrustação num processo de tratamento térmico.

Na Figura 6.19 e na Figura 6.20 são mostradas fotografias das placas da seção de aquecimento do trocador de calor com material seco incrustado após 6 horas de processamento de leite UHT e após 3 horas de processamento de leite cru. Lembrando que a seção de aquecimento contém 6 canais de troca térmica do produto, nas figuras seguintes são mostradas uma placa por canal da seção de aquecimento, indicando em cada placa o número de canal ao que pertence e a direção do fluxo. 

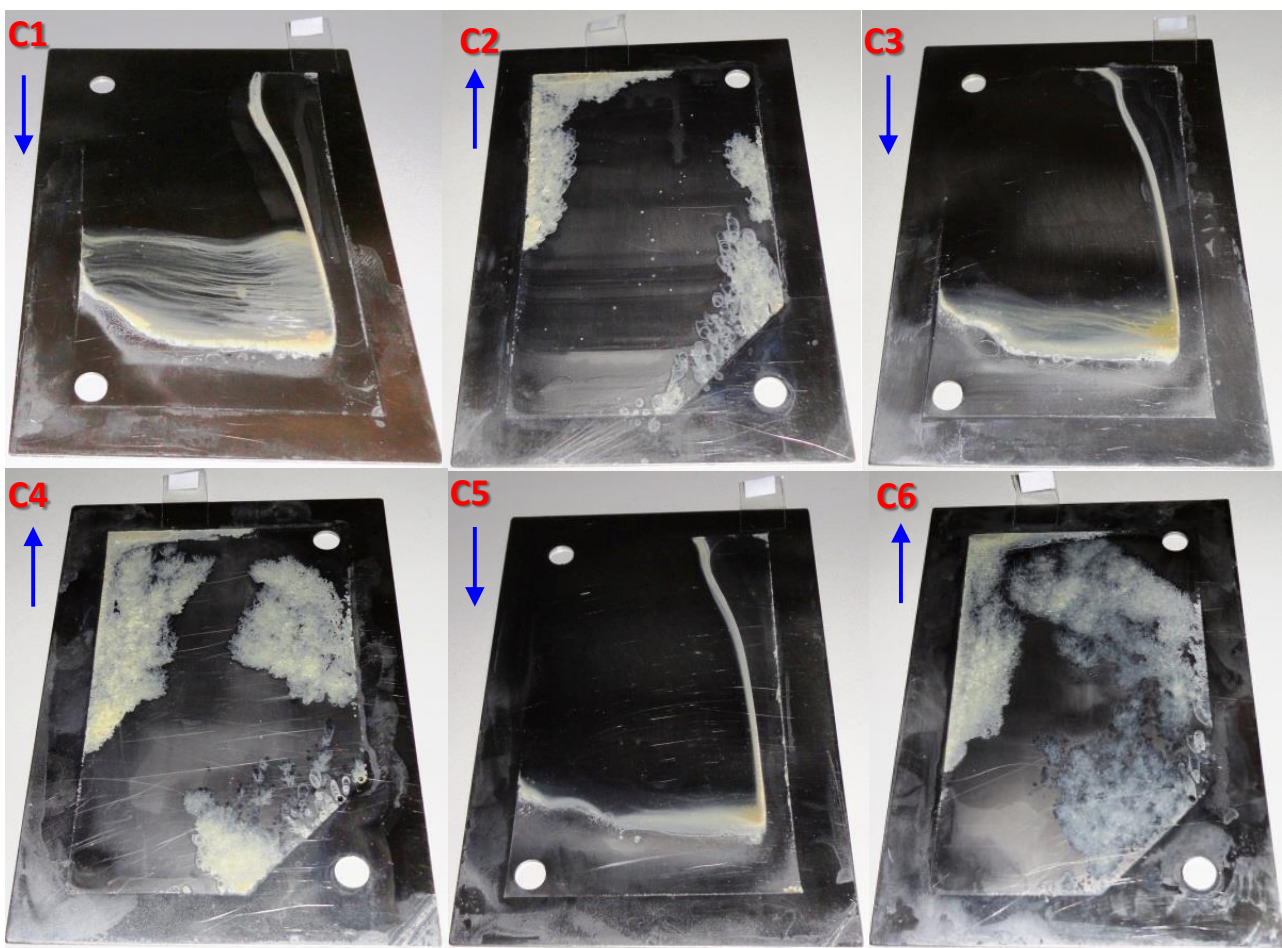

Figura 6.19 - Fotografia das placas da seção de aquecimento do trocador de calor com material seco incrustado após o ensaio com leite UHT (6 horas de operação).
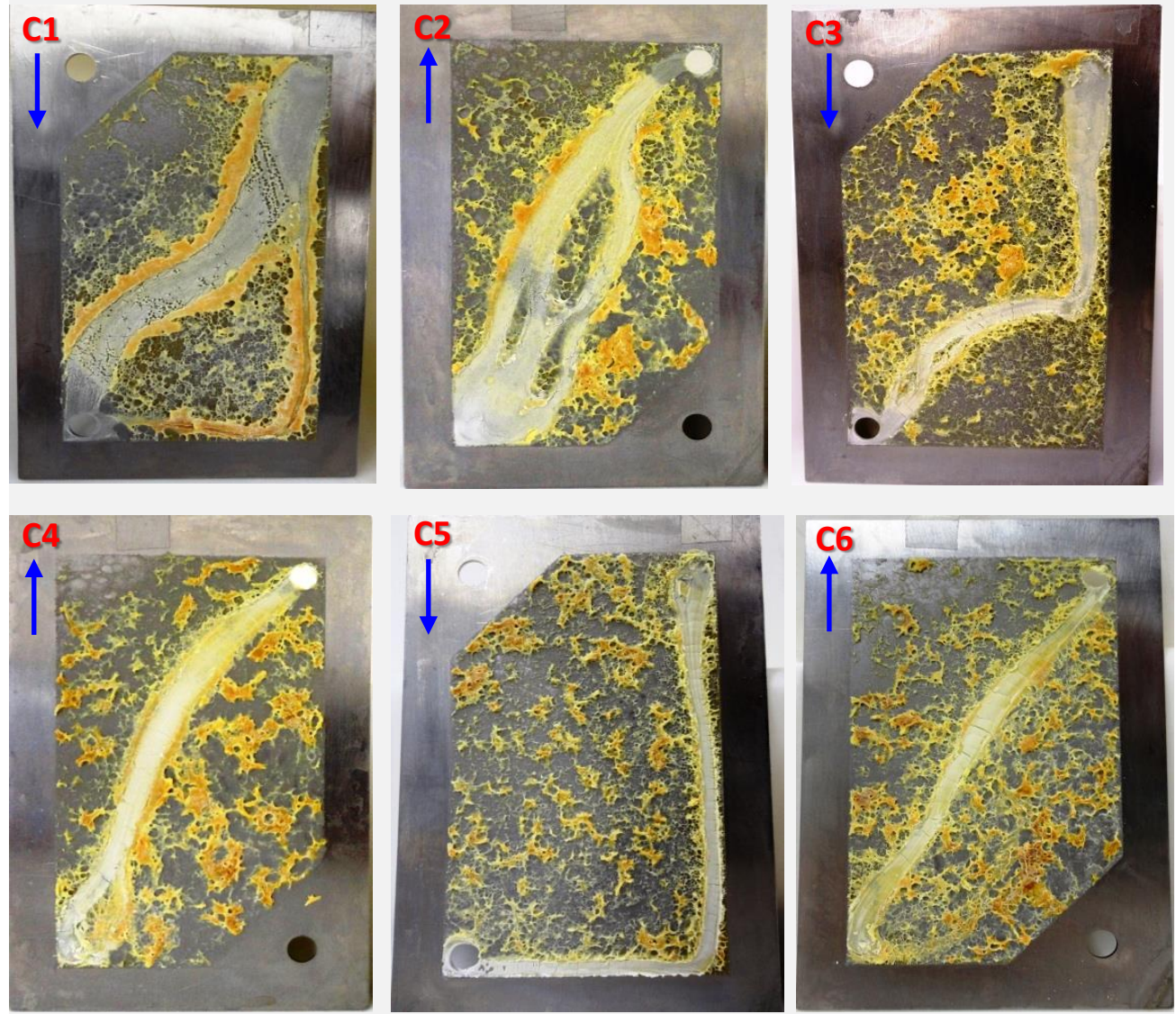

Figura 6.20 - Fotografia das placas da seção de aquecimento do trocador de calor com material seco incrustado após o ensaio com leite cru (3 horas de operação). 
Nas fotografias, pode ser claramente observada a formação de depósitos sobre a superfície das placas assim como a formação de canais preferenciais. Se bem, a formação de depósitos sobre a superfície de troca térmica das placas reduz o coeficiente global de troca térmica devido ao aumento da espessura da parede entre o fluido e a fonte de calor e à baixa condutividade da camada incrustante, a formação de canais preferenciais aumenta a velocidade de escoamento, que por sua vez, aumenta o coeficiente de calor convectivo e provoca o aumento do coeficiente global de troca térmica.

As placas incrustadas, após ser escorridas, foram fotografadas antes e depois de serem secas na estufa. A Figura 6.21 mostra as fotografias ampliadas do material incrustado sobre a superfície das placas. As indicações (a) e (c) da figura mostram a placa incrustada com material úmido e material seco respectivamente do ensaio com leite UHT. As indicações (b) e (d) mostram as placas com material úmido e material seco no ensaio com leite cru em escala próxima á real.
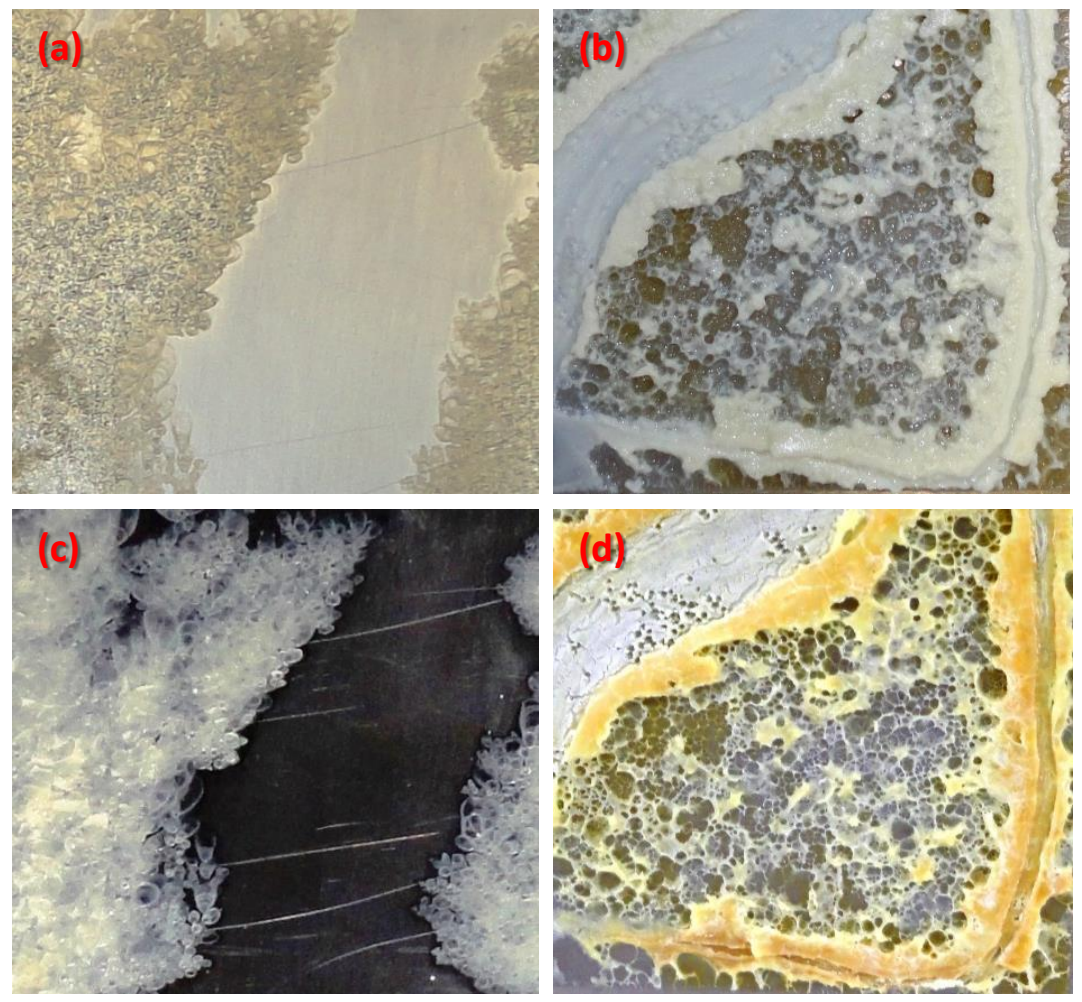

Figura 6.21 - Fotografia ampliada das placas incrustadas com material seco e material úmido após o ensaio de incrustação com leite UHT e leite cru. (a) e (c): incrustação úmida e seca de leite UHT; (b) e (d): incrustação úmida e seca de leite cru. 
A consistência da massa úmida depositada sobre a superfície das placas após o processo de pasteurização apresentou diferenças entre o processo com leite UHT e leite cru. O material incrustado no ensaio com o leite UHT apresentou maior consistência comparado com o material incrustado com o leite cru. Já uma vez secas as placas na estufa, a remoção do material incrustado nas placas do ensaio com o leite cru foi mais fácil comparado com a remoção da incrustação das placas do ensaio com leite UHT. Sendo que os dois ensaios de incrustação de leite foram operados com os mesmos parâmetros de processo (vazões e temperaturas de entrada do processo) a consistência do material incrustado pode ser atribuído à diferença na composição dos leites utilizados. Por outro lado, a aparência da massa incrustada úmida sobre a superfície das placas no ensaio com leite cru, faz referencia a uma possível floculação do leite devido ao baixo valor do $\mathrm{pH}$ do leite cru antes de ser processada (aproximadamente $\mathrm{pH} 6,3$ ).

A formação de bolhas no interior dos trocadores de calor, segundo Jeurnink (1995) pode contribuir à formação de depósitos se a superfície onde a bolha de ar prendida torna-se seca, como consequência gerando um incremento na diferença de temperatura entre a superfície da placa e o fluido, provocando a evaporação da água na interface liquido-vapor e como consequência gerando uma acumulação de proteínas do leite na superfície da bolha. Portanto, devido à concentração e alta temperatura do leite na superfície da bolha uma coagulação da proteína chegaria a ocasionar a formação de depósitos na superfície do trocador de calor. Na Figura 6.22, são mostradas fotografias ampliadas das placas incrustadas enfocando a formação de bolhas de ar, onde: (a) indica uma fotografia que mostra o comportamento padrão da incrustação do leite por Bennett (2007); (b) indica uma placa incrustada com direção do fluxo ascendente; e (c) indica uma placa incrustada com direção do fluxo descendente. 

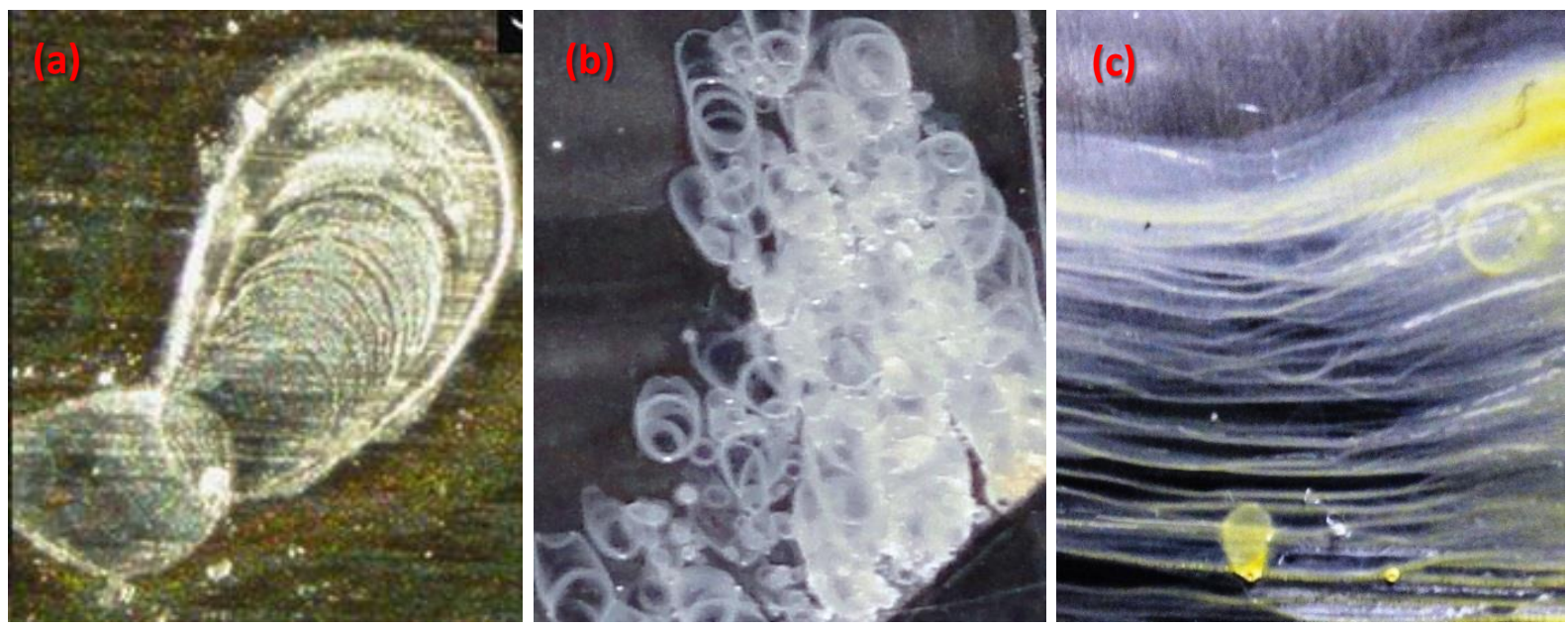

Figura 6.22 - Fotografia ampliada das placas incrustadas enfocando a formação de bolhas de ar: (a) Bennett (2007); (b) e (c) incrustação leite UHT.

A formação de bolhas de ar na superfície das placas aparentemente forma um anel de incrustação ao redor do perímetro da bolha, na Figura 6.22 a indicação (a) mostra o padrão de formação de incrustação do leite sobre a superfície das placas onde longe de permanecerem estáticas as bolhas se movimentam com a direção do fluxo formando pegadas de incrustação de forma oblonga. Na medida em que aumenta o tempo de residência das bolhas, elas se desprendem da superfície da placa e formam bolhas maiores (BENNETT, 2007). A indicação (b) mostra uma fotografia de uma placa de incrustação com leite UHT, com direção de fluxo ascendente, na qual pode ser observada claramente a formação de bolhas de ar no material incrustado e o crescimento das mesmas na direção do fluxo (ascendente), assim como indica a incrustação padrão do leite (a). Já na fotografia (c) as pegadas da formação de bolhas de incrustação apresentam outro formato. Levando em consideração que o fluxo deste canal foi descendente, assim como a evidência da formação de canais preferencias, um acúmulo de ar no canal pode ter ocasionado a formação de grandes bolhas de formato diferente ao padrão, onde também foi evidente o crescimento das bolhas na direção oposta ao fluxo o que poderia ser explicado como um acúmulo de ar dentro do canal que foi acrescentado com o tempo.

A maior quantidade de massa incrustada na superfície de troca térmica numa menor velocidade de fluxo (maior tempo de residência) durante um processo pode 
ser explicado pela criação de maior quantidade de pegadas de incrustação, devido ao maior tempo de residência das bolhas. Por outro lado, a presença de bolhas de ar pode também ser relacionada com a área da superfície incrustada assim como com a taxa de incrustação.

Na Figura 6.23 são mostradas fotografias ampliadas para mostrar as diferenças na estrutura do material incrustado sobre a superfície das placas do trocador de calor durante os ensaios de incrustação do leite. A indicação (a) mostra uma fotografia de uma placa incrustada de leite integral processada a uma temperatura de $88^{\circ} \mathrm{C}$ durante 4 horas de operação (BENNETT, 2007). As indicações (b) e (c) mostram fotografias das incrustações dos ensaios com leite cru e leite UHT respectivamente, sobre as placas da seção de aquecimento do trocador de calor. 

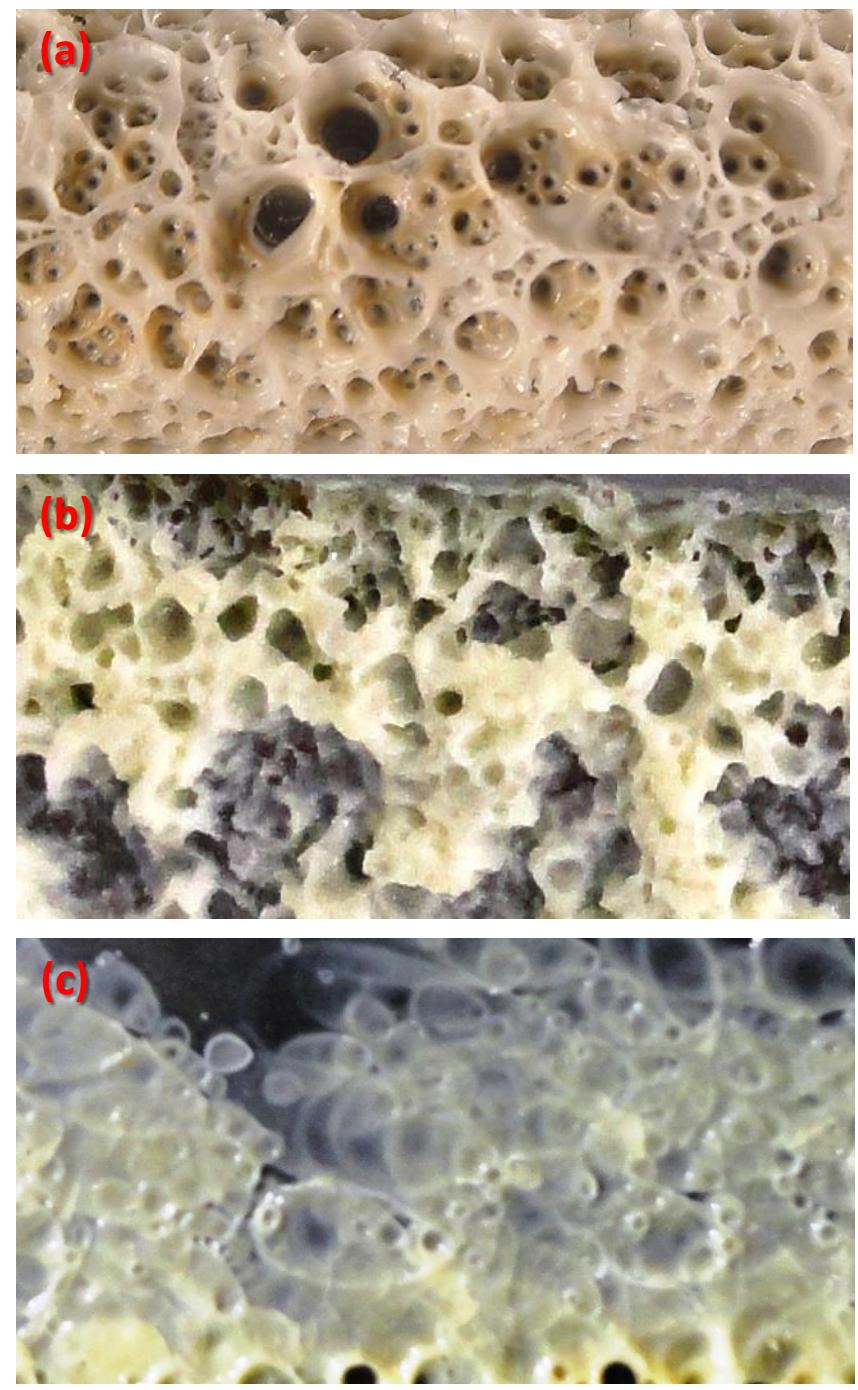

Figura 6.23 - Estrutura do material de incrustação do leite sobre a superfície das placas do trocador de calor: (a) Bennett (2007); (b) incrustação úmida leite cru e (c) incrustação úmida leite UHT.

Observando as três estruturas de incrustação da Figura 6.23 e considerando que a figura (a) é a estrutura padrão da incrustação do leite com 4 horas de operação, pode-se afirmar que a estrutura da incrustação com o leite cru (b), com 3 horas de operação, apresenta similaridade com a estrutura padrão, especialmente nas superfícies onde é observada a maior acumulação de massa incrustada. A diferença entre as duas estruturas (a) e (b), possivelmente poda ser atribuído à diferença entre os tempos de operação do processo. Na estrutura da incrustação do ensaio com leite UHT (c), com 6 horas de operação, aparentemente apresenta uma estrutura de incrustação inicial (formação de pegadas de bolhas de incrustação que indicam o início de uma incrustação padrão do leite) que com um aumento no tempo 
de operação possivelmente poderia chegar à formação de uma estrutura de incrustação padrão do leite. A diferença entre as estruturas (b) e (c) dos ensaios com leite cru e leite UHT, pode ser atribuído à composição do leite utilizado nos ensaios.

A Figura 6.24, apresenta a relação das massas secas incrustadas na superfície das placas de cada canal na seção de aquecimento do trocador de calor, para os dois ensaios experimentais de incrustação do leite.

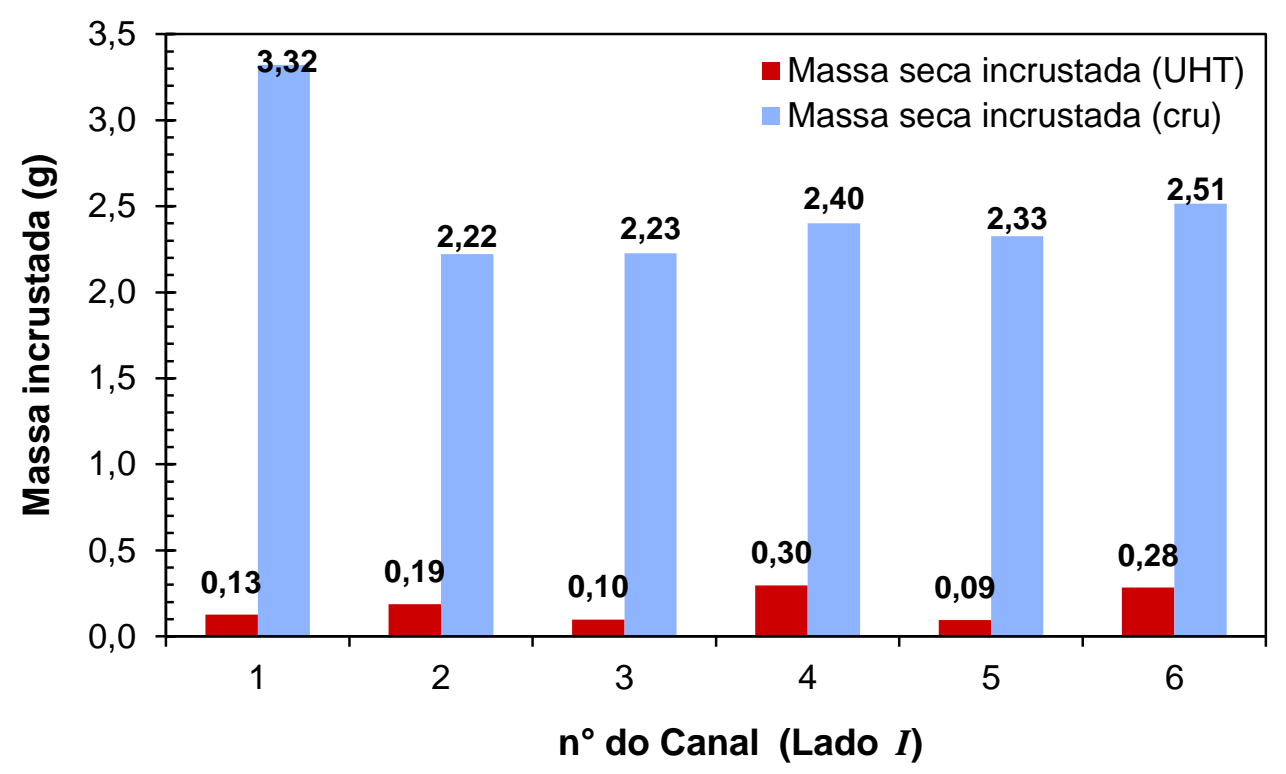

Figura 6.24 - Massa seca incrustada sobre a superfície das placas da seção de aquecimento do trocador de calor.

No gráfico da Figura 6.24 é possível observar que a quantidade de massa incrustada sobre a superfície das placas no ensaio com leite cru, com 3 horas de operação, foi evidentemente maior que a massa incrustada com leite UHT, com 6 horas de operação. Os valores da massa incrustada com leite UHT chegam a representar aproximadamente entre 4 e $12 \%$ do valor da massa incrustada com o leite cru, em cada canal da seção de aquecimento, o que também indica que durante o processamento do leite cru houve maior incrustação.

Os resultados dos ensaios experimentais de incrustação com os dois tipos de leite indicam que houve maior concentração de depósito nas zonas de baixa velocidade e foi observado que durante o processo houve formação de canais 
preferencias. O leite que apresentou maior incrustação foi o leite cru com 3 horas de operação em relação com o leite UHT com 6 horas de operação.

O processo de incrustação do leite UHT, mesmo apresentando a menor incrustação, teve influência no desempenho térmico do equipamento, ocasionando uma queda de cerca de $1{ }^{\circ} \mathrm{C}$ na temperatura de saída do produto na seção de aquecimento nas 6 horas de operação. Sendo que estudos quantificam que um desvio de $1{ }^{\circ} \mathrm{C}$ na temperatura adequada de pasteurização produz um erro de $25 \%$ no efeito de pasteurização (HASTING, 1992; IBARROLA et al. 2002), os resultados mostrados fazem referência à importância de levar em consideração o efeito de incrustação na operação do processo.

Por outro lado, a análise dos resultados dos ensaios experimentais de incrustação indica que, para uma correta consideração do fenômeno de incrustação no desenho e operação de um processo, é importante a determinação experimental de fatores de incrustação específicos para cada produto e processo utilizado.

Nos ensaios de incrustação realizados, não foi possível determinar experimentalmente a cinética de incrustação do leite. Durante o ensaio de incrustação com o leite UHT, a variação de temperaturas foi muito pequena o que dificultou a determinação da cinética, já no ensaio com o leite cru a incrustação desde o início foi muito intensa, por outro lado, houve outros tipos de fatores como o aumento da vazão de escoamento pela formação de canais preferenciais o que também dificultou a determinação da cinética de incrustação do leite. Por esta razão, para a simulação do efeito de incrustação no processo de pasteurização não serão utilizados os dados experimentais de incrustação.

\subsection{Resultado da simulação do processo de pasteurização com influência da incrustação}

As simulações do processo de pasteurização com incrustação foram realizadas de acordo com o procedimento descrito na Seção 4.5 e na Seção 5.6. Os resultados da simulação são apresentados, por separado, para cada modelo de incrustação. 


\subsubsection{Resultados de simulação do modelo de incrustação 1}

Os gráficos da Figura 6.25(a) apresentam as temperaturas obtidas da simulação do processo de pasteurização livre de incrustação comparadas com as temperaturas obtidas do processo com incrustação na seção de aquecimento do trocador de calor. As linhas pontilhadas vermelhas nos gráficos indicam o início da incrustação no processo.

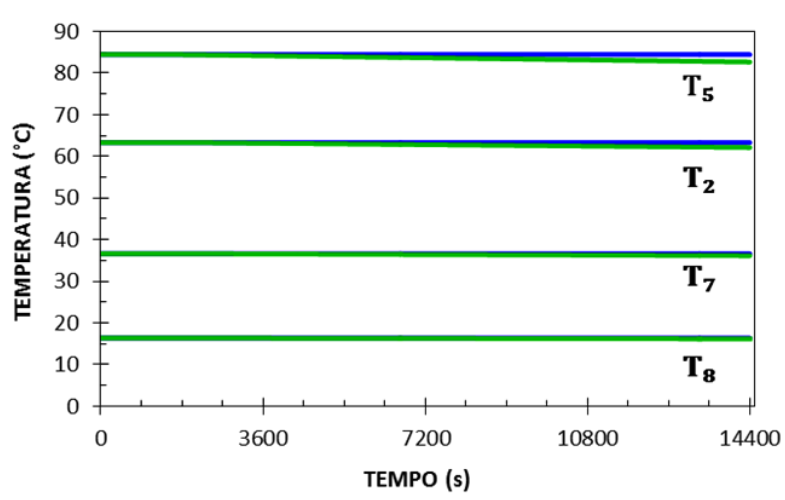

(a)

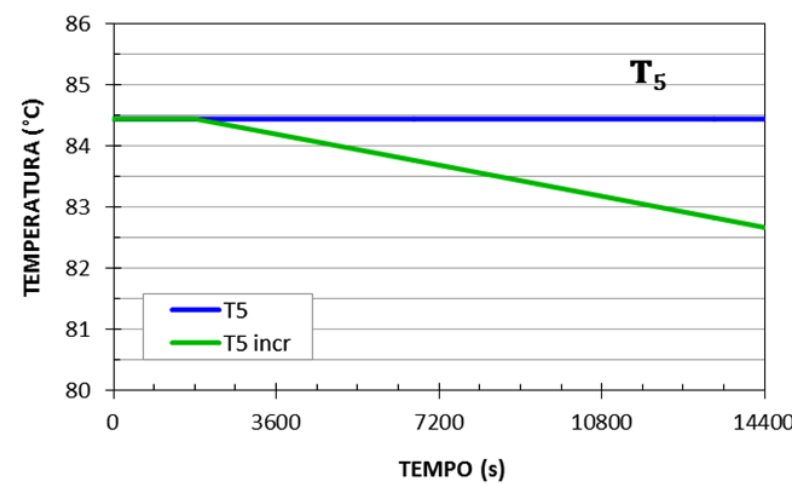

(b)

Figura 6.25 - (a),(b): Temperaturas da simulação do processo de pasteurização sem incrustação comparadas com temperaturas do processo com incrustação (modelo 1). Linhas azuis representam temperaturas sem incrustação e linhas verdes temperaturas com incrustação.

As temperaturas denominadas como $\mathrm{T} 2, \mathrm{~T} 5, \mathrm{~T} 7 \mathrm{e} T 8$, referem-se às temperaturas de medição do processo especificadas na Figura 5.2, as quais são consideradas como as mais relevantes do processo de pasteurização, em especial a temperatura T5 que representa a temperatura de saída do tubo de retenção, considerada também como a temperatura de pasteurização do processo.

No gráfico da Figura 6.25(a) que mostra as quatro temperaturas, pode parecer que a variação de temperaturas ao longo do tempo não seja representativa, entretanto, numa escala menor a mudança das temperaturas é perceptível, em especial da temperatura T5 como indica a Figura 6.25(b), sendo esta variação de temperatura de aproximadamente $2^{\circ} \mathrm{C}$, que para fins de controle de pasteurização é um valor significativo. 
A Figura 6.26(a) apresenta os coeficientes de troca térmica da seção de aquecimento do trocador ao longo do tempo para os processos de pasteurização simulados com e sem incrustação. Os coeficientes globais de troca térmica dos lados $I$ e II do trocador de calor são representados, nesta figura, pelos termos $U_{1} \mathrm{e}$ $U_{2}$ respectivamente, sendo $U_{1} \circ$ coeficiente global de troca térmica do lado preenchido pelo produto, neste caso leite com possibilidade de incrustação e $U_{2} \circ$ coeficiente de troca térmica do lado do trocador preenchido pelo fluido de aquecimento, neste caso água destilada, sem a possibilidade de incrustação. $\mathrm{Na}$ Figura 6.26(b) é mostrado o gráfico da porcentagem do coeficiente de troca térmica do lado $I$ que é utilizado durante o processo, em relação ao coeficiente inicial do trocador livre de incrustação.

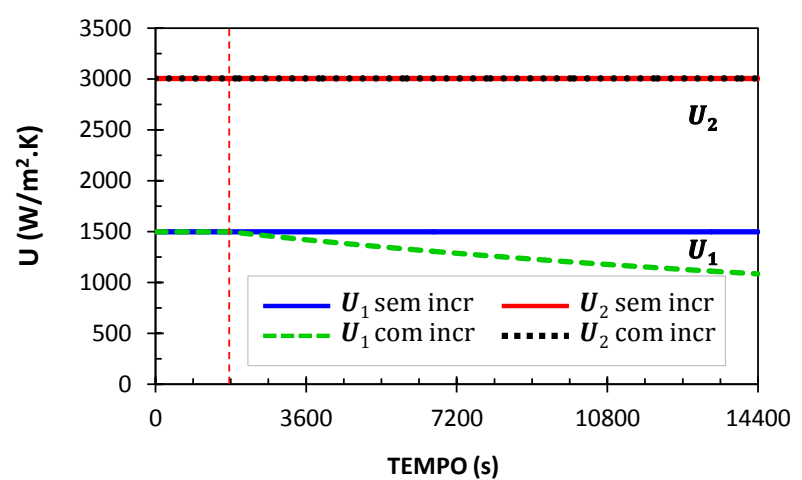

(a)

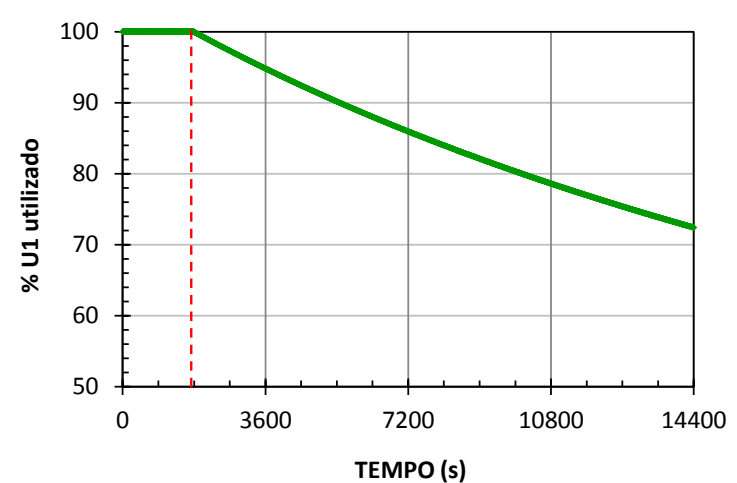

(b)

Figura 6.26 - (a): Coeficientes globais de troca térmica da seção de aquecimento do processo de pasteurização sem incrustação comparados com os coeficientes do processo com incrustação, (b):

Porcentagem do coeficiente global de troca térmica do lado $I$ utilizado durante o ensaio de incrustação (modelo 1).

A incrustação na superfície do trocador de calor cria uma barreira na troca térmica entre o fluido de aquecimento e o produto, fazendo com que o coeficiente de troca térmica diminua paulatinamente ao longo do processo. Esta diminuição é mais nítida no gráfico da Figura 6.26(b) da porcentagem do coeficiente global de troca térmica utilizada ao longo do processo em relação ao coeficiente de troca térmica livre de incrustação, valor que no gráfico estaria sendo representado como o $100 \%$ do valor do coeficiente de troca térmica utilizado. 


\subsubsection{Resultados de simulação do modelo de incrustação 2}

A simulação do processo de pasteurização com o modelo 2 de incrustação, apresenta diferenças de temperatura mais visíveis no início do período de incrustação comparadas com as temperaturas obtidas com o modelo de incrustação 1. A Figura 6.27(a) mostra um gráfico com as temperaturas T2, T5, T7 e T8 do processo e a Figura 6.27(b) mostra um gráfico com escala reduzida para uma maior visibilidade da mudança da temperatura T5 no processo. As linhas pontilhadas vermelhas nos gráficos indicam o início da incrustação do processo.

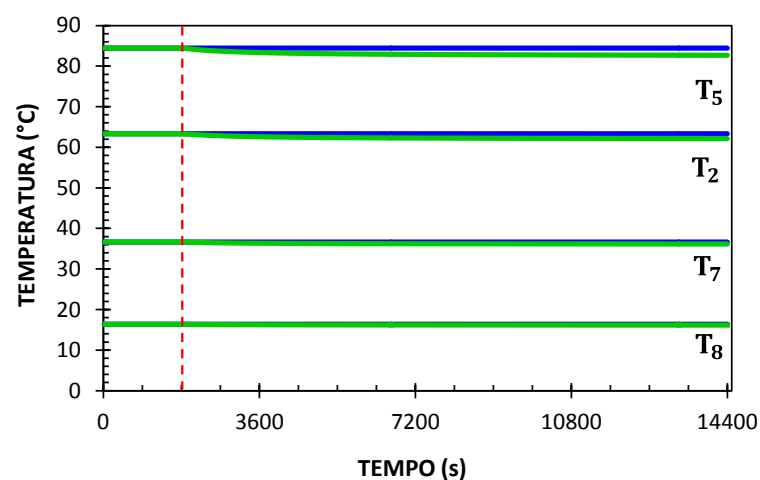

(a)

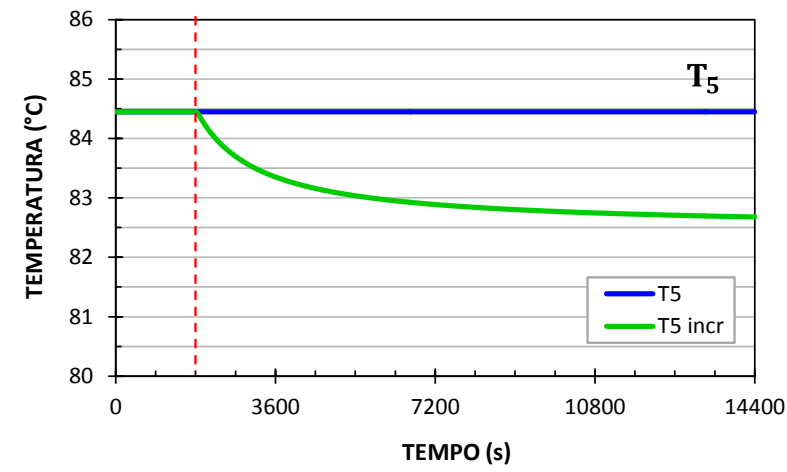

(b)

Figura 6.27 - (a),(b): Temperaturas da simulação do processo de pasteurização sem incrustação comparadas com temperaturas do processo com incrustação (modelo 2). Linhas azuis representam temperaturas sem incrustação e linhas verdes temperaturas com incrustação.

E possível observar na Figura 6.27(b) que a perda de temperatura T5, na primeira hora de operação, é de aproximadamente $1{ }^{\circ} \mathrm{C}$, sendo esta perda mais intensa comparada com a simulação do modelo 1 , que reportou, para o mesmo tempo de operação, uma perda de aproximadamente $0,25^{\circ} \mathrm{C}$. Já nas próximas 3 horas de operação, ambos modelos reportaram perdas de temperatura semelhantes de aproximadamente $2^{\circ} \mathrm{C}$.

Na Figura 6.28(a) é apresentado o gráfico dos coeficientes de troca térmica da seção de aquecimento e na Figura 6.28(b) o gráfico da porcentagem do valor do coeficiente de troca térmica utilizado ao longo do processo para o modelo de 
incrustação 2. Os termos $U_{1}$ e $U_{2}$ da figura representam os coeficientes globais de troca térmica dos lados $I$ e $I I$ do trocador respectivamente.

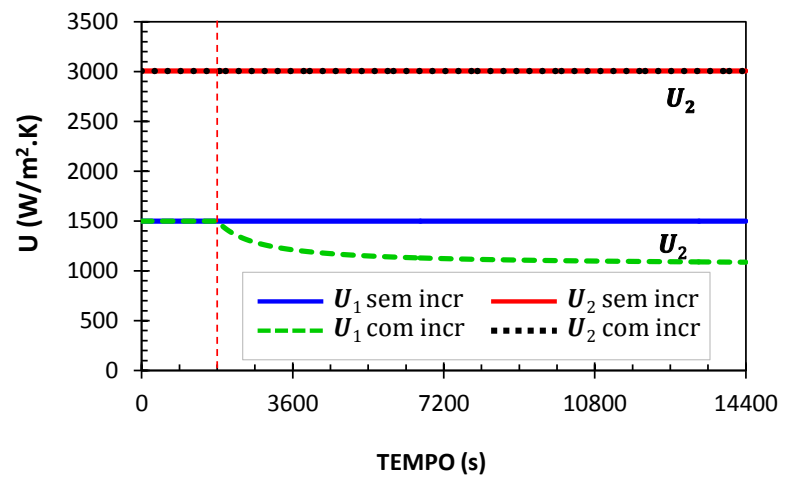

(a)

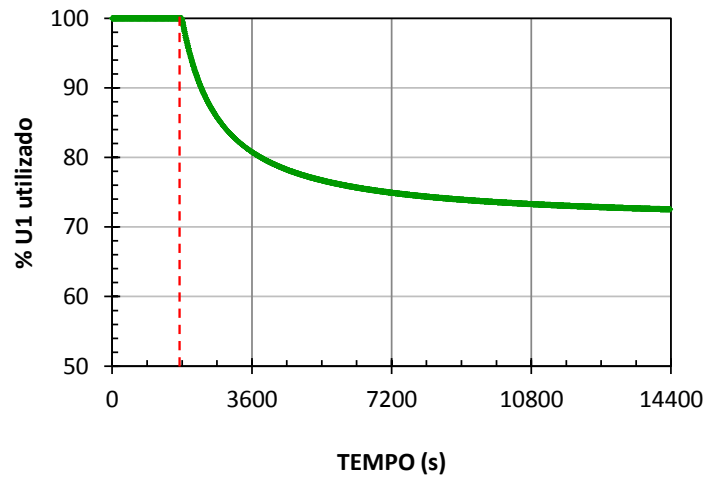

(b)

Figura 6.28 - (a): Coeficientes globais de troca térmica da seção de aquecimento do processo de pasteurização sem incrustação comparados com os coeficientes do processo com incrustação, (b):

Porcentagem do coeficiente global de troca térmica do lado $I$ utilizado durante o ensaio de incrustação (modelo 2).

Os resultados da simulação indicam que o grau de incrustação no modelo 2, no início do período de incrustação, é muito mais acentuado que no modelo 1, sofrendo uma perda de $20 \%$ do valor do coeficiente de troca térmica na primeira hora de operação. A Figura 6.29 mostra uma comparação entre os dois modelos de incrustação estudados, prolongando o tempo de operação por uma hora. 


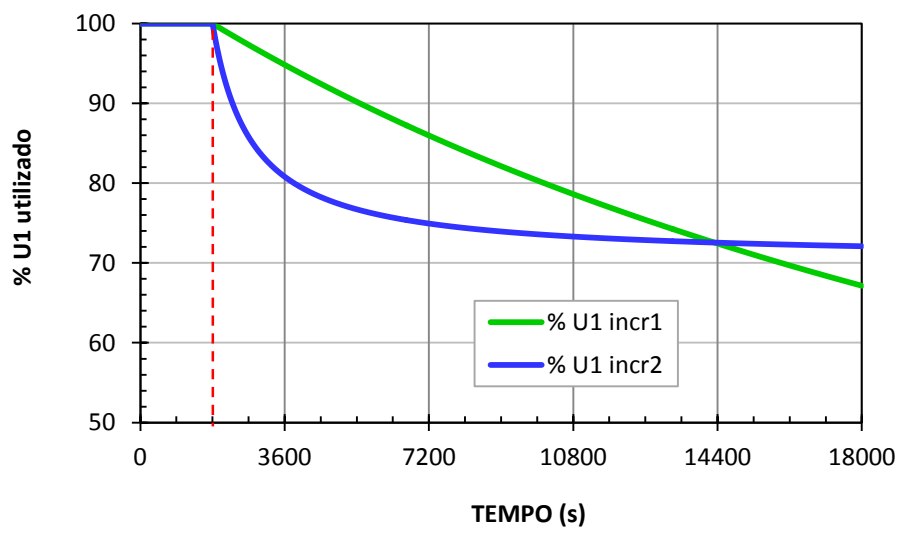

Figura 6.29 - Comparação das porcentagens de troca térmica utilizadas na seção de aquecimento para os dois modelos de incrustação simulados.

A análise dos dois modelos de incrustação utilizados na simulação do processo faz referência à importância de utilizar modelos realísticos para o produto e o processo utilizado para, desta maneira, conseguir predizer mediante a simulação tempos limites de operação mais apropriados para uma programação correta de paradas de processo, assim como possíveis comportamentos ou alterações durante o processo. 


\section{CONCLUSÕES}

Foi desenvolvido com sucesso um modelo dinâmico de um processo contínuo de pasteurização num pasteurizador de laboratório ARMFIELD modelo FT-43A, com trocador de calor a placas com três seções de troca térmica: aquecimento, regeneração e resfriamento para estudar sua operação em regime transiente. Os coeficientes de troca térmica do trocador de calor a placas assim como do tubo de retenção e conexões foram determinados experimentalmente.

Ensaios experimentais da partida do equipamento e de perturbações do processo foram realizados para a validação do modelo. Através da comparação entre os resultados experimentais e de simulação, verificou-se que o modelo dinâmico desenvolvido representa de forma satisfatória o comportamento experimental. A diferença entre os tempos de resposta experimental e simulados pode estar associada à inércia térmica do equipamento que não foi contabilizada na modelagem do processo (apenas as placas metálicas foram consideradas), assim como uma possível influência dos termopares em registrar as mudanças de temperatura.

Foram realizados ensaios experimentais de pasteurização do leite para estudar o efeito da incrustação no desempenho térmico do trocador de calor durante o processo. Para estudar alta e baixa incrustação no processo foram utilizados dois tipos de leite (UHT e cru). Foi comprovado que o efeito de incrustação foi mais acentuado na seção de aquecimento do trocador de calor, onde são registradas as temperaturas mais elevadas do processo.

Os depósitos formados na superfície das placas do trocador de calor, da seção de aquecimento, foram visíveis tanto para o leite UHT como para o leite cru. Estas incrustações foram notavelmente acentuadas no leite cru com 3 horas de operação em comparação com as 6 horas de operação do leite UHT. Este comportamento indica que além da temperatura, a composição do leite também é outro fator que influencia no fenômeno de incrustação.

A formação de depósitos sobre a superfície de troca térmica das placas, caracterizada com a formação de bolhas de ar e aparição de pegadas de 
incrustação em forma de anéis, assim como a estrutura do material incrustado no processamento do leite apresentaram similitude com o comportamento padrão de incrustação no processamento térmico do leite.

$\mathrm{Na}$ simulação do processo de pasteurização com a incorporação do efeito de incrustação na seção de aquecimento do trocador de calor, para os dois modelos de incrustação simulados, os resultados apresentaram diferenças significativas ao longo do processo. Estes resultados fazem referência à importância da utilização de tendências de incrustação apropriadas para cada produto, levando em consideração as propriedades do alimento, os parâmetros do processo e outros fatores que influenciam o fenômeno de incrustação. Desta forma, mediante a simulação do processo, podem-se determinar corretamente os efeitos provocados pela incrustação, assim como determinar o tempo limite de operação para a programação das paradas do processo, para limpeza e remoção do material incrustado, bem como para prever possíveis alterações durante o processo. 


\section{PERSPECTIVAS PARA TRABALHOS FUTUROS}

- Introduzir no modelo a capacidade calorífica das tubulações, grades conectoras e pedestal para verificar seu efeito na inércia de resposta do modelo frente a perturbações em variáveis do processo.

- Avaliar em laboratório e através de simulação casos de perturbação de processo com relação a variações na temperatura de alimentação da água quente.

- Estudar estratégias de controle utilizando como base a modelagem fenomenológica do pasteurizador desenvolvida, tendo como principal objetivo o controle das temperaturas do processo, em especial a temperatura do produto na saída do tubo de retenção onde é efetivada a pasteurização.

- Utilização do modelo matemático para a otimização dos custos de produção.

- Usar a distribuição de tempos de residência (DTR) obtidos para o equipamento estudado (GUTIERREZ et al., 2010, 2011) para determinar os tempos médios de residência e substituí-los pelos tempos espaciais para que os resultados de simulação sejam mais realistas.

- Realizar ensaios experimentais de incrustação utilizando um produto de composição padronizada (soro de leite ou solução de caseinato de cálcio) para ajustar um modelo de incrustação e estudar a influência das variáveis do processo (vazão, temperatura, tempo e arranjo do trocador) na incrustação do processo de pasteurização.

- Avaliar o efeito do estado transiente do processo sobre a letalidade. 


\section{REFERÊNCIAS BIBLIOGRÁFICAS}

ABU-KHADER, M. M. Plate heat exchangers: Recent advances. Renewable and Sustainable Energy Reviews, v. 16, n. 4, p. 1883-1891, 2012.

ALFA LAVAL. Products. The world leader in heat transfer. Plate heat exchangers. Disponível em:< http://www.alfalaval.com>. Acesso em 14 jan. de 2011.

ARMFIELD - Innovators in engineering education equipment and industrial food technology equipment. Plate heat exchanger-heating, economizing and cooling sections. Disponível em: <http://www.armfield.co.uk>. Acesso em 07 de nov. de 2012.

AZEREDO, H.M.C. Fundamentos de estabilidade de alimentos. Fortaleza: Embrapa Agroindústria Tropical, 2004. 195 p.

BALSA-CANTO, E.; ALONSO, A.A.; BANGA, J.R. A novel, efficient and reliable method for thermal process design and optimization. Part I: theory. Journal of Food Engineering, v. 52, n. 3, p. 227-234, 2002.

BANGA, J.R.; BALSA-CANTO, E.; MOLES, C.G.; ALONSO, A.A. Improving food processing using modern optimization methods. Trends in Food Science and Technology, v. 4, p. 131-144, 2003.

BANSAL, B.; CHEN, X.D. A critical review of milk fouling in heat exchangers. Comprehensive reviews in food science and food safety, v.5, p. 27-33, 2006.

BEHMER, M.L.A. Tecnologia do leite: produção, industrialização e análise.13. ed. São Paulo: Nobel, 1999, 320p.

BELMAR-BEINY, M.T.; FRYER, P. Preliminary stages of fouling from whey protein solutions. Journal of Dairy Research, v. 60, p. 467-483, 1993.

BENNETT, H.A.E. Aspects fouling in dairy processing. 2007. 172 f. Tese (Doutorado em Engenharía de Alimentos). Massey University, Palmerston North, New Zealand. 2007.

BERTO, M.I. Avaliação experimental do controle da pasteurização contínua de um fluido modelo de suco de laranja. 2004. 271f. Tese. (Doutorado em Engenharía de Alimentos). Universidade Estadual de Campinas. São Paulo. 2004.

BIRD, R.B.; STEWART, W.E.; LIGHTFOOT, E.N. Transport phenomena, 2nd ed., John Wiley \& Sons, 2001. $912 \mathrm{p}$.

BON, J.; CLEMENTE, G.; VAQUIRO, H.; MULET, A. Simulation and optimization of milk pasteurization processes using a general process simulator (ProSimPlus). Computers and Chemical Engineering, v. 34, n. 3, p. 414-420, 2010. 
BON, J;CLEMENTE, G.;VAQUIRO,H.;MULET, A. Simulation and optimization of milk pasteurization processes using a general process simulator (ProSimPlus). Computers \& Chemical Engineering, v. 34, n. 3, p. 414-420, 2010.

BOTT, T. R. Fouling of Heat Exchangers. New York: Elsevier B. V.,1995. 524p.

BOXLER, C.; WOLFGANG, A.; SCHOLL, S. Fouling of milk components on DLC coated surfaces at pasteurization and UHT temperatures. Food and Bioproducts Processing, 2012. in press. Disponível em (http://www.sciencedirect.com/science/article/pii/S0960308512001204)

BRASIL. ANVISA - Agência Nacional de Vigilância Sanitária. Resolução RDC nํ267, de 25 de setembro de 2003. Regulamento técnico sobre as boas práticas de fabricação para estabelecimentos industrializadores de gelados comestíveis. Brasília, 2000. Disponível em: <http://e-legis.bvs.br>. Acesso em 23 nov. 2011.

BYLUND, G. Dairy Processing Handbook. Tetra Pak Processing Systems AB, 1995, 436 p.

CASP, A.; ABRIL, J. Processos de conservación de alimentos. 2. Ed. [S.I.]: Mundi-prensa, 2003. 494 p.

CHANGANI, S. D.; BELMAR-BEINY, M. T.; FRYER, P. J. Engineering and chemical factors associated with fouling and cleaning in milk processing. Experimental Thermal and Fluid Science, v. 14, n. 4, p. 392-406, 1997.

CHEN, G.; CAMPANELLA, O. H.; CORVALAN, C. M. A numerical algorithm for calculating microbial survival curves during thermal processing. Food Research International, v. 40, p. 203-208, 2007.

CHENG, H.; FRIIS, A. Operability and Flexibility of Milk Production Line. Food and Bioproducts Processing, v. 85, n. C4, p. 372-380, 2007.

CHOI, Y.; OKOS, M. R. Thermal Properties of Liquid Foods - Review, In: OKOS, M. R. (Ed.). Physical and Chemical Properties of Food. St. Joseph: ASAE, 1986. p. 35-77.

CORRADINI, M.G.; NORMAND, M.D.; PELEG, M. Calculating the efficacy of heat sterilization processes. Journal of Food Engineering, v.67, n.1-2, p. 59-69, 2005.

DELPLACE, F.; LEULIET, J.C. Modelling fouling of a plate heat exchanger with different flow arrangements by whey protein solutions. Food and Bioproducts Processing, v. 73, n. C3, p. 112-120, 1995.

FELLOWS, P.J. Tecnologia do processamento de alimentos: princípios e prática. 2. ed. Porto Alegre: Artmed, 2006. 602p.

FITO, P.; LEMAGUER, M.; BETORET, N.; FITO, P. J. Advanced food process engineering to model real foods and processes: The "SAFES" methodology. Journal of Food Engineering, v. 83, n. 2, p. 173-185, 2007. 
FRYER, P.J.; BELMAR-BEINY, M.T. Fouling of heat exchangers in the food industry: a chemical engineering perspective. Trends in Food Science and Technology, v. 2, p. 33-37, 1991.

GALEAZZO, F.C.C.; MIURA, R.Y.; GUT, J.A.W.; TADINI, C.C. Experimental and numerical heat transfer in a plate heat exchanger. Chemical Engineering Science, v.61, n.21, p.7133-7138, 2006.

GEORGIADIS, M.C.; MACCHIETTO, S. Dynamic modeling and simulation of plate heat exchangers under milk fouling. Chemical Engineering Science, v. 55, n. 9, p.1605-1619, 2000.

GEORGIADIS, M.C.; ROTSTEIN, G.E.; MACCHIETTO, S. Optimal design and operation of heat exchangers under milk fouling. Computers \& Chemical Engineering, v. 44, n. 9, p. 2099-2111, 1998.

GHANI, A.G.A.; FARID, M.M.; CHEN, X.D. Theoretical and experimental investigation of the thermal inactivation of Bacillus stearothermophilus in food pouches. Journal of Food Engineering, v. 51, n. 3, p. 221-228, 2002.

GRIJSPEERDT, K.; HAZARIKA, B.; VUCINIC, D. Application of computational fluid dynamics to model the hydrodynamics of plate heat exchangers for Milk processing. Journal of Food Engineering, v. 57, n. 57, p. 237-242, 2003.

GRIJSPEERDT, K.; MORTIER, L.;DE BLOCK, J.; RENTERGHEM, R.V. Applications of modelling to optimise ultra high temperature milk heat exchangers with respect to fouling. Food Control, v. 15, n. 2, p. 117-130, 2004.

GUT, J.A.W. Configurações ótimas para trocadores de calor a placas. 2003. 244 f. Tese (Doutorado em Engenharía Química) - Escola Politécnica, Universidade de São Paulo. São Paulo, 2003.

GUT, J.A.W.; FERNANDES, R.; PINTO, J.M.; TADINI, C.C. Thermal model validation of plate heat exchangers with generalized configurations. Chemical Engineering Science, v. 59, n. 21, p. 4591-4600, 2004.

GUT, J.A.W.; PINTO, J.M. Conhecendo os trocadores de calor a placas. Revista de Graduação da Engenharia Química. São Paulo, v. 1, n. 11, p. 9-16, 2003b.

GUT, J.A.W.; PINTO, J.M. Modeling of plate heat exchangers with generalized configurations. Internacional Journal of Heat and Mass Transfer, v. 46, n. 14 , p. 2571-2585, 2003a.

GUT, J.A.W.; PINTO, J.M. Optimal design of continuous thermal processing with plate heat exchangers. In: ERDOGDU, F. (Ed). Optimization in Food Engineering, Boca Raton:CRC Press, p. 597-631, 2009.

GUTIERREZ, C.G.C.C. Distribuição do e tempo de residência em processo de pasteurização com trocador de calor a placas. Dissertação (Mestrado). Escola Politécnica da Universidade de São Paulo, 2008. 
GUTIERREZ, C.G.C.C.; DIAS, E.F.T.S.; GUT, J.A.W. Investigation of the residence time distribution in a plate heat exchanger with series and parallel arrangement using a non-ideal tracer detection technique. Applied Thermal Engineering, v. 31, n. 10, p. 1725-1733, 2011.

GUTIERREZ, C.G.C.C.; DIAS, E.F.T.S.; GUT, J.A.W. Residence time distribution in holding tubes using generalized convection model and numerical convolution for non-ideal tracer detection. Jornal of Food Engiennering, v. 98, n. 2, p. 248-256, 2010.

HASTING, A.P.M. Practical considerations in the design, operation and control of food pasteurization processes. Food control, v. 3, n. 1, p. 27-32, 1992.

IBARROLA, J.J.; GUILLÉN, J.C.; SANDOVAL, J.M., GARCÍA- SANZ, M. Modelling of a high temperature short time pasteurization process. Food Control, v. 9, n. 5, p. 267-277, 1998.

IBARROLA, J.J.; SANDOVAL, J.M.; GARCÍA- SANZ, M.; PINZOLAS, M. Predictive control of a hiht temperature-short time pasteurization process. Control Engineering Practice, v. 10, n. 7, p. 713-725, 2002.

IGUAL, M.; GARCÍA-MARTÍNEZ, E.; CAMACHO, M.M.; MARTÍNEZ-NAVARRETE, $\mathrm{N}$. Effect of thermal treatment and storage on the stability of organic acids and the functional value of grapefruit juice. Food Chemistry, v. 118; n. 2, p. 291299, 2010.

JAESUNG, L; GONUL, K. Evaluation of heat inactivation of escherichia coli and lactobacillus plantarum by differential scanning calorimetry. Applied and Environmental Microbiology, v. 68, n. 11, p. 5379-5386, 2002.

JEURMINK, T.J.M. Fouling of Heat Exchangers by Fresh and Reconstituted Milk and the Influence of Air Bubbles. Milchwissenschafl Milk Science International, v. 50, n. 4 , p. $189-193,1995$.

JEURNINK, T.J.M.; VERHEUL, M.; COHEN, S.M.; KRUIF, C.G. Deposition of heated whey proteins on a chromium oxide surface, Colloids Surfaces B: Biointerfaces, v. 6, p. 291-307, 1996.

JUN, S.; PURI, V.M. Fouling model heat exchangers in dairy processing: A review. Journal of Food Process Engineering, v. 28, n. 1, p. 1-34, 2005.

JUNG, A.; FRYER, P.J. Optimising the quality of safe food: computational modeling of a continuous sterilization process. Chemical Engineering Science, v. 54, n. 6, p. 717-730, 1999.

KAKAÇ, S.; LIU, H. Heat exchangers: selection, rating and thermal design. Boca Raton, 2002.

KERN, D.; SEATON, R.E. A theoretical analysis of thermal surface fouling. British Chemical Engineering, v. 4, n. 5, p. 258-262, 1959. 
KIM, H.B.; TADINI, C.C.; SINGH, R.K. Heat transfer in a plate exchanger during pasteurization of orange juice. Journal of Food Engineering, v. 42, p. 79-84, 1999.

LAKSHMANAN, C.C.; POTTER, O.E. Dynamic simulation of plate heat exchangers. International Journal of Heat and Mass Transfer, v.33, n.5, p. 995-1002, 1990.

LEWIS, M.; HEPPELL, N. Continuous thermal processing of foods: pasteurization and UHT sterilization. Gaithersburg: Aspen Publishers, 2000. $447 p$.

MABIT, J.; BELHAMRI, R.; RAYOLLE, F.; LEGRAND, J. Development of a time temperature integrator for quantification of thermal treatment in scraped surface heat exchangers. Innovative Food Science and Emerging Technologies, v. 9, p. 516-526, 2008.

MACHUDA, F.; URRESTA, O. Educational software for the teaching of the dynamics and control of shell and tube heat exchangers. Rev. Fac. Ing. Univ. Antioquia. Medellín, v. 44, p. 52-60, 2008.

MANIK, M.H.; BILDEA, C.S.; GRIEVINK, J.; MARSHMAN, C. Modelling and optimisation of milk pasteurisation processes. Computer Aided Chemical Engineering, v. 18, p. 955-960, 2004.

MASUBUCHI, M.; ITO, M. Dynamic analysis of a plate heat exchanger system. Bulletin of the JSME, v. 20, n. 142, p. 434-441, 1977.

MIURA, R.Y. Estudo da troca térmica em um trocador de calor a placas com configurações generalizadas. Relatório de iniciação científica FAPESP. Orientador: Jorge Andrey Wilhelms Gut, 2006.

NARATARUKSA, P.; TRIRATANA, P.; PANA-SUPPAMASSADU, K.; HEGGS, P.J.; TIA, S. Dynamic simulation of plate and frame heat exchanger undergoing food fouling: coconut milk fouling case study. Science Asia, v. 34, n. 2, p. 229-237, 2008.

PARTRIDGE, J.A. Pasteurization of milk: historial impact on tuberculosis. Michigan Diary Review, Departament of food science and human nutrition, v 19, July 2000.

PEREIRA, R.N.; VICENTE, A.A. Environmental impact of novel thermal and nonthermal technologies in food processing. Food Research International, v. 43, p. 1936-1943, 2010.

PETERMEIER, H.; BENNING, R.; DELGADO, A.; ZULOZIK, U.;HINRICHS, J.; BECKER, T. Hybrid model of the fouling process in tubular heat exchangers for the dairy industry. Journal of Food Engineering, v.55, p.9-17, 2002.

POTTER, N.N.; HOTCHIKISS, J.H. Food Science. 5th ed. New York: Chapman \& Hall, 1995. 608p. 
RAO, B.P.; KUMAR, P.K.; DAS, S.K. Effect of flow distribution to the channels on the thermal performance of a plate heat exchanger. Chemical Engineering and Processing, v. 41, n.1, p. 49-58, 2002.

ROBBINS, P.T.; ELLIOTT, B.L.; FRYER, P.J.; BELMAR, M.T.; HASTING, A.P.M. A Comparison of Milk and Whey Fouling in a Pilot Scale Plate Heat Exchanger: Implications for Modelling and Mechanistic Studies. Food and Bioproducts Processing, v. 77, n. 2, p. 97-106, 1999.

SANCHO, M.F.; RAO, M.A. Residence time distribution in a holding tube. Journal of Food Engineering, v. 15, p.1-19, 1992.

SANDU, C.; SINGH, R.K. Energy increase in operation and cleaning due to heat exchanger fouling in milk pasteurization. Food Technology, v. 45, n. 12, p. 84$91,1991$.

SHAH, R.K. Heat exchanger basic design methods. In: KAKAÇ, S.; SHAH, R. K.; BERGLES, A. E. (Eds.). Low Reynolds Number Flow Heat Exchangers, New York: Hemisphere, p. 21-72, 1983.

SHARIFI, F.; NARANDJI, G.; MEHRAVARAN, K. Dynamic simulation of plate heat exchangers. International Communications in Heat and Mass Transfer, $v$. 22, n. 2, p. 213-225, 1995.

SRIHARI, N.; RAO, B.P.; SUNDEN, B.; DAS, S.K. Transient response of plate heat exchangers considering effect of flow maldistribution. International Journal of Heat and Mass Transfer, v. 48, n. 15, p. 3231-3243, 2005.

TEJEDA, M.U. Estúdio de la formación de crosta en un intercambiador de calor de placas. Tese (Graduação em Engenharía de Alimentos) - Departamento de Ingeniería Química y Alimentos,.Escuela de Ingeniería, Universidad de las Américas. Puebla-México. 2003

THONON, B.; MERCIER, P.; FEIDT, M. Flow distribution in plate heat exchangers and consequences on thermal and hydraulic performances. Design and Operation of Heat Exchanger, v. 18, p. 245-254, 1992.

TIRUMALESH, A.; RAO, H.G.; JAYAPRAKASH, H.M. .Fouling of heat exchangers. Industrial Journal of Dairy Bioscience, v. 8, p. 41-44, 1997.

TOLEDO, R.T. Fundamentals of Food Process Engineering. 2.ed. New York: Chapman \& Hall, 1999, 579p.

TORRES, E.A.F.S.; CAMPOS, N.C.; DUARTE, G.M.L.; GABERLOTTI, M.L.; PHILIPPI, S.T; MINAZZI-RODRIGUES, R.S. Composição centesimal e valor calórico de alimentos de origem animal. Ciência e tecnologia e alimentos, v. 2, n. 20, p. 145-150, 2000.

TRYSTRAM, G. Modelling of food and food processes. Journal of Food Engineering, v. 110, p. 269-277, 2012. 
TUCKER, G.; HEYDON, C. Food particle residence time measuremente for the design of commercial tubular heat exchangers suitable for processing suspensions of solids in liquids. Institution of Chemical Engineers, v. 76, p. 208-216, 1998.

VISSER, J., JEURMINK, T.J.M. Fouling of heat exchangers in the dairy industry. Experimental Thermal and Fluid Science, v.14, n. 4, p. 407-424, 1997.

YOUCEF, M.; ABDELKADER, M.; LOUNES, O. A dynamic model for milk fouling in a plate heat exchanger. Applied mathematical modelling, v. 33 , n. 2, p. 648662, 2009.

ZHENHUA, J.; GITAE, P.; YONGHUN, L.; SOONHO, C.; HANSHIK, C.; HYOMIN, J. Design and Performance of Pressure Drop and Flow Distribution to the Channel in Plate Heat Exchanger. In: EngOpt 2008 - International Conference on Engineering Optimization, Rio de Janeiro. 2008. 
APÊNDICE A - Registro de temperaturas simuladas e experimentais do ensaio da partida do pasteurizador nos 12 pontos de medição de temperatura do processo
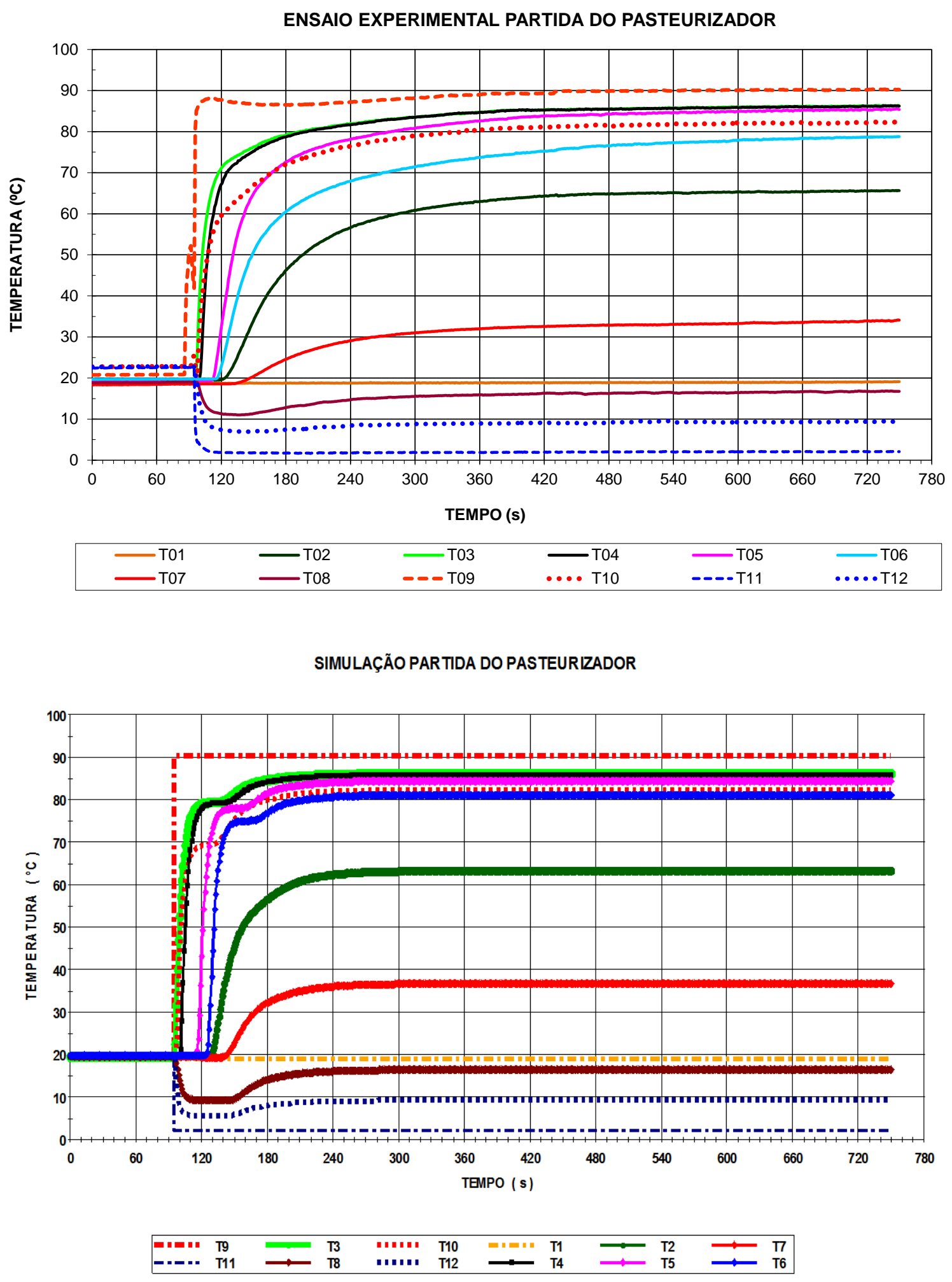
APÊNDICE B - Registro de temperaturas simuladas e experimentais do ensaio dinâmico de perturbação A

DADOS EXPERIMENTAIS DO ENSAIO DE PERTURBAÇÃO A

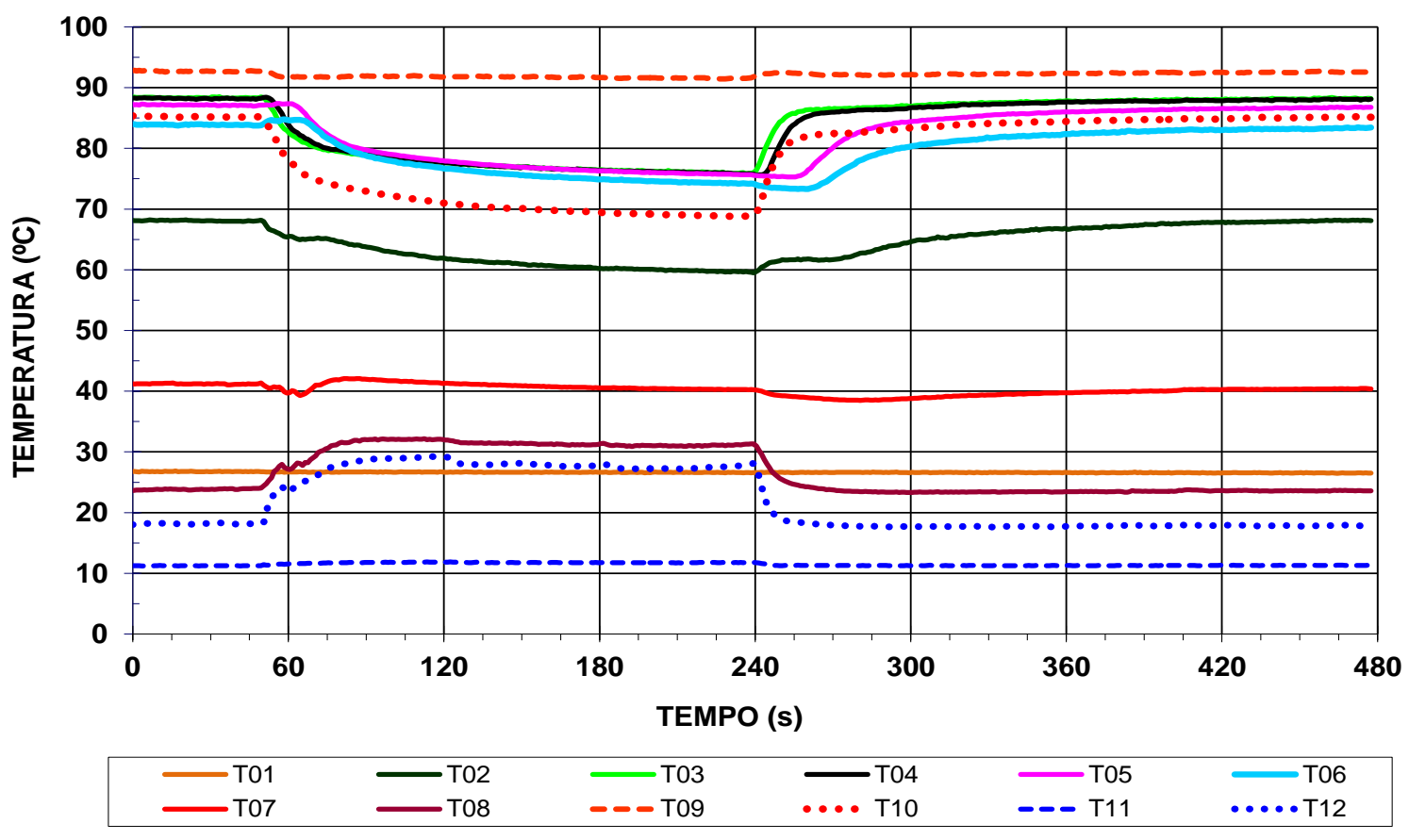

SIMULAÇÃO DO ENSAIO DE PERTURBAÇÃO A

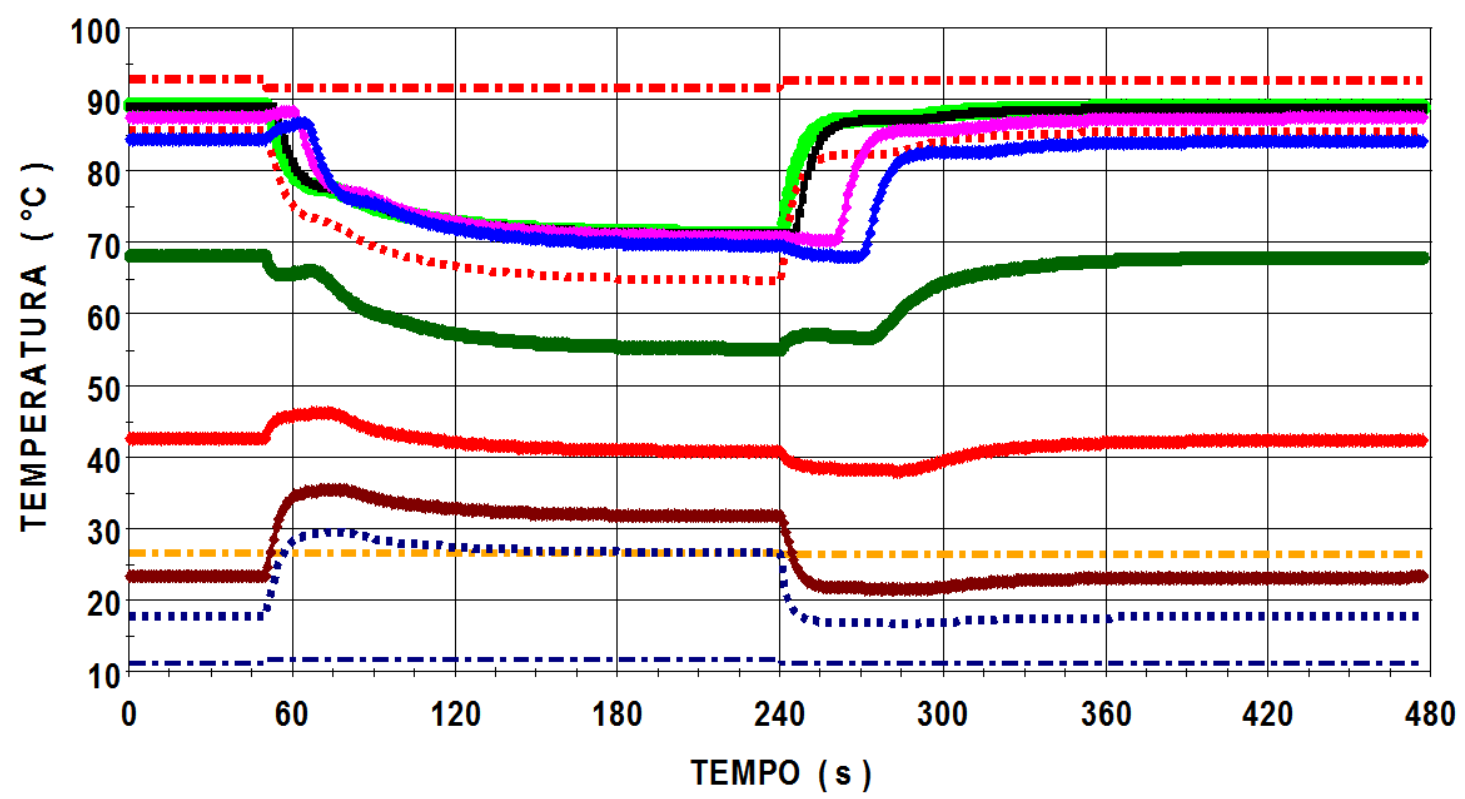

\begin{tabular}{|c|c|c|c|c|c|c|c|c|c|c|c|}
\hline 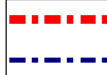 & $\begin{array}{l}\text { T9 } \\
\text { T11 }\end{array}$ & $\longrightarrow$ & $\begin{array}{l}\text { T3 } \\
\text { T8 }\end{array}$ & 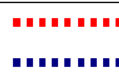 & $\begin{array}{l}\text { T10 } \\
\text { T12 }\end{array}$ & 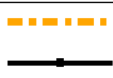 & $\begin{array}{l}\text { T1 } \\
\text { T4 }\end{array}$ & $\longrightarrow$ & $\begin{array}{l}\text { T2 } \\
\text { T5 }\end{array}$ & $\longrightarrow$ & $\begin{array}{l}\text { T7 } \\
\text { T6 }\end{array}$ \\
\hline
\end{tabular}


APÊNDICE C - Registro de temperaturas simuladas e experimentais do ensaio dinâmico de perturbação $B$

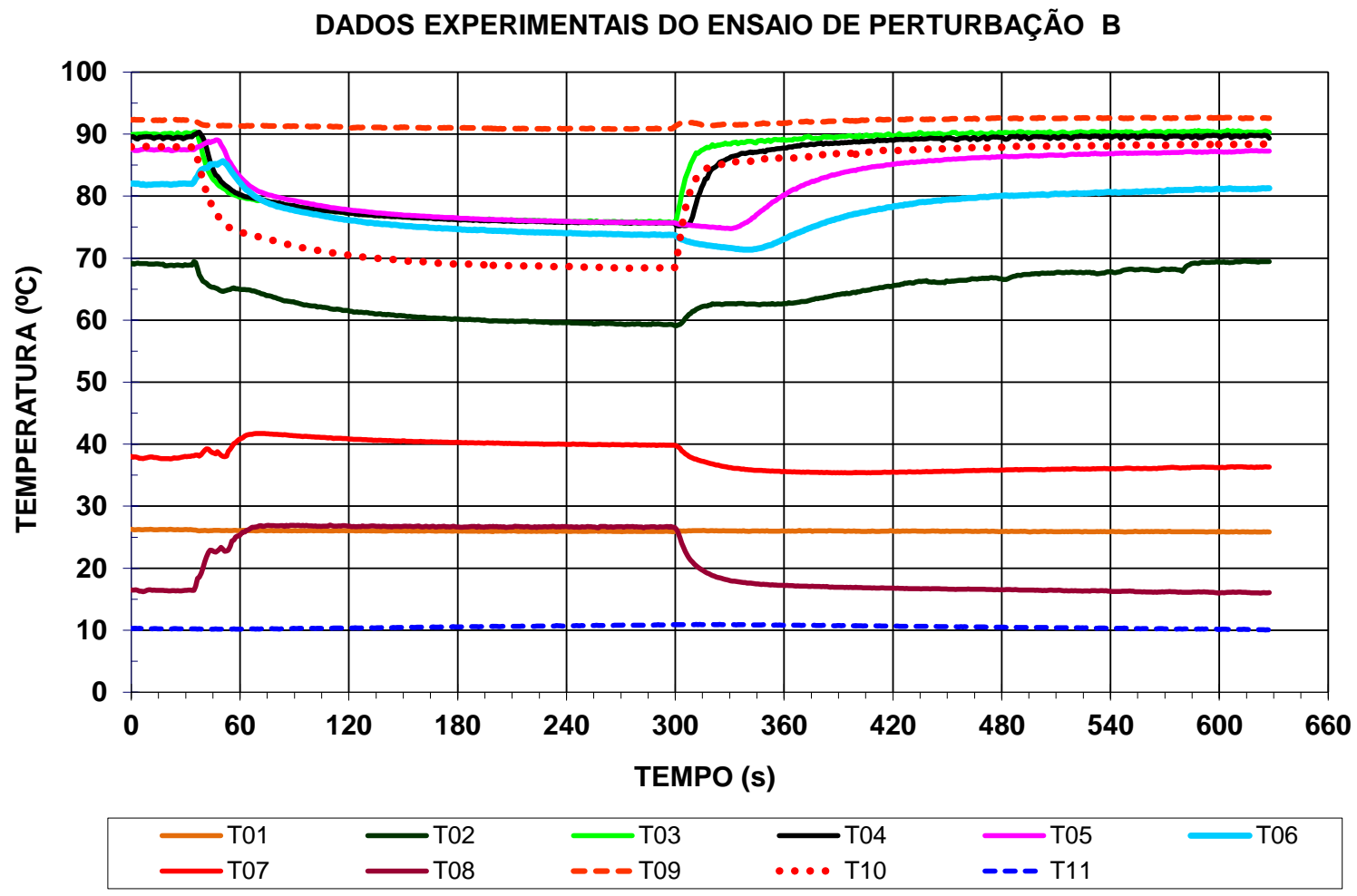

SIMULAÇÃO DO ENSAIO DE PERTURBAÇÃO B

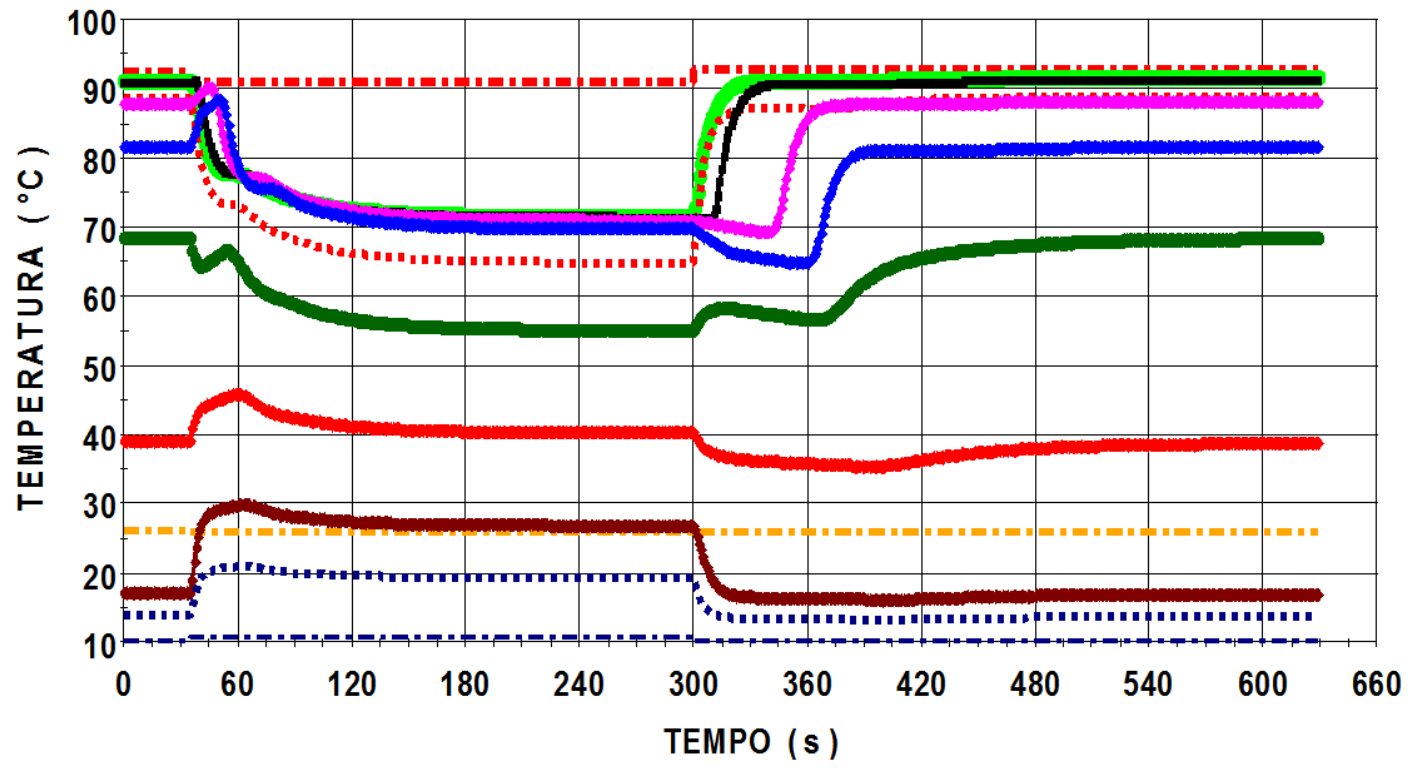

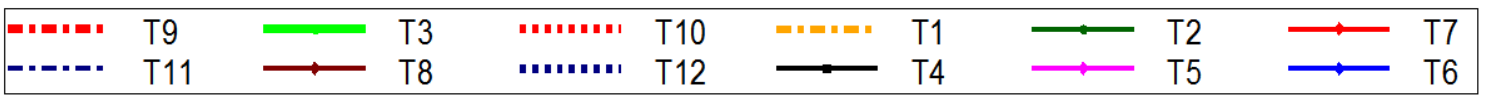


APÊNDICE D - Registro de temperaturas simuladas e experimentais do ensaio dinâmico de perturbação C

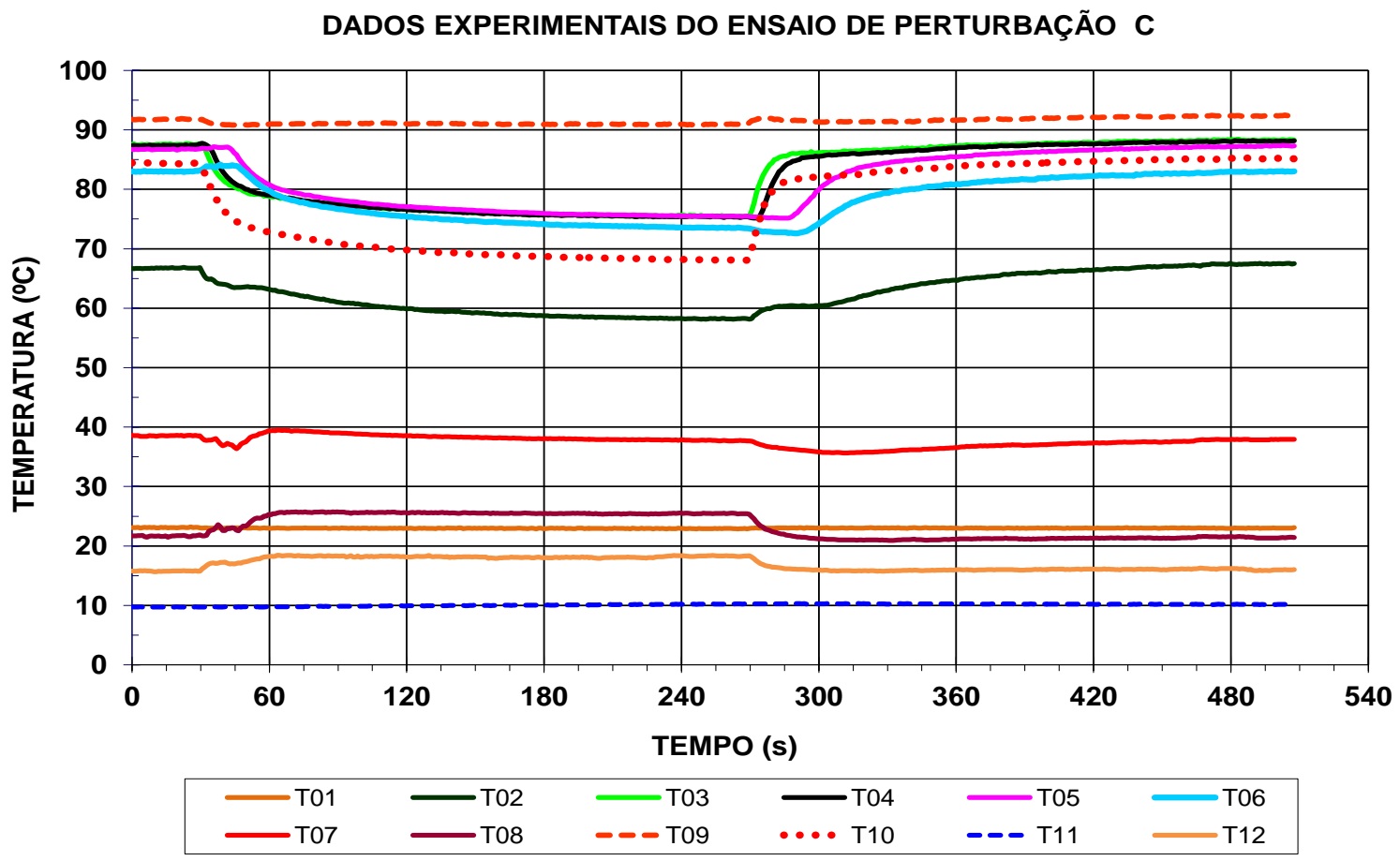

SIMULAÇÃO DO ENSAIO DE PERTURBAÇÃO C

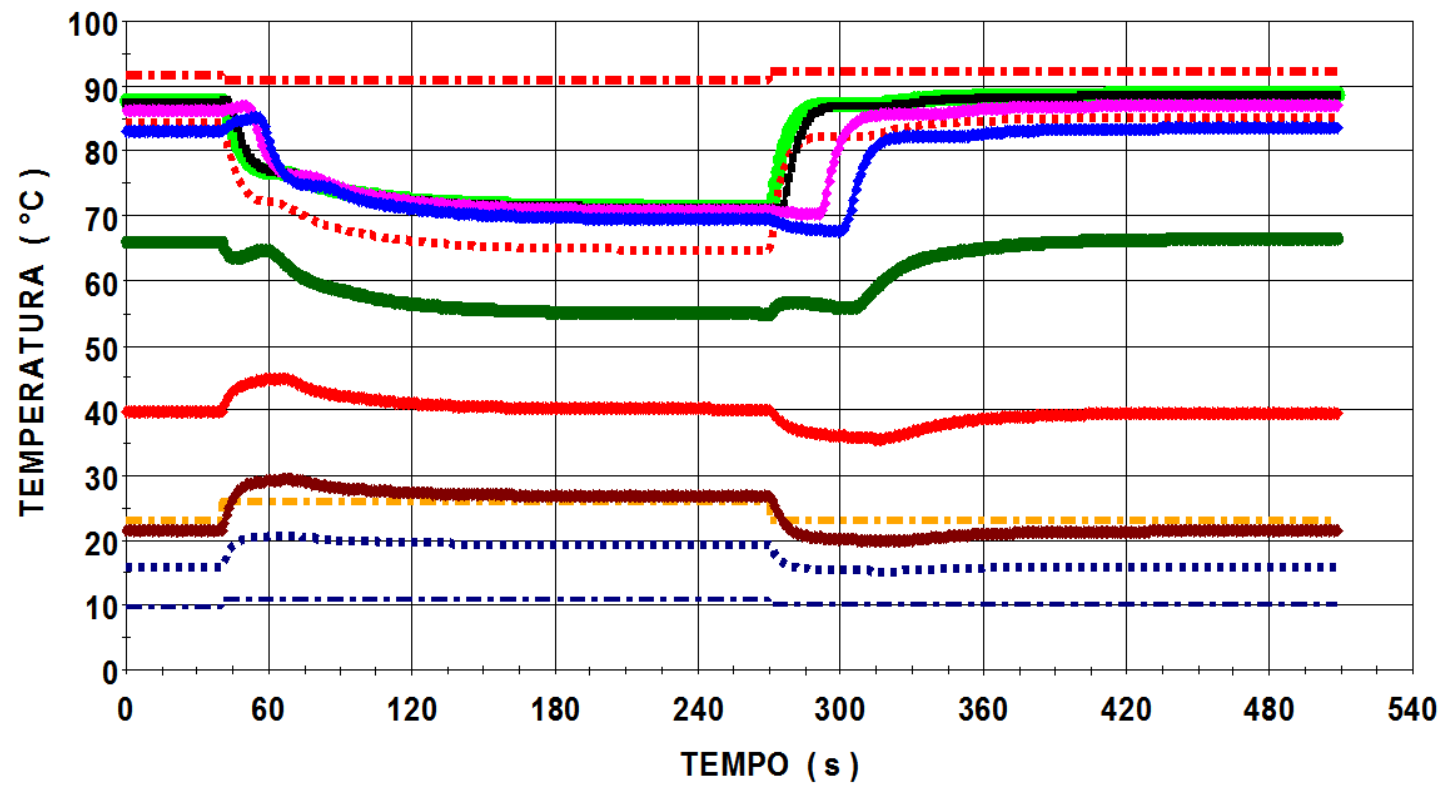

\begin{tabular}{|c|c|c|c|c|c|c|c|c|c|c|c|}
\hline 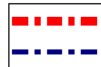 & $\begin{array}{l}\text { T9 } \\
\text { T11 }\end{array}$ & $\longrightarrow$ & $\begin{array}{l}\text { T3 } \\
\text { T8 }\end{array}$ & 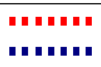 & $\begin{array}{l}\text { T10 } \\
\text { T12 }\end{array}$ & $\underline{-1=1-1=}$ & $\begin{array}{l}\text { T1 } \\
\text { T4 }\end{array}$ & $\longrightarrow$ & $\begin{array}{l}\mathrm{T} 2 \\
\mathrm{~T} 5\end{array}$ & $\longrightarrow$ & $\begin{array}{l}\text { T7 } \\
\text { T6 }\end{array}$ \\
\hline
\end{tabular}


APÊNDICE E - Registro de temperaturas simuladas e experimentais do ensaio dinâmico de perturbação $D$

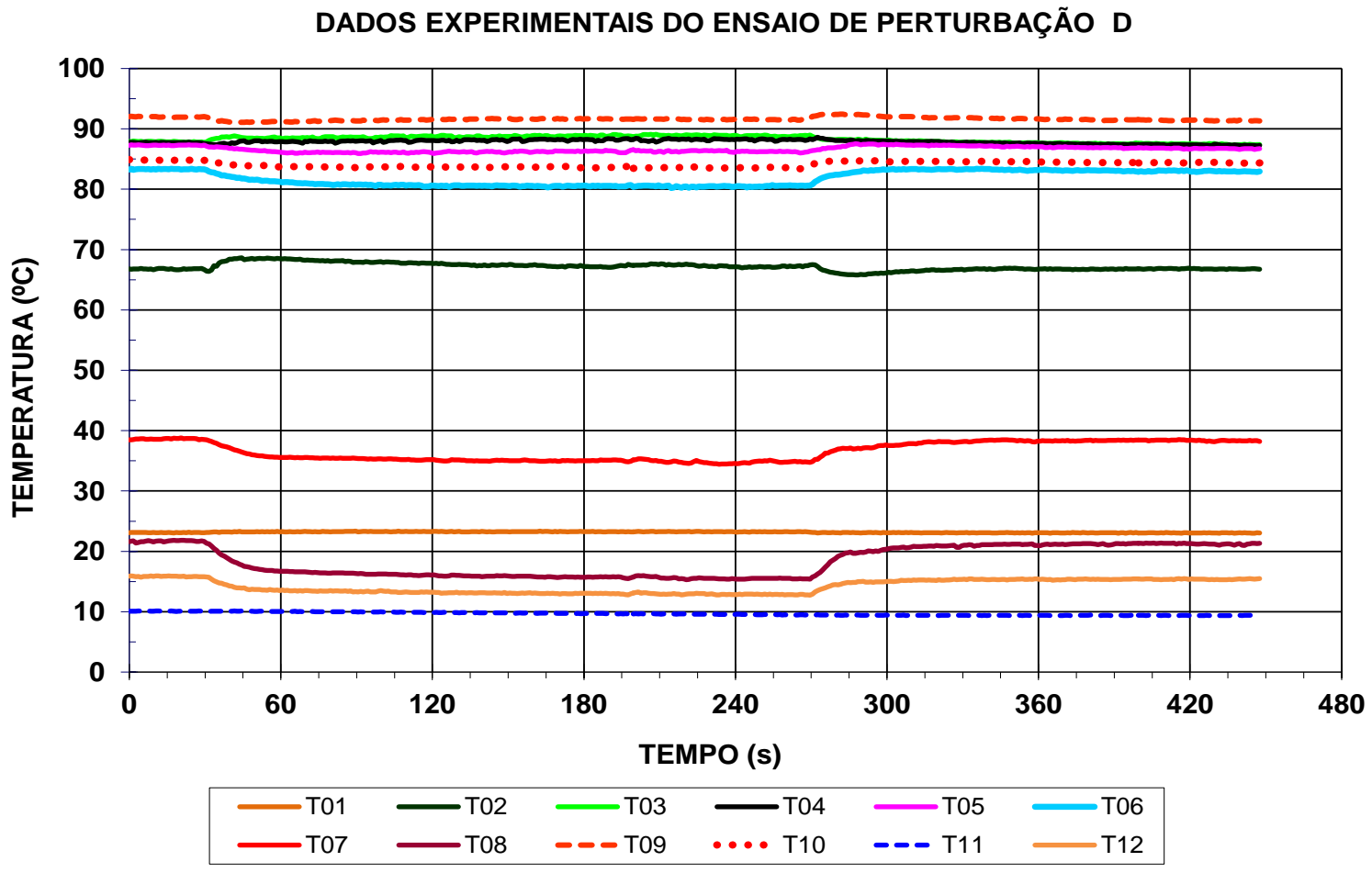

SIMULAÇÃO DO ENSAIO DE PERTURBAÇÃO D

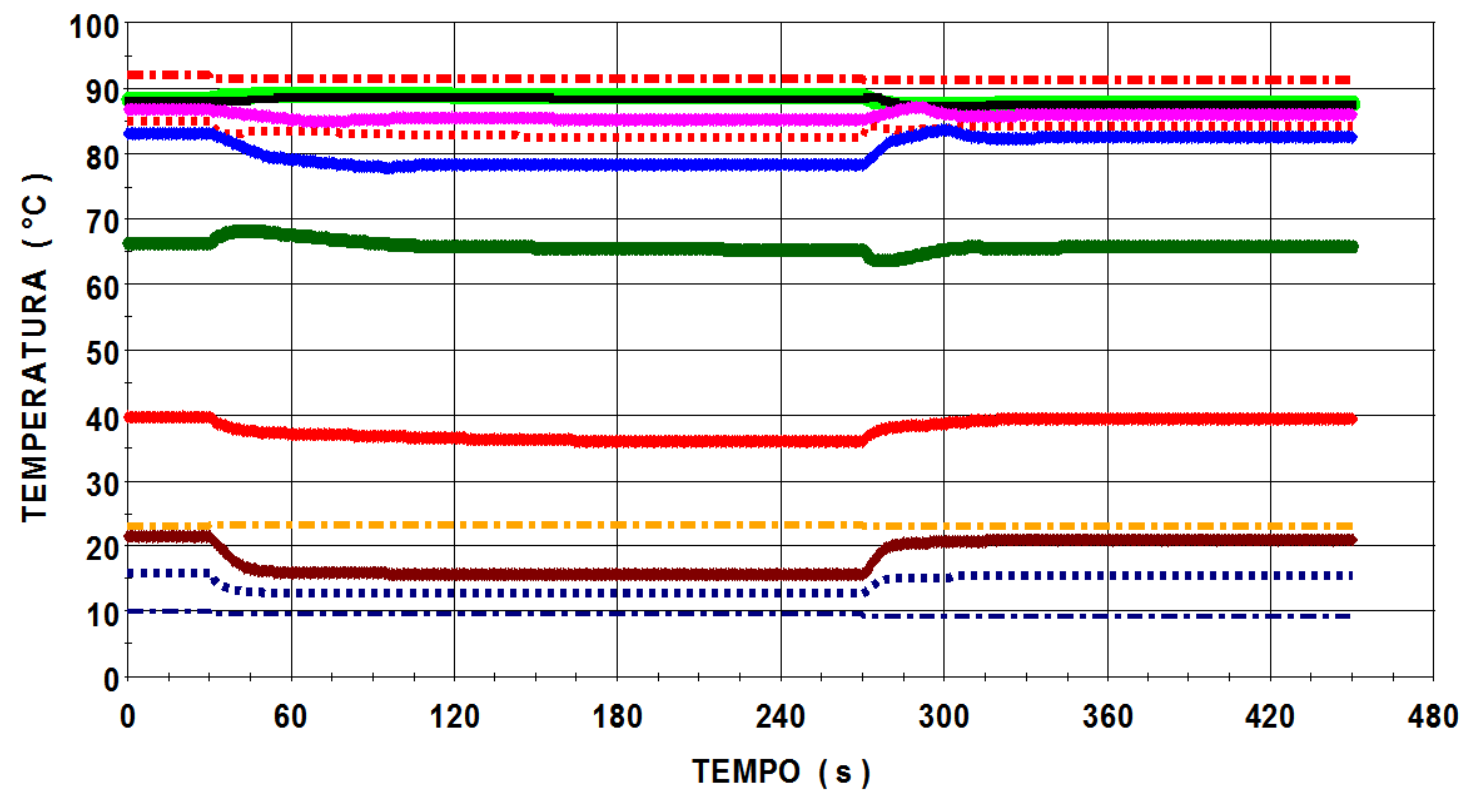

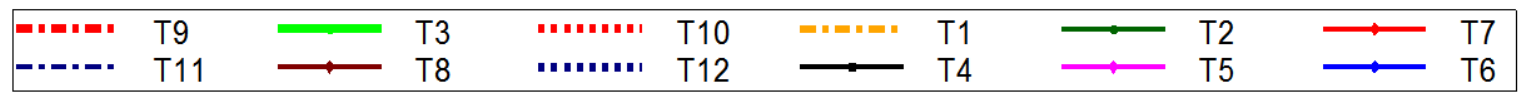


APÊNDICE F - Registro de temperaturas simuladas e experimentais do ensaio dinâmico de perturbação $E$

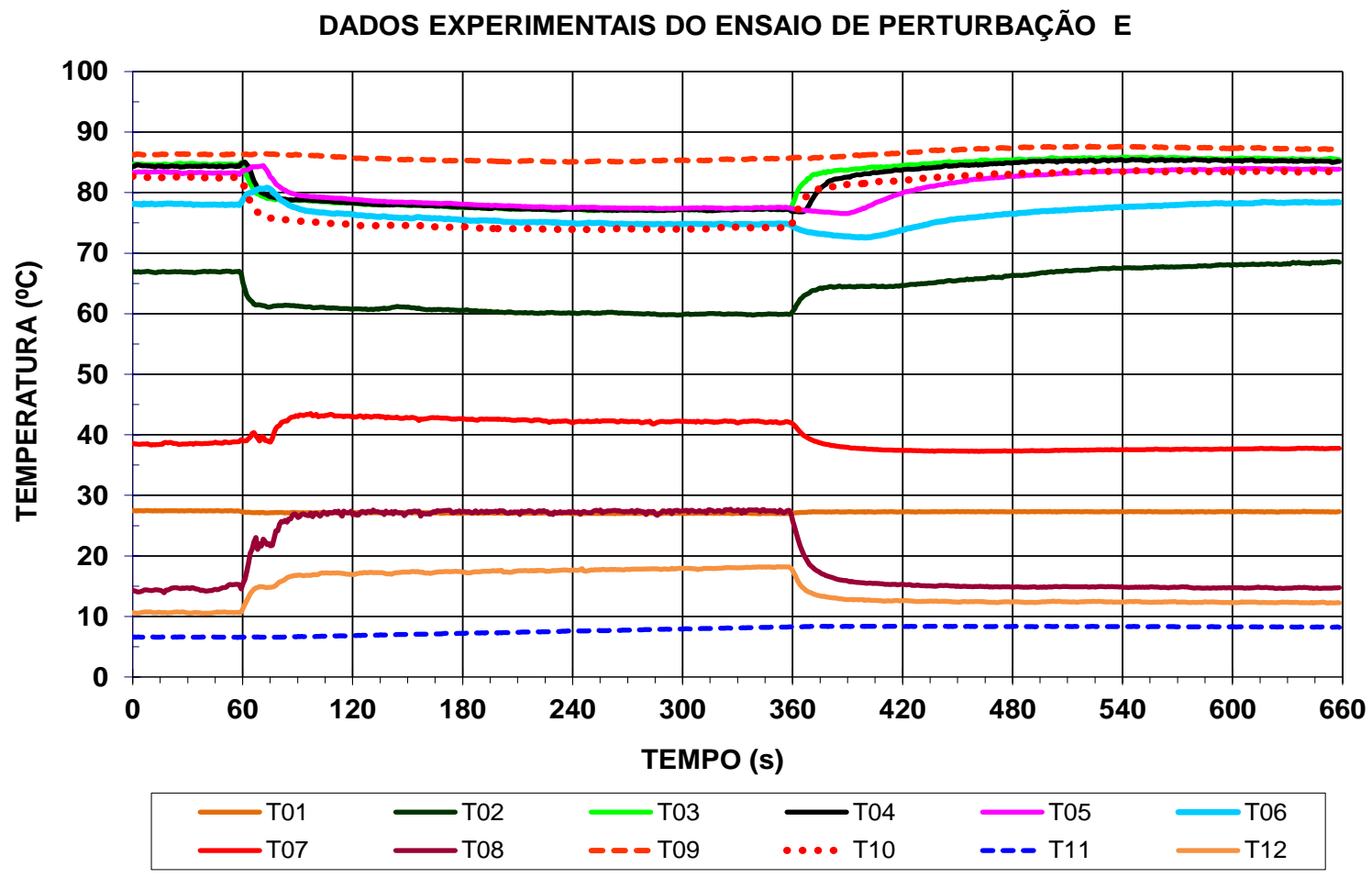

SIMULAÇÃO DO ENSAIO DE PERTURBAÇÃO E

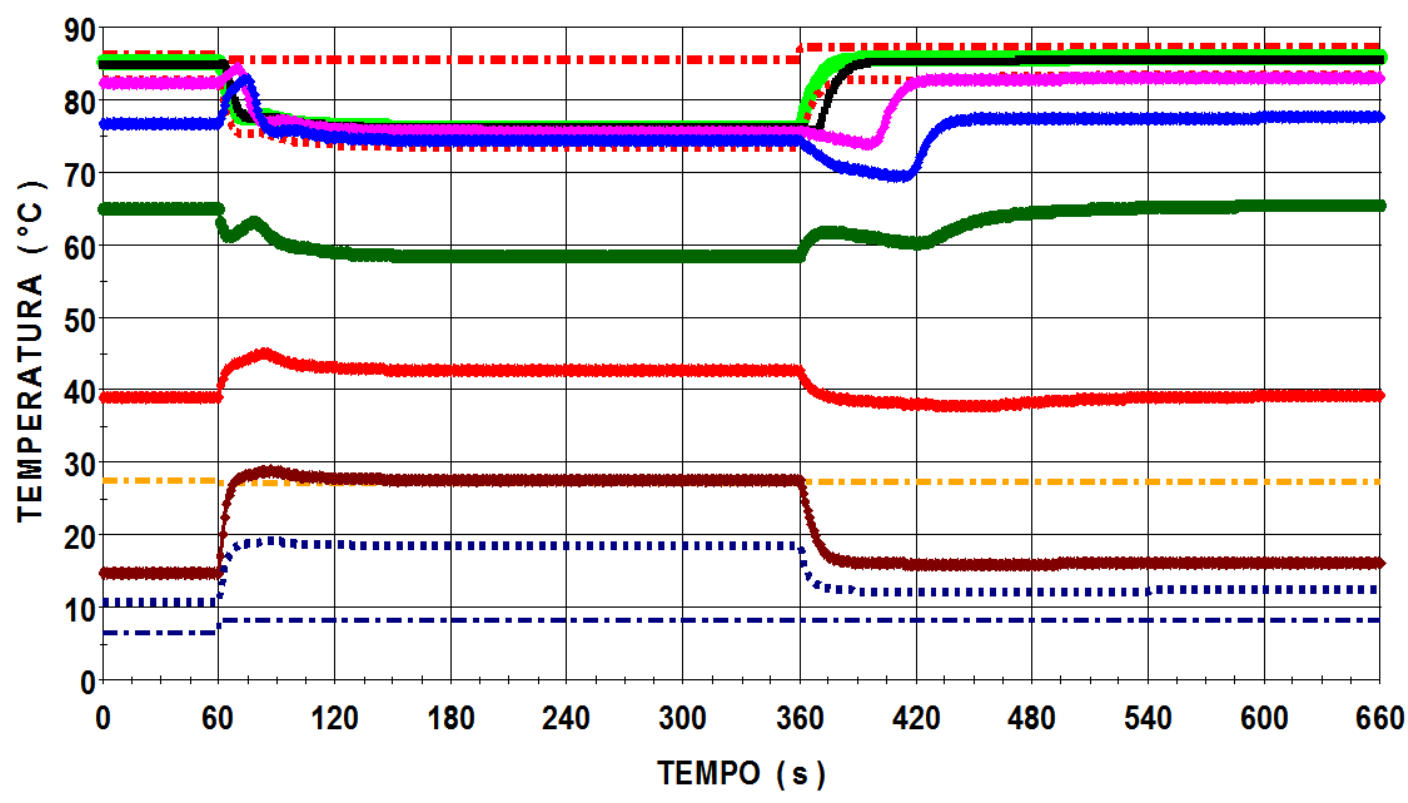

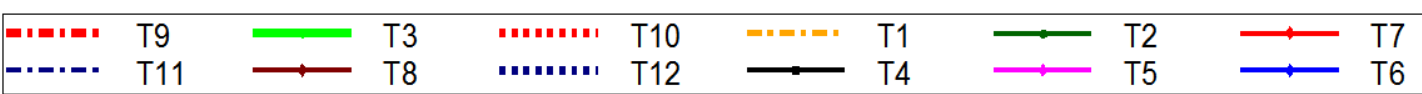


APÊNDICE G - Registro de temperaturas simuladas e experimentais do ensaio dinâmico de perturbação $F$

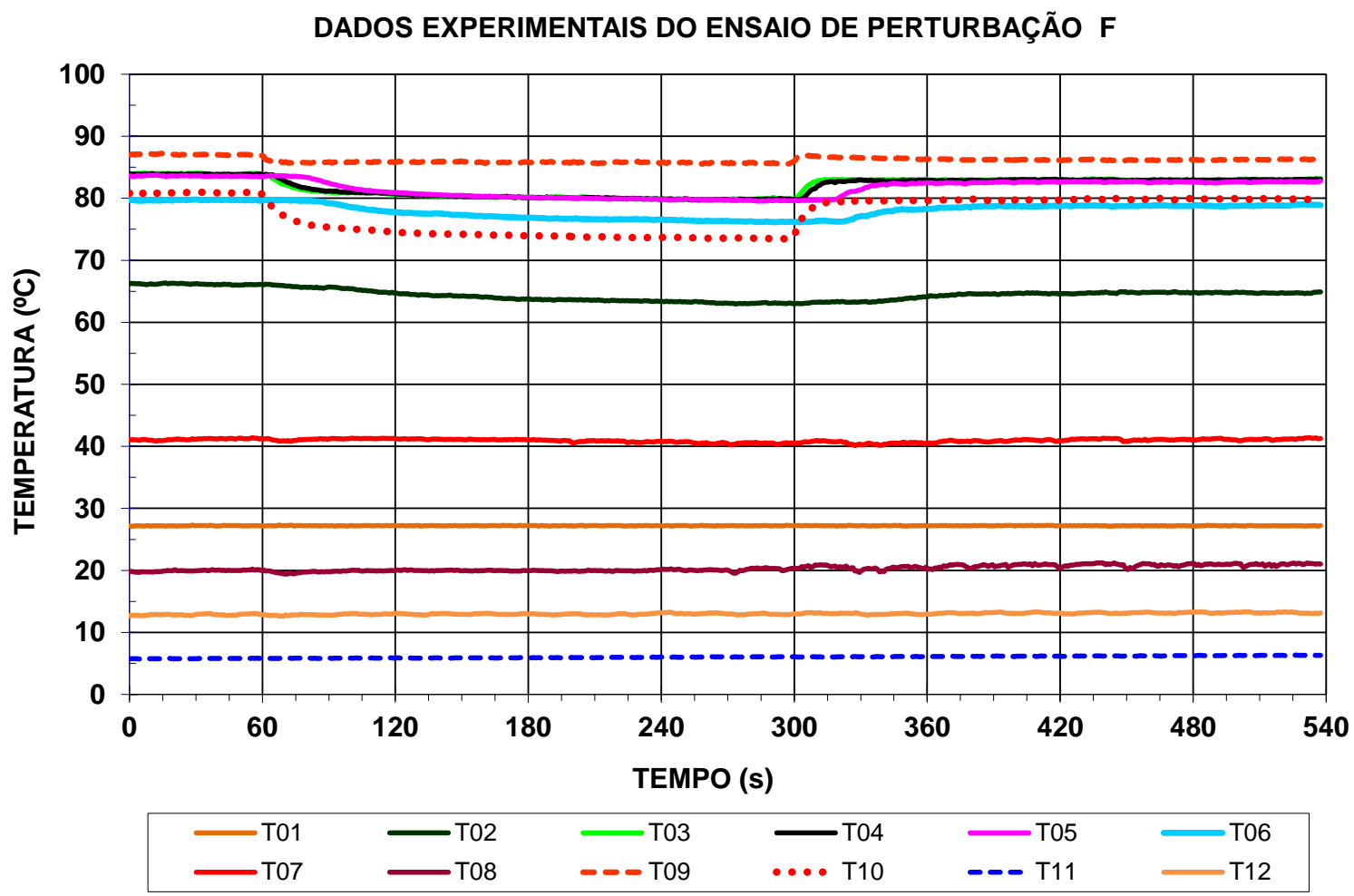

SIMULAÇÃO DO ENSAIO DE PERTURBAÇÃO F

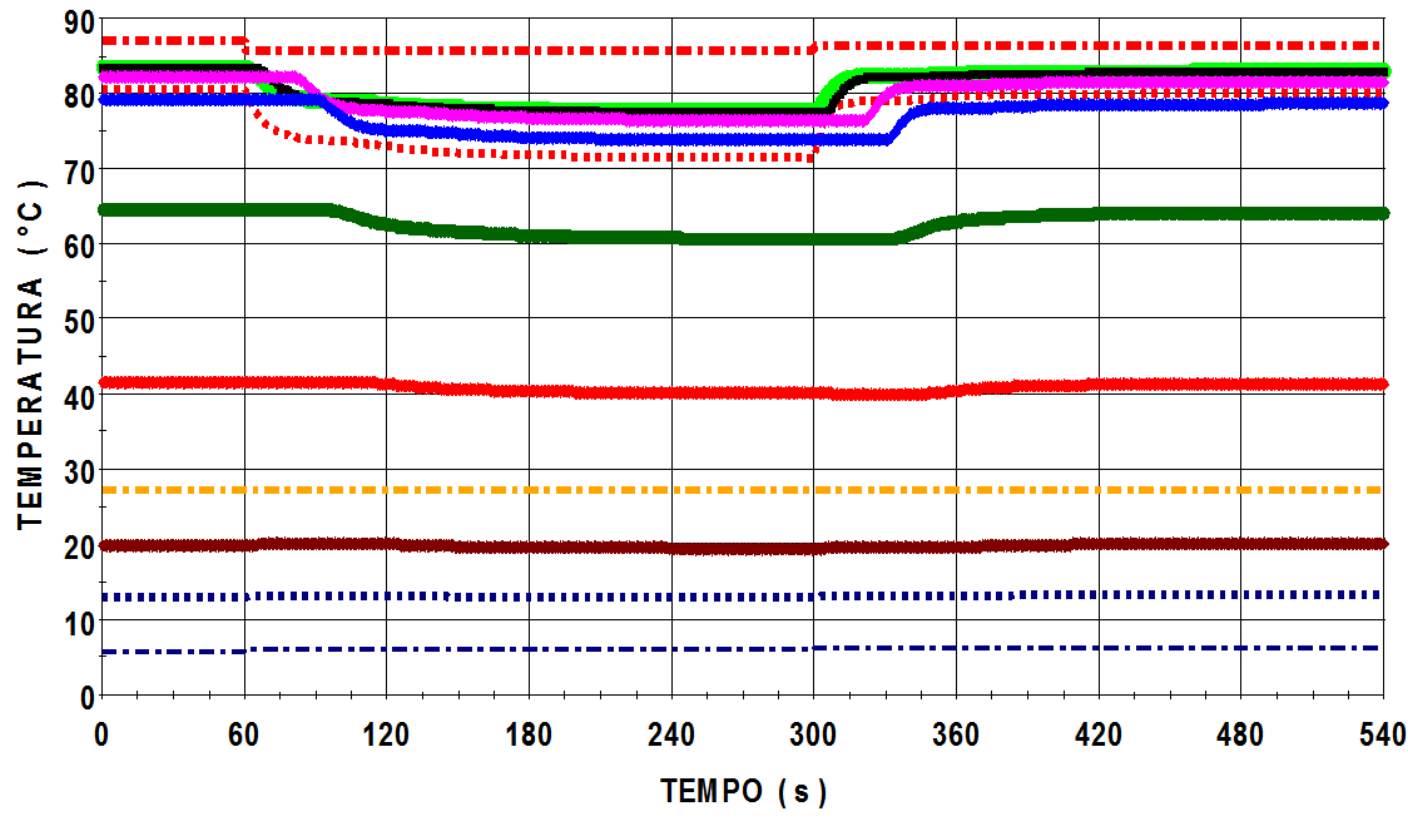

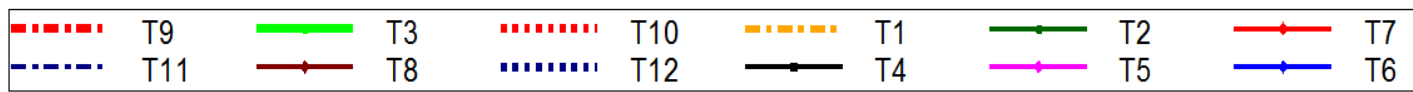




\section{APÊNDICE H- Tabela de dados do ajuste experimental para a determinação dos coeficientes de troca térmica do trocador de calor a placas.}

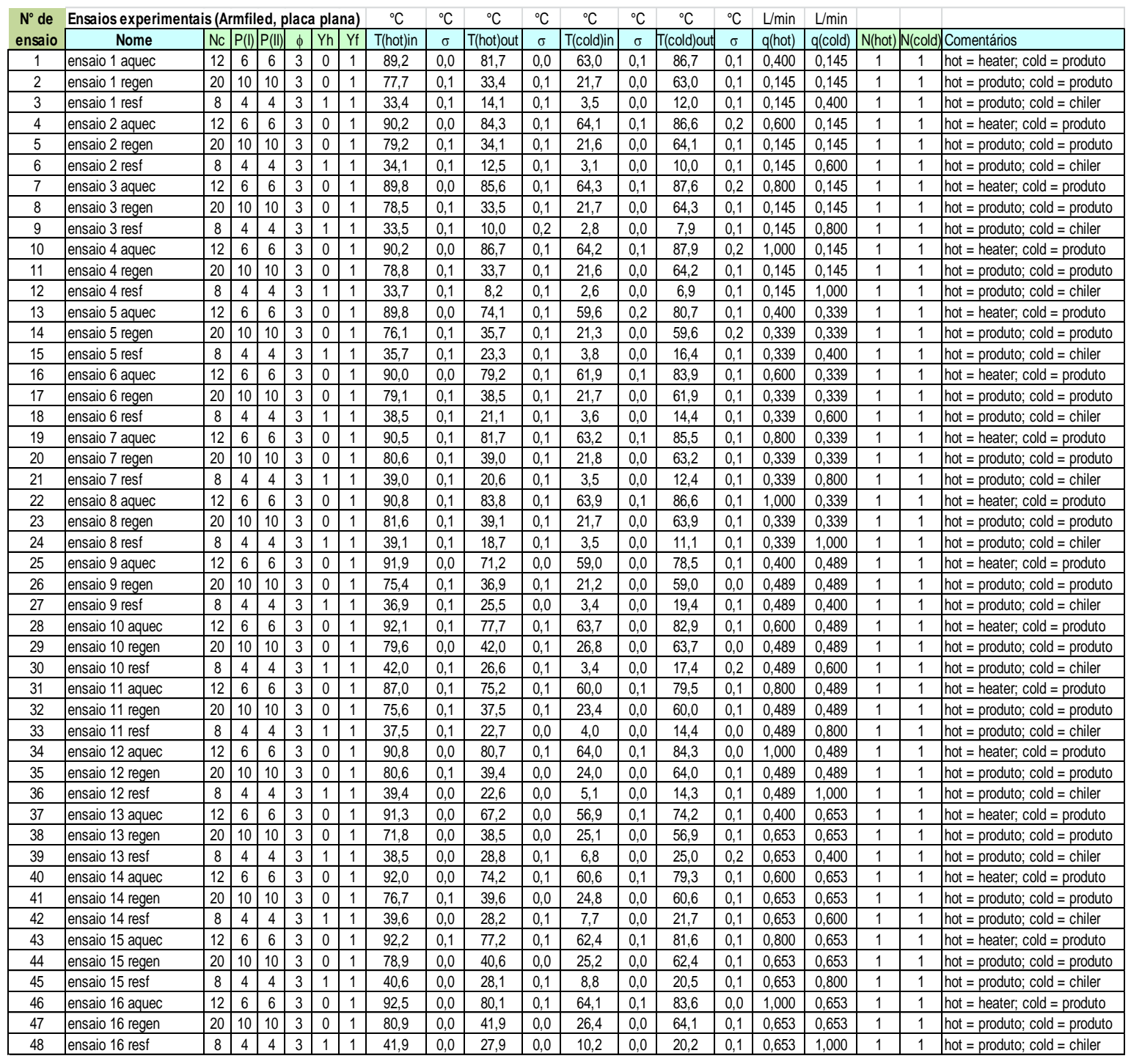

